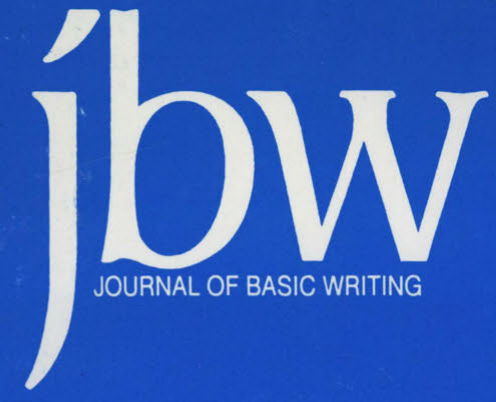

\title{
FALL 1999
} VOLUME 18 NUMBER 2

Unraveling at Both Ends: Anti-Undergraduate Education, AntiAffirmative Action, and Basic Writing at Research Schools Gail Stygall

Inventing Academic Discourse: Teaching (and Learning) Marginal Poise and Fugitive Truth Jane E. Hindman

Building Bridges To Academic Discourse: The Peer Group Leader in Basic Writing Peer Response Groups Laurie Grobman

Just Writing, Basically: Basic Writers on Basic Writing Linda Adler-Kassner,

The Representation of Basic Writers in Basic Writing Scholarship, or Who is Quentin Pierce? Susanmarie Harrington

Investigating Our Discursive History: JBW and the Construction of the "Basic Writer's" Identity

Laura Gray-Rosendale 


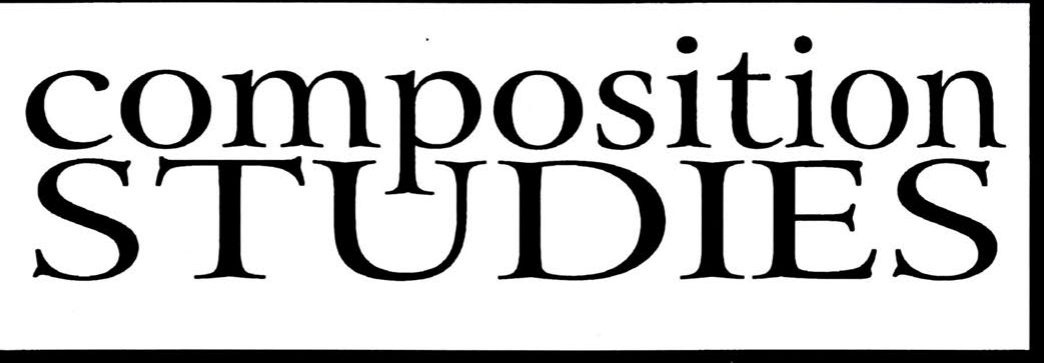

\section{Freshman English News}

Volume 27, Number 2 Fall 1999

Includes the work of

Patricia Bizzell, Bill Bolin, Sidney I. Dobrin, Richard Miller

\section{Call for Papers}

Composition Studies requests submissions for its new feature, Course Designs - a unique opportunity for writing/rhetoric teachers at all postsecondary levels to publish full descriptions of curricular development. Visit our web site for a complete overview and submission guidelines.

Quality essay submissions on issues of general interest to rhetoric and composition teachers and scholars are also strongly encouraged. Three titled, letter-quality copies conforming to current MLA guidelines for format and documentation, free of authors' names and other identifying references, should be accompanied by a cover letter.

\section{SubSCRIPTIONS}

Individuals $\$ 12$ - Institutions $\$ 25$ - Graduate Students $\$ 9$

\section{www.depaul.edu/ compstud}




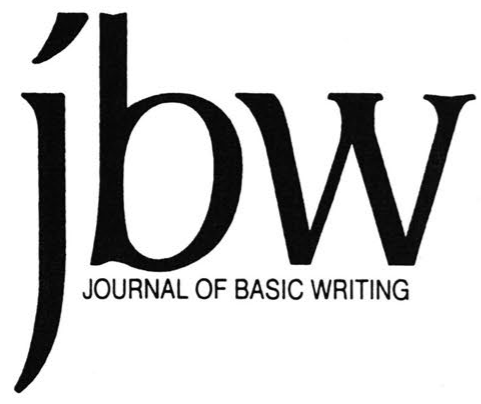

VOLUME 18 NUMBER 2

FALL 1999

The Journal of Basic Writing publishes articles of theory, research, and teaching practices related to basic writing. Articles are refereed by members of the Editorial Board (see overleaf) and the Editors.

\section{Trudy Smoke and George Otte Editors}

\section{Rhona Cohen and Mikhail Gershovich Editorial Assistants}

\section{Mary E. Carney, Subscriptions}

The Journal of Basic Writing is published twice a year, in the spring and fall. We welcome unsolicited manuscripts and ask authors to consult the detailed "Call for Articles" in this issue. Subscriptions for individuals are $\$ 15.00$ for one year and $\$ 28.00$ for two years; subscriptions for institutions are $\$ 20.00$ for one year and $\$ 38.00$ for two years. Foreign postage is $\$ 5.00$ extra per year. ADDRESS:

Journal of Basic Writing City University of New York 555 West 57 Street, Room 1601

New York, NY 10019 


\section{JOURNAL OF BASIC WRITING}

\section{EDITORIAL BOARD}

Peter Dow Adams

Essex Community College, Baltimore

Akua Duku Anokye

University of Toledo

Chris M. Anson

University of Minnesota

David Bartholomae

University of Pittsburgh

Sarah Benesch

College of Staten Island, CUNY

Bill Bernhardt

College of Staten Island, CUNY

Patricia Bizzell

College of the Holy Cross

Lynn Z. Bloom

University of Connecticut, Storrs

Nancy Carriuolo

University of New Haven

Richard Courage

Westchester Community College,

SUNY

Donald Daiker

Miami University

Suellynn Duffey

Ohio University

Sarah Warshauer Freedman

University of California, Berkeley

Karen L. Greenberg

Hunter College, CUNY

Brenda M. Greene

Medgar Evers College, CUNY

Muriel Harris

Purdue University

Irvin Hashimoto

Whitman College

Warren Herendeen

Mercy College

Myra Kogen

Brooklyn College, CUNY
Patricia Ondek Laurence

City College, CUNY

Elaine O. Lees

Carlow Hill College

AndreaA. Lunsford

Ohio State University

Jane Maher

Nassau Community College

Peter Miller

College of Staten Island, CUNY

Susan Miller

University of Utah

Nathaniel Norment, Jr.

Temple University

Jerrold Nudelman

Queensborough Community

College, CUNY

Jane Peterson

Richland College, Dallas County

Community College Distnct

Nell Ann Pickett

Hinds Community College

Charles I. Schuster

University of Wisconsin, Milwaukee

Tony Silva

Purdue University

Lynn Quitman Troyka

Oueensborough Community

College, CUNY, ret.

Karen S. Uehling

Boise State University

Billie J. Wahlstrom

University of Minnesota

Evelyn E. Webb

Mississippi State Board for

Community and Junior Colleges

HanveyS. Wiener

MarymountManhattan College 


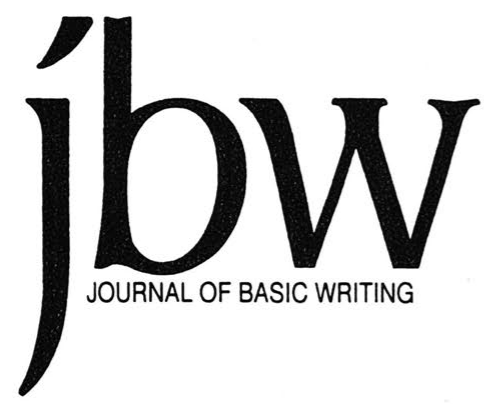

VOLUME 18

Unraveling at Both Ends: Anti-Undergraduate Education, Anti-Affirmative Action, and Basic Writing at Research Schools Gail Stygall

Inventing Academic Discourse: Teaching (and Learning)

Marginal Poise and Fugitive Truth

Jane E. Hindman

Building Bridges To Academic Discourse: The Peer Group Leader in Basic Writing Peer Response Groups

Laurie Grobman

Just Writing, Basically: Basic Writers on Basic Writing

Linda Adler-Kassner

The Representation of Basic Writers in Basic Writing

Scholarship, or Who is Quentin Pierce?

Susanmarie Harrington

Investigating Our Discursive History: JBW and the Construction of the "Basic Writer's" Identity Laura Gray-Rosendale

News and Announcements 


\section{CALL FOR ARTICLES}

We welcome manuscripts of 10-20 pages on topics related to basic writing, broadly interpreted.

Manuscripts will be refereed anonymously. We require five copies of a manuscript and an abstract of about 100 words. To assure impartial review, give author information and a short biographical note for publication on the cover page only. Papers which are accepted will eventually have to supply camera-ready copy for all ancillary material (tables, charts, etc.). One copy of each manuscript not accepted for publication will be returned to the author, if we receive sufficient stamps (no meter strips) clipped to a self-addressed envelope. We require the MLA style (MLA Handbook for Writers of Research Papers, $4 r d$ ed., 1995). For further guidance, send a stamped letter-size, self-addressed envelope for our style sheet and for camera-ready specifications.

All manuscripts must focus clearly on basic writing and must add substantively to the existing literature. We seek manuscripts that are original, stimulating, well-grounded in theory, and clearly related to practice. Work that reiterates what is known or work previously published will not be considered.

We invite authors to write about such matters as classroom practices in relation to basic writing theory; cognitive and rhetorical theories and their relation to basic writing, social, psychological, and cultural implications of literacy; discourse theory, grammar, spelling, and error analysis; linguistics; computers and new technologies in basic writing; English as a second language; assessment and evaluation; writing center practices; teaching logs and the development of new methodologies; and cross-disciplinary studies combining basic writing with psychology, anthropology, journalism, and art. We publish observational studies as well as theoretical discussions on relationships between basic writing and reading, or the study of literature, or speech, or listening. The term "basic writer" is used with wide diversity today, sometimes referring to a student from a highly oral tradition with little experience in writing academic discourse, and sometimes referring to a student whose academic writing is fluent but otherwise deficient. To help readers therefore, authors should describe clearly the student population which they are discussing.

We particularly encourage a variety of manuscripts: speculative discussions which venture fresh interpretations; essays which draw heavily on student writing as supportive evidence for new observations; research reports, written in nontechnical language, which offer observations previously unknown or unsubstantiated; and collaborative writings which provocatively debate more than one side of a central controversy.

A "Mina P. Shaughnessy Writing Award" is given to the author of the best JBW article every two years (four issues). The prize is $\$ 500$, now courtesy of Lynn Quitman Troyka. The winner, to be selected by a jury of three scholars/teachers not on our editorial board, is announced in our pages and elsewhere. 


\section{EDITORS' COLUMN}

We write this column at a time of great change for the institution of public higher education in the United States and, most particularly for us at CUNY. For the first time in almost three decades, starting in the spring 2000 semester, CUNY will not allow the admission of "remedial" students to four of its senior colleges: Baruch, Brooklyn, Hunter, and Queens Colleges. Much debate has occurred since the "no remediation" policy was passed by the CUNY Board of Trustees in January 1999. The last step in the process took place this past November 22nd. As Karen Arenson wrote in the New York Times, "The New York State Regents...cleared the way for the City University of New York to begin to exclude students from its bachelors' degree programs who cannot demonstrate that they are ready to begin collegelevel work in both mathematics and English" (23 November 1999:A1+). Looking at this sentence, we notice several problematic phrases. What does it mean to say students "cannot demonstrate" readiness-and who gets to determine that? Is there a generally accepted definition of "college-level work"? We might benefit from doing a close analysis of this and other articles on CUNY to understand the cultural dynamics at work in the demise of basic writing and remedial programs in the senior colleges.

Using just such a close analysis, Gail Stygall examines a similar situation that she faced at the University of Washington. Her description of the political climate that existed as the public considered the 1998 Washington State Initiative I-200 affirms the role of media in influencing voters. The question put to the voters was whether "government should be prohibited from discriminating or granting preferential treatment on the basis of race, sex, color, ethnicity, or national origin in public employment, education, and contracting." Stygall uses the tools of critical discourse analysis to illustrate how an article in a major Seattle newspaper, which seemingly supported the rejection of I-200, in fact ended up arguing for it. The initiative was passed by more than half the voters. The effect of this anti-affirmative action initiative has been a $31.6 \%$ decline in enrollments of new underrepresented freshmen at the University of Washington from 1998 to 1999.

The need to understand the values inherent in and the complexities of language use are presented in a different but related way in Jane Hindman's essay, "Inventing Academic Discourse: Teaching (and Leaming) Marginal Poise and Fugitive Truth." Hindman contends that as long as we English teachers alone decide what is good writing and assign grades for it, we cannot de-center authority. Nor, therefore, 
will we be able to enable real change in the students' understanding of standards and means of evaluation in the university. She describes a collaborative project in which students learn to "read" placement exams, to negotiate possible scores, to discover what is valued in the academy, and ultimately to evaluate the essays. Particularly instructive in the project are those instances when students rate an essay a " 1 " and teachers rate it a " 4 " (the lowest and highest possible scores respectively).

Learning to understand and respond to writing while working in a group is the focus of Laurie Grobman's essay, which describes how students learn to respond to their peers' writing online. She explains how by working with a peer response leader (a sophomore student guide), students in the peer response group learned how to discuss each other's writing electronically. Grobman presents the difficulties that emerged from the project and then makes suggestions intended to improve the relationship between peer response leader and peer response group and to make this model even more effective

In light of recent political actions at CUNY and elsewhere to eliminate basic writers from senior colleges, Linda Adler-Kassner urges student-centered research both as a means of protecting programs and knowing our students better. Her article focuses on interviews with two students placed in basic writing classes. What is especially revealing is that these students, Tom and Susan, do not know that they are, nor do they see themselves as "basic writers." They realize they are not in the "regular" first-year composition course, but they do not know that the "Writing Techniques" class into which they have been placed is basic writing. When they are asked about what it means to be a basic writer, Tom says that it must mean "writing simple," and Susan says that it must be a person who "writes things just... like their given assignment." Are Tom and Susan basic writers? What does this term mean to us today and what has it meant over time?

The next two essays provide reflective, historicizing answers to such critical questions. What has JBW meant to the definition of basic writing? What has it meant to the students, teachers, and researchers involved in basic writing programs? By categorizing articles that appeared in volumes 1 to 17 , Susanmarie Harrington examines the role $J B W$ has played in constructing the basic writer. Harrington's examination of general trends looks particularly at the inclusion of student voices in research. Beginning with the notion that "JBW institutionalizes basic writing," she has become increasingly concerned that as we have begun to publish more theoretical articles and essays on teacher expectations, the students have become invisible. Urging more "student-present scholarship" (she 
explicity has Adler-Kassner's and implicitly Grobman's and Hindman's - sort of research in mind), Harrington's exhorts us to realize that such scholarship is especially critical at a time when politicians are controlling the fates of our programs and students.

The Harrington essay connects directly with Laura GrayRosendale's "Mapping Our Discursive History: The Journal of Basic Writing and the Construction of the 'Basic Writer's' Identity." GrayRosendale reflects on the role JBWhas played in basic writing history from 1975 to the present by focusing primarily on a 1978 text by Louise Yelin, the Myra Kogen/Janice Hays debate of 1980, and a series of articles that articulate the conflict model. It is her contention that these texts disrupted and contested previous theories of basic writing that, in fact, it should be the function of $J B W$ to disrupt, call into question, and contest the metaphors and previous constructions of our field.

So it is that this issue of $J B W$ has at its heart self-reflection and close analysis: the close reading of public documents, the examination of the language of inclusion and exclusion, the deep description of students, and a discursive history of $J B W$ itself. At this moment, as the place of basic writers is being questioned, as public higher education is being restructured nationally, and as JBWnears its twenty-fifth birthday, we must consider and question what our role will be in the next century - whether, indeed, our students will have a place in the postsecondary education of the future.

-- Trudy Smoke and George Otte 


\section{UNRAVELING AT BOTH ENDS: ANTI-UNDERGRADUATE EDU- CATION, ANTI-AFFIRMATIVE ACTION, AND BASIC WRITING AT RESEARCH SCHOOLS}

ABSTRACT: This article describes the double bind of basic writing programs at public research institutions on the West Coast, offering the situation at the University of Washington as a case study. With a conflict between the university's perceived mission as research and graduate education and its commitment to diversity, the university's Educational Opportunity Program writing sequence is itself at risk in the face of the anti-affirmative action movement, Initiative 200. Using Critical Discourse Analysis to analyze the university's public documents on mission and diversity, a Seattle newspaper's description of the EOP program and the consequences of the passage of I-200, and the documents of a gubernatorial commission of the future of higher education in Washington state, the author advocates using this analysis in the public debate about diversity and basic writing programs.

Initiative I-200: The Washington State Civil Rights Act Shall government be prohibited from discriminating or granting preferential treatment based on race, sex, color, ethnicity or national origin in public employment, education, and contracting?

Passed 58.5\%, November 3, 1998

While Maureen Hourigan and others have argued that the theorizing and practice of basic writing should not originate in the research universities (1996), where basic writing is often beneath the horizon, basic writing programs at Carnegie Research 1 universities remain an important facet of work and thought in issues of basic writing. Think of us as educational canaries, if you will, whose lost voices may preface the dismantling of diversity in U.S. public universities, and con-

Gail Stygall is Associate Professor of English Language and Literature at the University of Washington, where she teaches courses in writing, rhetorical theory, and discourse analysis. She is Director of Expository Writing, which includes the Educational Opportunity Writing Program. Her most recent work in composition and rhetoric includes a collection, Discourse Studies and Composition, coedited with Ellen Barton (Hampton Press, 2000), and an analysis of the job market for Ph.D.s in rhetoric and composition to appear in the Spring 2000 Issue of Rhetorical Review. 
tributing to a system that permanently locates basic writing students and students of color in lower tiers of the hierarchy. Part of the reason for this lies in the sheer numbers of degrees granted by RU-1 schools. As the recent Boyer Commission report notes, while research institutions "make up only 3 percent of the total number of institutions of higher learning ... they confer 32 percent of the baccalaureate degrees" (1998). For basic writers, often first generation college students and/ or students of color, access to baccalaureate degrees at research schools is often through or enhanced by enrollment and participation in basic writing and academic support programs. Indeed, diversity and retention of underrepresented students at public research schools may well be a partial function of the success of their basic writing programs.

Currently though, on the West Coast, basic writing programs at public research institutions are caught in a double bind. On the one hand, the public research institutions typically perceive their educational mission to be research and graduate education. The consequence of this perception is to undervalue even retaining first- and secondyear undergraduate students at their campuses, or at the very least, limit them as my institution suggests, to "select freshmen most prepared to take advantage of a research based university ... result[ing] in a rise in the admissions index" (Strategy II). With more "efficient" use of resources demanded by the deepening corporatization of the university, lower division undergraduate writing instruction, itself often construed as "remediation," conflates with all writing instruction to make it superfluous, especially basic writing instruction.

This movement is not limited to my institution: for many of the West Coast's RU-1 universities, the change has been under way for most of the past decade. And, unlike schools in the East and Midwest, mainstreaming of underprepared students has not been the primary response from writing programs. Instead, the "intensive," "stretch" or "turbo" course has seemed the better option for providing continuing support for underprepared students. ${ }^{1}$ Sometimes the move from a separate, "remedial" writing course to one of these options has been generated by university-level, higher administration. As Glynda Hull reports, the University of California system simply abolished "remediation" in 1991. She says that, while generations of faculty had repeatedly affirmed the need to teach all students who had been admitted to Berkeley over the $20^{\text {th }}$ century, the administration made the change by fiat, driven by financial needs. As she indicates, this

... represented a new strategy on the part of the administration, which through this century, had been content to let faculty and individual campuses struggle with the remedial question and decide their own answers. In April, 1991, the UC President issued a directive, which came to be known as the 
"Gardner Initiative," instructing all campus administrators to transfer remedial courses in English and mathematics to community colleges or Extension programs. (19)

The result for the University of California campuses was a rethinking of how to support underprepared students, with the new system offering "turbo" courses, intensive, smaller, more theoretically sound writing courses. ${ }^{2}$ Nonetheless, even while the 1991 Gardner Initiative was generated by finances and resulted in positive change in writing instruction, the symbolic value of removing "remedial" courses is important. When pressed financially, research universities cut courses deemed less central to their mission.

On the other hand, the recent successful anti-affirmative action ballot initiatives, in California and in my home state of Washington have contributed to decreasing public research institutions' ability to attract, recruit, and admit representatively diverse student populations. Last November, the voters of the state of Washington overwhelmingly answered "yes" to the question in the "The Washington State Civil Rights Act" query:

Shall government be prohibited from discriminating or granting preferential treatment based on race, sex, ethnicity or national origin in public employment, education, and contracting?

You'll note that the ballot question says nothing about banning affirmative action, but that of course was its entire intent. By December of 1998, the three-decades old Educational Opportunity Program at the University of Washington, whose two-course, for credit, compositionrequirement fulfilling writing sequence is housed in the Expository Writing Program which I direct, was as much at risk as its students. ${ }^{3}$ And in California, the effect of Proposition 209 had been to significantly decrease the population of underrepresented students at the most elite schools of the University of California system, with underrepresented students "cascading" down to the less elite campuses (Miller 46). ${ }^{4}$

These two movements-the falling away from lower division undergraduate services at public research institutions and the embracing of the anti-affirmative action crusade-are often addressed administratively as separate issues. Yet the interaction between the two movements is invidious and has contributed to our losing sight of the main event. While we have argued about whether to mainstream basic writers, whether to test basic writers, and even whether to acknowledge the social perceptions that "create" the subject position of basic writers, those who have no interest in a wider educational franchise are 
closing the doors at research institutions. The canaries are gasping.

As Michael Bérubé characterizes the current educational impasse between progressives and liberals in the face of conservative forces,

In such stormy political weather as this, liberals [and progressives] have a crucial role to play in educational policy, and it consists largely of supporting American children's right to a public education system unmarked by savage inequalities, and of maintaining higher education policies that make college as widely available as possible. . . [For progressives] To engage in mundane-and fundamental-local policy struggles such as these [financing education] without the aid of liberal constituencies is to treat American public education as if its existence were beyond question, as if there were no way that conservatives could shrink the franchise, as if it only remained for us to talk about multicultural theory and curricular procedure. (237)

He argues in Public Access that we must become public intellectuals in the local sense, engaging in the fight to retain a vital public education system. When progressives and liberals argue about basic writing and the categorization of basic writers, we need to remember that none of us intends for the access to education itself to disappear. Yet that is clearly the thrust of initiatives such as California and Washington's initiatives.

Using the case of Washington as an example, I examine the two "unraveling" ends of basic writing at research schools-lower division undergraduate education and anti-affirmative action. In doing so, I analyze, primarily through critical discourse analysis, the textual-rhetorical space of lower-division writing in the University of Washington's public documents on future enrollment, a lengthy local newspaper article on the Educational Opportunity Program at the University of Washington in the shadow of I-200, and the report of the Governor's "2020 Commission on Higher Education." I want to foreground the need for rhetoric and composition specialists, especially those also responsible for basic writing or Educational Opportunity Program writing, to participate vocally in the available university and political forums. The challenge for rhetoric and composition scholars in reading these materials is to take seriously those public documents that educational institutions and governmental commissions on education produce. Legislators and educational policy makers in state governments treat university policy documents as just that-policy contracts. So when these documents contradict and undo other policy initiatives, such as diversity commitments, we must point to the contradictions and present counter arguments. With attention, and through attention to the pro- 
duction of knowledge, we can make local, public resistance possible and effective.

\section{Scene 1}

It was my first meeting as a member of the Faculty Senate's Executive Committee. English was the largest unit in the division and I had served in the Senate for several years, agreeing to serve on the Executive Committee. I was just getting ready to go through the tenure process. We had a new president, coming to us from the University of North Carolina, and we all were interested in what was in store. To say the Senate had been "reactive" rather than "proactive" in the past few years would be putting it mildly. The Provost began to tell us about the new master plan, which apparently had been completed before the academic year began. We were seeing this "master plan," the new president's first public statement on the future of the university, for the first time. The meeting virtually halted as the President of the Senate asked for copies of the report, the Provost replying that he didn't realize that we might want them. Every Executive Committee member wanted one.

\section{End of Scene}

Who speaks? What can they speak? Who is silent? My method in analyzing the documents arising from Scene 1 attempts to answers those questions.

I took the report home, reading with interest that the largest growth in the college population over the next 20 years was likely to be in under-represented populations. However, when I reached the following paragraph, I became quite concerned:

There is also the transition from $\mathrm{K}-12$ to higher education. The question of remedial education is a vexing one. At the heart of the problem is an inadequate link between $\mathrm{K}-12$ and the colleges and universities. There is no question that we are bound together: We provide K-12 with teachers and they provide us with students. The quality of teachers and students matters to both. Running Start is one example of a partnership at work, but it is not enough. Every time the University of Washington must offer another space for remedial education-in foreign language, in mathematics, and in English-it is using instructional resources to do something that should already have been done.

For nearly three decades, the compositionists in the English department had been insisting that our "basic writing" program was NOT 
remedial, that its students should have and finally did receive full credit, as well as satisfying the composition part of the general education requirements. In fact, we had come to think of it as the place where talented students who may not have been on an academic track in high school could get needed information about and practice in academic writing, in richer, longer, ultimately better ways than our other one quarter, "regular" composition course provided. So I took my place in that line of compositionists, and I squawked, complained, and argued. I alerted the potential allies of the program, and together we insisted that there were no remedial English composition courses.

Yet what I later realized was that all lower division writing is remedial, superfluous, unnecessary in an "efficient" system. The reference in the passage to "Running Start" makes the efficiency trope clear. Running Start is a Washington state program in which high school juniors and seniors can simultaneously attend high school and community college, receiving credit for both, and thus eliminating the need for lower division courses at baccalaureate institutions. Just a few years old, 500 of last year's entering first year class at the University of Washington (a little more than $20 \%$ of the entering class) had Running Start credit, and almost every one of them had it in composition and thus had no further composition requirement.

So who is speaking this document? Without faculty input, the document presented us an unusually clear instance of the administration speaking, stripped of any pretense of faculty input. The "we" of the document, the university's upper administration, speaks to the "you" of a Higher Education Coordinating Board, state legislator, state administrator, state business community audience. The document proposes that its readers consider the current state of educational cooperation to be parallel with the moment of the domestication of wild grasses for agriculture (12), presumably before the benefits and opportunities of agribusiness, and argues that inter-institutional cooperation, like large-scale agriculture supporting early civilizations, is the key to solving access to higher education. That is, the RU-1's share of agricultural duties is to grow the top of the line hybrids.

Confirmation of the continuing sense of lower division composition as superfluous came two years later in the revised "master plan" on enrollment demand, produced in November of 1997. The corresponding segment now read:

Education should be a seamless process: high school graduates prepared for freshman level work in community colleges or universities; community college transfers ready for a university major. It is not. Large numbers of students repeat in college materials that they should have mastered in high school, especially in foreign languages, math and science. Commu- 
nity college transfers often find that they have not taken the right courses, or enough courses, or what they learned does not match what they are expected to know.

\section{Recommendations (several lines later)}

\section{To Prepare Freshmen}

- With $\mathrm{K}-12$, coordinate teaching and learning in areas related to university proficiencies or core areas of study, especially in the following areas:

- Mathematics including general quantitative reasoning, precalculus and calculus.

- Foreign language instruction, especially the commonly taught languages of French, Spanish and German.

- Science instruction including chemistry, physics and biology.

- Writing composition.

Thus while the earlier outcry managed to displace the overt designation of any particular composition course as remedial, the system designated all "writing composition" as suspect. The revised document contains several other so-called strategies to improve efficiency, couched in the language of corporate higher education, including moving students directly from community colleges into majors to not hiring faculty whose major responsibilities involve lower division courses [read composition faculty]. In short, the most efficient, streamlined, smart business operation virtually eliminates lower division instruction. To be maximally efficient, the university should admit only those students who can benefit from attending a research university, presumably the students who have APed, CLEPed, or Running Started themselves out of a lower division general education. If only we could get them to select their major while in their junior year of high school (first year of Running Start), it would be ever so much more efficient.

But a whole group of people have disappeared since the original document: the underrepresented students, a population largely coterminous with our Educational Opportunity Program basic writing students. In the original draft report, the college populations expecting the most growth were Asian Americans, projected to increase 252\%, African Americans at $80 \%$, and Latina/o students at $113 \%$. It is this group of students who represent the greatest part of the enrollment pressure on the state's four-year institutions, the very genesis of the need for any enrollment strategy report. These same students, however, are absent in the final report, presumably dispersed via the elimi- 
nation of remediation, and the inefficiency of supposedly duplicated educational services. And these students also disappear from the fouryear baccalaureates in a statistical shell game. The Higher Education Coordinating Board chooses to report aggregate minority enrollment figures from both the community college system and the six baccalaureates. Doing so allows them to claim that minority enrollment in higher education matches state's minority population. Ignoring the separation of minority students into the community college has important effects as Eric Branscomb points out: to strand and to permanently place underrepresented students in community colleges. And conveniently, the elite institutions can quit bothering with this messy commitment to diversity.

\section{Scene 2}

It's approximately three weeks before the November election. I'm reading the paper at home and spot an article reporting on a poll showing that more than $60 \%$ of Washington state's population plans to vote "yes" on Initiative 200, banning "preferential" treatment of anyone in government. I shake my head, thinking that surely we aren't going to imitate California. The article hangs over me for days. And in that same week on Sunday, I read Marsha King's article in the Sunday Seattle Times, and I worry. If this article is in a newspaper which has publically taken a vigorous stand against I-200, supporters of affirmative-action are in deep trouble.

\section{End of Scene}

They were in deep trouble; the vote came in at $58.5 \%$ in favor of Initiative 200. In this second analysis, I review that particular article that I found so troubling through the lens of critical discourse analysis. While the Seattle Times opposed Initiative-200, the positions adopted in this article suggest deep contradictions in that support. I'm identifying two of those positions here-the ideologies of fairness and of numbers, as examples of arguments that we, as public advocates of our students and teaching, must counter.

The two ideologies are pervasive in discussion about education, and they point to one of the most profound problems in making our case to the public. The ideologies undercut commitments to diversity in public higher education, yet they are widely held by the public, who have rarely examined them closely. Because these ideologies undercut commitments to diversity, we need a clear understanding of how they work, particularly in public forums. The first, that of fairness, is pervasive in discussions about affirmative action and civil rights, at least in part because fairness and equality are closely related concepts 
in government and law. Legal scholar Martha Minow has written eloquently of the problem within legal analysis of associating "sameness with equality and difference with inferiority or disability" (89). In her argument, even the notion of equality itself creates the framework of inequality: if some are equal, then there must be others who are not. The problem as she analyzes it is that bi-polar categories help maintain inequality. If this larger legal framework maintains inequality, the internal conventions maintain that all parties are ideally equal, even when it is manifestly obvious that they are not. Contract law is one area in which this presumption is voiced, and equality is presumed even when one individual signs a contract with a giant corporation. A valid contract assumes equality to bargain and a meeting of the minds. Think of the "contracts" you sign with credit card companies or mortgage or rental agreements: take our terms or go without. With the ideologies of equality and fairness so embedded in the political and legal systems, it should be no surprise to find its principles applied to educational situations in which, once again, it is manifestly obvious that the "system" produces neither fairness nor equality. Mentioning fairness and equality in the educational context brings to mind the individual student, each of whom must be treated fairly and equally, and masks the treatment of groups of underrepresented students. The ideologies of fairness and equality in discussions of affirmative action thus become "conversation stoppers," halting talk at the point we perceive that anyone might be treated unfairly. This ideological construction is threaded throughout the Seattle Times article, undermining the newspaper's anti-I-200 position.

The second ideology, that of numbers, quantification, and statistics, is equally powerful. In this ideology, numbers are fair and objective, telling the "real" story, outside of human prejudices. As historian and philosopher of quantitative science Theodore M. Porter has argued, the rise of statistics co-occurs with the rise of Western democracies. They are, in fact, part of governing. He argues:

It is, on the whole, external pressure that has lead to the increasing importance of calculation in administration and politics. Those whose authority is suspect, and who are obliged to deal with an involved and suspicious public, are much more likely to make their decisions by the numbers than are those who govern by divine or hereditary right . . . Calculation is one of the most convincing ways by which a democracy can reach an effective decision in cases of potential controversy, while simultaneously avoiding and minimizing the disorderly effects of vigorous public involvement. (28)

Those who govern can turn to the numbers and say to the public, "what 
else can we do when we are faced with these numbers?" deflecting discussion away from whether those are the right numbers to be considering at all. As Porter suggests, "[q]uantitative rigor is most valued when there is political need of its odor of objectivity, as a defense against suspicions of ideological bias or, worse, corruption" (30). Porter sees the rhetorical power of quantification in part as restricting the domain of what can be discussed in a numerical framework. The numerical framework of limits and statistical analysis always within those limits are another feature of the coverage of educational affirmative action in the Seattle Times article. So with this framework in place, let us turn to the Seattle Times and this key article.

The Seattle Times is one of two daily newspapers in Seattle. While Washington state is approximately $90 \%$ European American, Seattle has a large population of Asian and Pacific Islanders, some large pockets of Eastern European immigrants, East Africans, and an African American community of about $10 \%$ of the city's population. The author of the article Marsha King had been on the education beat for several years often writing lengthy feature articles. This article, "Diversity Efforts Have Not Been Without Controversy," was a Sunday feature, the lead article in the "Local News" section, a little more than 1,000 words long. While the article's lead section focuses on the Educational Opportunity Program, its second and subsequent sections move away from "educational" efforts, that is, support for underrepresented students at the university, to the key point: admissions. Undergraduate admissions to the University of Washington is first, followed by a subhead "Gaps in Grades and Test Scores," a reference to high school grades and SAT scores, and then moves to graduate and professional admission. Two brief sections on actual enrollment and graduation rates follow, with the final section headed "Diversity Efforts Continue." The article's photograph is centered on the fold line on the front page, with the article beginning below, while the continuation inside takes two entire pages.

I followed the lexical chains in the article to isolate agency, action, and the stakes being described. In particular, I was interested in what actions university administrators could enact, what people of color could do, and what work was distributed to "statives," marking university life. I was also interested in the adjectives and nouns designating each group of stakeholders in the university's admissions process. To give you a sense of how the chaining works in this article, I quote the opening below:

One afternoon in May 1968, members of the University of Washington's newly formed Black Student Union (BSU) marched into the office of their school's president and demanded, among other things, that the UW admit more minor- 
ity students. President Charles Odegaard and faculty leaders pledged to address the concerns.

With that start, here are the actions open to people of color in this article: one subset of actions includes marched, demanded, pushed, contended, stormed, rendered, prodded, raged. Another subset includes couldn't compete, didn't graduate, weren't mentioned, were identified, lag, dropped, remained. From the lexical chains of verbs alone, people of color were argumentative and emotional; at the same time, they weren't competitive, constituting the leftovers, the less able. University officials on the other hand pledged, estimated, counted, knew, looked, created, admitted, found, projected, recruited, set up, toughened, complied, appealed, ruled, in short governed a university community rationally. Race was represented as a factor (as in deciding or significant factor), extra credit, boost, leg up, points, advantage, or consideration. Students of color were represented as minorities, race-based admissions, subject to growth, minority pool, separate, less academically qualified, quotas, special cases, 15\% below the minimum, underrepresented, and then specifically as African American, Hispanic, Native American, Filipino and Pacific Islander.

What was at stake here was the real estate of "undergraduate slots," "room," and the "offers" that Washington's schools could make. In short, the stake is sketched as a kind of property interest in available slots. These offers and slots were characterized throughout the article in quantitative terms, arrived at through numerical grade point averages and SAT scores, minimum admission criteria and selection procedures that totaled numerically. And this numerical orientation interlocks with the ideology of fairness. What could be more fair than admitting students by the numbers? "Fairness" as a background condition for the argument against affirmative-action programs and support programs for underrepresented groups is suggested in the passages below.

168 If extra credit for race were taken away,

169 these young men and women would have been denied admission.

170 In their place would be different young men and women, primarily Caucasians and Asian Americans.

200 It's fair to say

201 that the national gap of about 90 points on the SAT between large groups of blacks and whites is considered significant.

So what underrepresented students are getting is "unfair," because they receive "extra credit," and the students who should have been admitted were not. Moreover, "it's fair" to mention that black stu- 
dents typically score 90 points lower on the SAT, without comment about the arguments over cultural, racial, and gender bias on the SAT.

Another aspect of the fairness ideology is also embedded into journalism practices. As we know from critical discourse analysts such as Teun van Dijk, and Norman Fairclough, the newspapers and other media do constant work preserving hierarchy. One of the ways they do this in the U.S. is through the maintaining of even-handedness or "fairness" in the reporting of events. Thus, rough equality is given to "sides" or "perspectives," ignoring the issue of value, flattening important distinctions. While much has been made of "advocacy" journalism, the standard daily fare in most U.S. newspapers is giving all sides "equal" say, because that is what's "fair." This discussion of "fairness" is a constant refrain within the article. In the first example, lines 29-35, appearing near the beginning of the article, read as follows:

29 Most people would likely agree

30 that helping to increase the number of collegeeducated minorities is a good thing for those individuals and societies.

31 But there's one strategy

32 that's been used around the nation

33 that many people don't like:

34 awarding some college applicants an advantage for their race, effectively displacing others who have equal or better grades and test scores.

So, fair-minded people want to help individuals and societies by increasing the number of college-educated minorities except of course unless they displace others (read white, middle class) students "who have equal or better grades and test scores." In lines 168-170, we have fairness raised in terms of the "extra credit" given to race, and that point is emphasized in the assertion of a significant gap between black and white students on the SAT scores.

The playing out of the ideology of numbers has two distinct patterns in this discourse. One is in the assertion of the limitation of the educational franchise. That is, there are only so many slots and they are limited and apparently cannot be expanded.

48 But few would disagree

49 that the debate potentially is critical for this state

50 where demand for undergraduate slots is projected to increase dramatically

51 due to the children of baby boomers

52 and due to the growth rate of the minority population, 
which is expected to be much higher than nonminorities.

54 Across the nation, race-based admissions policies are used by selective institutions-schools for the most part

55 that have more applicants

56 than they have room.

Notice in lines 48-56 that the emphasis falls on the "growth rate of the minority population which is expected to be much higher than nonminorities," giving the other framework for numbers-the minorities who will overpopulate our educational institutions (even though the children of the baby boomers participate in this as well). The emphasis on place, room, and more applicants than space, then is applied to the two most selective state schools in Washington state, Western Washington University and the University of Washington.

153 Washington's colleges and universities made about 27,000 offers to high-school seniors

154 who applied for admission this fall.

155 Of those, the UW and Western accounted for 14,000.

156 Race made the difference in roughly 440 cases, primarily at the UW.

Here we have an actual count for just how many admission offers were affected by "race." And our discussion has been limited to space at the most competitive, in-state universities. As Porter suggested, quantification sets the parameters: there are only so many spaces, and in a specific number of those spaces "race made a difference."

\section{Scene 3}

In a large lecture hall on the University of Washington campus, the Washington 2020 Commission held a public meeting, attended by both students and faculty. The meeting was not intended to gather information from students and faculty; it was simply to present the Commission's perspectives. Both students and faculty ask questions, sometimes heatedly, about the direction of the Commission. Much of what the Commission members have to say translates into "bottom line" rhetoric. I ask why the Commission is advocating new admissions standards at the same time it asserts a commitment to "reaching out" to underrepresented groups. At this point, one of the members accuses faculty of avoiding numerical assessments of students, refusing to separate the truly capable, refusing to be "accountable." No one mentions that the proposals for electronic education and outsourcing will handle stu- 
dent growth by keeping some students off campus.

\section{End of Scene}

Once again, the questions of who speaks and who is silent are at issue. The final document that I want to consider briefly is a political one, the product of a gubernatorial commission, charged with setting the direction of higher education in Washington state for the next twenty-five years. No faculty member sat on the commission and only one community college student was a member. It was composed primarily of executives of major corporations in the state, many of whom had served at various times as regents of the various four-year institutions. I have included below two excerpts from their final report, which appeared less than a week after Initiative-200 was successful.

\section{Excerpt 1}

To fully serve the educational needs of Washington's people and its employers, we must do more than simply respond to those seeking entry to our post-secondary institutions. We must reach out to those who traditionally have been underrepresented and under-served by post-secondary education: people from low-income families, people of color, families with no prior experience with post-secondary education and people who live far from traditional campuses. This will require not just system expansion, but also active recruitment of students from these families and communities, and a commitment to adapt service delivery to their needs.

\section{Excerpt 2}

Given the immediacy of the increase in demand, the enrollment plan should give priority to strategies that expand capacity without requiring new construction. Priority should be given to proposals that: (a) reduce the cost of delivery by adding capacity at marginal cost, or (b) expand programs in high demand/high cost areas, subject to the provision of start-up funds. Simultaneously, the state should expedite the build-out of branch campuses that have already been authorized. These campuses are needed now to serve urban communities that lack access to education beyond the community college level.

In addition, this Enrollment Plan should provide for contracting with independent and for-profit providers when public institutions are full. If the state can make agreements with independent 
providers that expand capacity less expensively than expanding the capacity of full public institutions, then this option should be used.

In the first excerpt, the commission makes clear that it intends to stay committed to broadening the educational franchise. They speak in terms of "reaching out," and "not just system expansion but also active recruitment" of underrepresented students. In the second excerpt, paragraphs 2 and 3 , we see the means by which this is apparently to be accomplished-the further corporatization and privatization of our public universities. The metaphor of the economy applied to university is literalized, with phrases like "adding capacity at marginal cost," entrepreneurial language such as "start up funds" and contract language of "contracting with independent and for-profit providers." And once again, we see the ideology of numbers in the background-we have only so many slots on the current campuses, so further access to education must come without building new buildings, and by "outsourcing" the excess demand to "independent and for-profit providers." So we will actively recruit the under-represented students into something less than the regular universities. For "them" we'll contract outside the university.

\section{Aftermath}

From the October 28, 1999, University of Washington's University Week:

The enrollments of new underrepresented freshmen (African Americans, American Indians and Latinos) declined by 31.6 percent, after the passage of Initiative 200, the law that prohibits the consideration of race or ethnicity in admissions. The changes from 1998 to 1999 are: African American, from 124 to 83 (down 33 percent); American Indian, 53 to 41 (down 23 percent); Latino, 196 to 131 (down 33 percent); Asian American and Pacific Islander, 1,053 to 1,118 (up 6 percent); and Caucasian, 2,299 to 2,439 (up 6 percent). (1-2)

The effect on the Educational Opportunity Program writing course enrollment reflects these changes. From our typical 12 sections of the initial course in the two-course sequence with 18 students registered in each, we dropped to seven sections, with the cap lowered to 15 students. The real estate of admission "slots" previously awarded to underrepresented students now returns to its rightful owners. 


\section{Conclusion}

The use of critical discourse analysis, here combining of the analysis of agents and actions along with the ideological tropes of fairness and the objectivity of numbers, helps explain how the newspaper that supports the rejection of the anti-affirmative action initiative ends up arguing for it and how the 2020 Commission can both welcome and reject the increase in enrollment in underrepresented students. Pointing to those moves is work for local, public intellectuals-writing program administrators and rhetoricians challenging conventional understandings, persuading governing boards to examine the contradictions in policy, broadening the public debate. Thus, this paper is not only about the double bind of anti-lower division undergraduate education and anti-affirmative action, but it is also a paper investigating the sociopolitical linguistic milieus in which our programs exist.

But we can't simply speak out without doing our homework. We must read our institution's internal documents and analyze them for inconsistencies and contradictions. The contradictions found in my institution's documents were not glaring wake-up calls to eliminate programs that enhanced diversity, a move that might have awakened more sympathetic faculty attention. Instead, they were more subtle, identifying the courses as duplications that most underprepared students would need to succeed in the university. Similarly, the 2020 Commission's call for increased recruitment is canceled when the means of educating those newly recruited students are moved off campus, to the "kitchen table computer" or "independent and for-profit providers." ${ }^{15}$ We need to know where the competing commitments conflict. We must analyze the local scene and become familiar with the ways in which these issues are debated in public as well.

Critical discourse analysis is one method by which we can pinpoint the ruptures and contradictions, knowledge we need to have on hand if we are to speak as public intellectuals. Along with political and rhetorical analysis, it is a tool that anyone considering a career in rhetoric and composition needs, and as such, it is a required course for our doctoral students. By keeping the ideological in close focus, critical discourse analysis-with its attention to agency, action, stakes, and absence as well as presence-provides us with the analysis tools we need to assess our situations. Once we assess the local terrain, we can begin to challenge the unconsidered ideologies that govern public discussion about access to higher education. How we go about doing that is to take on roles that most faculty never imagined themselves doing: contacting legislators, staying in close contact with our university's representative to the state legislature, asking our professional organizations to provide education about guidance in lobbying, 
and talking with the reporters who cover education in the local media. As Cary Nelson and Stephen Watt put it, "Devote substantial energy to multiple forms of public outreach, from lobbying legislators to explaining our work to general audiences" (13). Tom Fox's fourth chapter of Defending Access: A Critique of Standards in Higher Education sketches the type of political work that can be done on our local campuses; clearly this is one part of the "tactics" we need to use. We also need to take seriously the ordinary documents and local news that describe us and our students, rather than dismissing them as just university politics or local news. As Susan Miller suggests in the introduction to Assuming the Position, "ordinary texts unite experience, official discursive practices and fleeting statements on graphic surfaces that make specific cultural signatures legible" (6). Our work also requires that we attend to those ordinary texts.

No one should expect this to be easy. Academics in general have left the playing field of public intellectual discourse. We are a seldom heard voice on issues of public policy that intersect with higher education. Some, like Stanley Fish, insist that our voices on public and political issues are irrelevant. ${ }^{6}$ But this ignores that fact that what we teach is what will be taught elsewhere, not only in higher education, but in the curriculum of the public schools. And those of us at Carnegie 1 universities need to recognize our role as canaries in the access and diversity debate-if we don't speak, situated as we are in tenured or tenure-line positions at ranked public institutions, we abandon the commitment many of us made to democratic education. As Nelson and Watt put it, "we can work to make things better, losing some battles and winning others, or we can passively let things get worse" (14). I'm opting for learning to speak.

\section{Notes}

1. Arizona State University, for example, has moved to the "stretch" approach, where students produce the same work over two courses instead of one. See, for example, Greg Glau's extensive analysis of the program and its successes, in "The 'Mainstreaming+' Approach," ERIC ED 419237, and "Bringing Them Home: Arizona State University's New Model of Basic Writing Instruction,” ERIC ED 403558.

2. Hull's report, a close study of the history of Subject A testing and courses at the UC-Berkeley campus and a report on the changes in support in writing courses for underprepared students, is a model of the kind of local site studies we need.

3. Students at the University of Washington fulfill the first-year com- 
position requirement in a single quarter's course. Students in the Educational Opportunity Program, whose writing is assessed as needing extended course work, enter a two-quarter sequence. Both quarters count as credit-bearing courses, with one fulfilling the composition requirement, the other counting in general education credit, and students must successfully complete both courses for credit. Students are also required to take two more " $\mathrm{W}$ " courses, originally aimed at disciplinary writing, but these requirements were effectively gutted in 1995, when three first-year writing courses were designated as acceptable fulfillment of the " $W$ " course requirement. While our EOP writing students are typically not the basic writers enrolled in open admissions schools, they are, in this context, less traditionally prepared than their cohort, and as such, are "basic" writers.

4. James Miller, of course, sees this as a positive outcome of Proposition 209.

5. Governor Gary Locke's spokesperson for higher education, former UW Law School Dean, Walter Loh, created a considerable faculty reaction when he suggested that access to higher education could expand by "kitchen table computers" connected to electronic courses at the universities.

6. For an extended discussion of this position, see Fish's Professional Correctness: Literary Studies and Political Change (Cambridge, MA: Harvard UP, 1995).

\section{Works Cited}

Bérubé, Michael. Public Access: Literary Theory and American Cultural Politics. London: Verso, 1994.

Branscomb, H. Eric."Politics and the Basic Writer." Atlanta, GA: Conference on College Composition and Communication, March 1999.

Boyer Commission on Educating Undergraduates in the Research University. "Reinventing Undergraduate Education: A Blueprint for America's Research Universities." <http:// notes.cc.sunysb.edu/Pres/boyer.nsf>

Fox, Tom. Defending Access: A Critique of Standards in Higher Education. Portsmouth, NH: Boynton/Cook, Heinemann, 1999.

Hourigan, Maureen. Literacy as Social Exchange: Intersections of Class, Gender, and Culture. Albany, NY: SUNY Press, 1994.

Hull, Glynda. "Alternatives to Remedial Writing: Lessons from Theory, from History, and a Case in Point." Paper presented at the Con- 
ference on Replacing Remediation in Higher Education. Stanford University. February,1998.

King, Marsha. "Diversity Efforts Have Not Been Without Controvery." Seattle Times 16 Oct. 1998. B1+.

Miller, James. “The Class of Prop. 209." New York Times Magazine 2 May 1999. 44-51, 76, 78-9.

Miller, Susan. Assuming the Positions: Cultural Pedagogy and the Politics of Commonplace Writing. Pittsburgh, PA: University of Pittsburgh Press, 1998.

Minow, Martha. Making All the Difference: Inclusion, Exclusion, and American Law. Ithaca, NY: Cornell University Press, 1990.

Nelson, Cary, and Stephen Watt. Academic Keywords: A Devil's Dictionary for Higher Education. New York: Routledge, 1999.

Porter, Theodore M. “Objectivity as Standardization: The Rhetoric of Impersonality in Measurement, Statistics, and Cost-Benefit Analysis." Annals of Scholarship 9.1-2 (1992): 19-59.

2020 Commission. "Learning for Life: Report of the 2020 Commission on the Future of Post-Secondary Education." Olympia, WA: Washington State Government, 1998.

University of Washington. "The Master Plan for Higher Education, Background Briefing." Seattle, WA: University of Washington, 1995.

University of Washington. "Report of the President's Task Force on Enrollment Planning." Seattle, WA: University of Washington, 1997.

University Week. “UW's 1999 Autumn Quarter Enrollment Figures Are In." University Week 28 Oct. 1999. 1-2. 


\section{INVENTING ACADEMIC DISCOURSE: TEACHING (AND LEARNING) MARGINAL POISE AND FUGITIVE TRUTH}

ABSTRACT: This article further develops earlier versions of transformative pedagogy (e.8., Bartholomae and Petrosky's, Bizzell's, Lu's, Horner's), demonstrating how the self-reflexive tactics required in an analysis of professional practice make visible the ways that compositionists authorize academic discourse. David Bartholomae describes this as the teachers' unconscious need to "see ourselves in what [students] do." The pedagogical method proposed explains how features like "objectivity," "clarity," and [constraining] "voice" in academic discourse are misrecognized in our own rhetoric AND in our evaluations of our students. Because we demand these stylistic and institutionalized conventions of academic discourse from our students, we should - the paper argues - include students in the practices by which we "normalize" these conventions. This article suggests how we might include students in our evaluative practices and discusses the successful results of one such effort.

The course we've defined ... demonstrates our belief that students can learn to transform materials, structures and situations that seem fixed or inevitable, and that in doing so they can move from the margins of the university to establish a place for themselves on the inside. At the end, however, these relationships may remain hesitant and tenuous - partly ... because they have learned ... that successful readers and writers actively seek out the margins and aggressively poise themselves in a hesitant and tenuous relationship to the language and methods of the university. (Bartholomae and Petrosky, 305)

For well over a decade now, we compositionists have been honing our search for pedagogy that disrupts hegemonic, oppressive power structures in the academy and its discourse. Our on-going effort to teach students how to transform rather than merely reproduce existing authoritative discourse(s) has produced various tools. Nonethe-

Jane E. Hindman is an Assistant Professor in the Rhetoric and Writing Studies Department at San Diego State University. Her work appears in the Journal of Basic Writing, Pre/Text, LIT: Literature Interpretation Theory, Rhetoric Review, Journal of Advanced Composition, and others. She's currently completing a book, tentatively entitled Inside Out, dedicated to regendering professional discursive practices. 
less, we have seen little, if any, actual transformative effect emerging from this pedagogical theory and practice.

Pierre Bourdieu's concept of misrecognition helps us understand this persistent lack of substantive change: like the order operating in other social groups Bourdieu examined, our own daily professional practices "deny a truth known and recognized by all, a lie that would deceive no one, were not everyone determined to deceive him- [or her-] self" (133). With respect to writing instruction, this denied truth is that we ourselves - in our positions as writing instructors and in our disciplinary activities - are at least in part responsible for the practices that disenfranchise our students; we are at the center of the procedures of discourse. Breaking this cycle of institutional denial requires recognizing that the source of academic discursive authority is academic disciplinary practice. Such recognition facilitates our further realization that destabilizing the authority of academic discourse requires disrupting our professional practice. To enable this disruption, our pedagogy must make visible what we as teachers of writing take to be the "natural" and therefore - to us - uncontestable (because invisible) aspects of academic discourse.

In other words, a disruptive, transformative pedagogy must alter not just how students see but also how we see and practice academic discourse. Within these pages, I will demonstrate how we can move our recent disciplinary efforts forward in order to construct such pedagogy. I'll also describe one concrete application of a pedagogical approach that does intervene in our disciplinary practice. To conclude, I'll interpret the results of my piloting that approach with groups of basic writing students.

\section{One Blade Shy of a Sharp Edge}

Most of our efforts to identify and apply counter-hegemonic pedagogy have been concerned with empowering students to conceive of and practice academic discourse as a socially constructed process wherein writers negotiate the inevitable conflicts of authority present in competing discourses and/or positionalities. For instance, some feminist applications of critical pedagogy have introduced a concept called "positioned teaching." In general terms, positionality purports to de-center authority through the process of the teacher's and/or students' articulations and defense of their differences, their positions. By exploring conflicting positions, students come to see that hegemonic conceptions of True or Natural or Right are individual rather than universal truths (Jarratt, Bizzell).

Other scholarly accounts of our disciplinary efforts to enable students' critique and subversion of the authority and conventions of aca- 
demic discourse center on the social contexts wherein discursive appropriation and surrender of power and privilege occur. For instance, many of us have accepted the challenge to apply to the classroom Mary Louise Pratt's notion of the "contact zone," a social space where people of unequal levels of power and differing language backgrounds meet to negotiate (or coerce) meaning and authority. Min-Zhan Lu, in her critique of the ideology of "linguistic innocence" and her interpretation of student "error," specifically attends to the configuration of power relations in the writing classroom ("Redefining"). Challenging earlier views of students' mis-appropriations of academic discourse, Lu considers "error" as writers' negotiations - sometimes intentional, sometimes not-between codes of Standard English and other discourses rather than as writers' cognitive or linguistic deficiencies. This reading of student "error," she shows us, disrupts students' hegemonic understanding and teachers' oppressive transmission of Standard English because it "broadens students' sense of the range of options and choices facing a writer. . [and] leaves them to choose in the context of the history, culture, and society in which they live" ("Professing" 457-8).

Bruce Horner likewise reconsiders the "sociality of error"; he enjoins us to teach editing as a means for negotiating the conventions of different discourse communities and thus to position students as empowered agents exercising their choice to communicate effectively with a particular group of readers. Interpreting conventional editing practices as an exercise in mandatory error correction, Horner also argues that the process reinforces students' powerlessness and discourages their taking responsibility for their writing ( "Rethinking").

Surely, we can see that these pedagogical approaches are commendable and useful. Indeed, all these methods can alter how students see language, can reveal its interface with power and politics. Yet these methods do little to intervene in the process by which discursive power is formed at the academy, for illumination of the source of discursive authority of language does not, of itself, subvert that authority; it simply reveals the authority for what it is. The illumination that these methods offer is only partial, for their presentations of the source of discursive authority ignore our inscription in it.

Since we compositionists are the gatekeepers whose evaluations sanction or deny composition students' written product, we are at the center of the interface of language and power at the academy. Like all academics, we are the mainstay of our self-defined, self-professed, and self-authorized discipline; in particular, we writing instructors are the disciplinarians whose practices profess Academic Discourse, as opposed to, say, the Victorian Novel or Biological Psychology or Business Ethics. In effect then, we compositionists are the central authorizers of an autobiographical discipline: our practices define and embody academic discourse, and those practices drive our disciplinary 
knowledge.

Though this wording may seem strange - in its gesture to autobiography, for instance - the vision of professional practice that I'm presenting here is not unprecedented. More than a decade ago, David Bartholomae gave us this perspective on the authority of academic discourse when he described our positive evaluation of student writers as a matter of "seeing ourselves in what they do." He further applied Foucault's understanding of discourse and power to the enabling relationship between basic writers and the academy:

$\ldots$ if the university officially places some students on the margins (in remedial writing courses), that position is a representation (perhaps in its most dramatic and telling form) of the position of every writer. ("Margins" 70)

And, of course, it was Bartholomae and Petrosky who showed us how to involve students in the self-authorizing practices through which scholars create disciplines, a process essential to "inventing the university" and appropriating its discourse. Their curriculum proposed to show students how to "actively seek out the margins and aggressively poise themselves in a hesitant and tenuous relationship to the language and methods of the university," how to write simultaneously from inside and outside the dominant discourse ("Facts" 305).

Nonetheless - and despite the widespread popularity of their curricular improvements over earlier, atomistic and far-lesscontextualized versions of writing pedagogy, despite their perspicacity in understanding our collusion in students' marginal positionsBartholomae and Petrosky's Facts did not transform students' position in the dominant discourse at the academy. Their approach better illuminated the source of academic discursive authority, but it did not disrupt the practices that construct that authority.

Elsewhere, I've specifically demonstrated why the transformation promised by Bartholomae and Petrosky's curriculum did not occur and explained how the political, institutional contexts of writing program and placement practices not only position every writer at the university but also undermine any curriculum's capacity to enable students (or us) to self-liberate from institutional inscriptions ("Reinventing"). I don't need to rehearse those arguments here. Instead, I hope to facilitate our recognition of a crucial condition of transformative pedagogy: it must initiate not just new writing assignments and/or new rhetorical positions, nor even new understanding of the power relations in our discourse and our discipline, but rather new practices in our profession. Because our discursive practices drive our disciplinary knowledge, de-stabilizing hegemonic conceptions of academic discourse requires re-vision of disciplinary practice within the academic 
site(s) wherein our determinations of what constitutes academic discourse are most likely to be publicly staged and [self-]authorized.

In order to make clear this crucial point about the formative power of disciplinary practices, I turn to Evan Watkins' notion of academics' "compensatory function." Watkins argues that professors' primary labor is not simply to perform their own competence but also to evaluate that of their students. In essence Watkins' claim is this: while English professors' concrete labor might be writing articles, giving lectures, facilitating group work, or advising students, the abstract form of their labor is evaluation. This abstract labor is the form that gets circulated as cultural capital. Unfortunately, the circulation of our evaluations does not enforce the ideological values represented in our courses' content or in our positionality as professors; rather, the importance of the content of any of our specific English studies courses "exists at all insofar as it also functions to circulate grades" (19). In this latter capacity, Watkins contends, we serve the market economy and thus the status quo:

For you don't report to the registrar that [your student John negotiated] ... a revolutionary fusion of contradictory ethical claims ... . You report that 60239 got a 3.8 in Engl 322, which in turn, in a couple of years, is then circulated to the personnel office at Boeing as 60239's prospective employer. (17-18)

Thus, Watkins argues, altering the content of the English studies courses we teach does not significantly subvert hegemonic values, for the cultural capital circulated from the classroom remains consistent with capitalist values.

Perhaps now we can more easily understand the difficulty inherent in effectively transforming existing power dynamics in academic discourse: disciplinary practice-grounded as it is in the values derived from the social organization of the institution-co-opts the subversive potential of the values derived from our ideological critique(s). In our practice as evaluators, we remain at the center of academic power relations, disciplined into a certain and substantive relationship to the language and methods of the university.

It's not surprising then that our effort to construct transformative writing pedagogy has had little disruptive effect on oppressive social values. Positioned teaching, for instance, has certainly revealed its proponents' political position(s) within our practice and thus made it possible for students to debunk the pretense of an "unbiased" composition teacher who professes a "natural" discourse exemplifying clarity and/or impartiality. However, this teaching method neither illuminates nor disturbs the institutional context within which the selfauthorizing work of academic discourse takes place. Likewise, view- 
ing "errors" as social negotiations between conflicting discourses has indeed altered how some students view the agency involved in their decisions to conform (or not) to the conventions of academic discourse. However, that perspective does not of itself significantly disrupt how we teachers perceive academic discourse; nor does it destabilize our hegemonic practices of evaluating student writing.

\section{A Sharper Edge}

My purpose here then is to extend that re-vision of pedagogy, to build on my earlier proposal of an alternative curriculum that "contextualizes the institutional practice of evaluating and placing writers in the university" and that consequently illuminates "for basic writers not only their position as writers in the university but also the position of non-basic writers, of honor students, and of the evaluators of writing in English courses" (62). First, I want to elaborate the method for my earlier suggestion that students "observe and record the language practices of academic groups" and then compare their observations with academics' (63); second, I want to evidence my earlier prediction that the strength of my proposed curricular approach is in "includ[ing] students in the process by which placement exam essays are evaluated [such that] they will be engaging in our practice as composition instructors" (74).

Let me begin by explaining briefly and in general terms what I see as the method for contextualizing the disciplinary practices of us experts on academic discourse-a group for whom evaluation is the most frequent practice. I ask students to participate in "mock" sessions ${ }^{1}$ for grading Freshman Placement Exams. Equally suitable would be student participation in sessions for evaluating Writing Assessment Tests, Upper Division Proficiency Tests, Transfer Writing Assessment Tests, or any other institutionally-organized and holistically-graded exam whose purpose is to assign students to or exempt them from appropriate[d] writing locations within the university.

To support my argument that this approach will destabilize dominant discourse and practice, I ask you to consider that - in addition to placing students - these grading sessions have at least one other formative purpose: to calibrate instructors' notions of "unsatisfactory," "average," and "sophisticated" college level writing with the standards existent in specific departmental and institutional contexts. This staging of disciplinary wielding of power constitutes one of the very few instances of explicit discursive self-authorization performed in a moreor-less public setting wherein evaluators can be held immediately accountable, even if only to each other. Within this context, crucial institutional and disciplinary legacies are passed on, for here we specialists 
tangibly identify the boundaries of discursive authority and our definitions of composition and academic discourse. In other words, our professional practice of holistically grading placement exams (especially as it involves graders from disciplines other than Composition Studies or English) provides the site wherein professors, by explicitly articulating their notions of "good writing," discover and/or re-assert their professional prerogative to authorize particular examples of academic writing and to denounce others. Thus, this context proves quite fruitful for student writers AND compositionists who want to examine, internalize, and/or critique the language practices of the university.

In some cases, students participating in this "mock" grading session may have already "flunked" or "passed" an exam prior to enrolling in the course which would require them to examine the context of placement exam evaluation; however, the purpose of students' studying and/or contributing to this context is not necessarily to better position themselves within our matrix of institutionally assigned placements. Rather, the purpose of including students in our evaluative practice is fourfold:

- to make explicit to students what their instructors see as "good" writing,

- to provide students the opportunity to analyze and critique the language system valued in composition courses and - some would argue - throughout the academy,

- to facilitate our recognizing the invisible [to us] ideologies of our own discursive practice, and

- to expose our evaluative practices to students' critique by staging evaluators' accountability for their [self-]authorizations of particular examples of academic discourse.

In other words, the purpose of including students in our practice should be to establish for students and for us the ways that English professors' evaluations of student writing are determined by their own social practice rather than by any transcendent or fixed standard. Professing otherwise is a mystification of our practice that delimits not just student writers but all writers in the institution, for it keeps us all in a dependent relationship to the hegemonic, foundational notions of our discipline and of the institution.

The brand of transformative pedagogy that I advocate here enables students to examine the ways in which authority is meted out in any language system and illuminates what Elbow describes as the "inherently problematic and perplexing" mystery of academic discourse: "It tries to peel away from messages the evidence of how those mes- 
sages are situated at the center of personal, political, or cultural interest; its conventions tend toward the sound of reasonable, disinterested, perhaps even objective (shall I say it?) men" (141). Because of academic discourse's inherent masking effect, an empowering and destabilizing writing pedagogy should reveal what's at stake for English teachers in the practice of teaching English; it must recognize that their self-authorization is essential to their definition of "good" writing in the academy. Developing multiple literacies and recognizing difference alone do not confer this critical consciousness; neither does simply studying the concept of discourse(s), noting the contextually-bound authority of texts and their authors, and negotiating one's own authority among those competing discourses. To enable critical consciousness in our students and destabilize their inscription in hegemonic and oppressive power relations, we should foster students' analysis of the context surrounding the relation of their writing to ours and to the missions of the institution AND insist on their participation in at least some of the multiple, disciplinary practices that sanction academic writing. Such activities would develop and sustain "a hesitant and tenuous relationship to the language and methods of the university."

I call this collaborative process of knowledge-making and selfauthorizing "inventing academic discourse." Crucial to this invention process is students' participation, for it empowers not just their critical consciousness but ours, destabilizes not just their inscription but our re-inscription in the academy's language and methods. In the process of generating new disciplinary/academic knowledge, students contribute an awareness that we as teacher/researchers often don't have and critically need: they can make "strange" what's "natural" for us. Like an ethnographer observing a foreign (to her) culture, a student can ask without pretense and with the genius of the uninitiated the same questions that seem clever when posed by sophisticated insiders who've spent careers "discovering" them, questions like "What's so ordinary about [your] ordinary language?" If our disciplinary practice were to demand that we answer such questions without pretense, that we collude with non-initiates in our articulations of what constitutes good writing and thus in our invention of appropriate academic discourse, then our practice would require us to recognize the ideology informing our own commonplace knowledge and language. Such practice would surely de-center our insider vision.

Such practice would also enhance our local, "practical" knowledge, capitalizing on the theory-building power of what Steven North describes as "practitioner lore." According to some, such improvement is crucial to furthering our disciplinary project and improving teacher/ researcher methodology. Patricia Harkin, for instance, contends that learning to capitalize on our teaching lore will reveal not just "ways of construing relations of relatedness to which our ideology has made us 
blind" but also the methods by which disciplinary "strategies achieve coherence by shutting out or repressing the contradictions that have their source in history" (135). At issue in her revisionary view of the authority of teacher practice, Harkin believes, is "nothing less than getting the academy to change its understanding of knowledge production ... [to] look first to ways we might adapt existing frameworks to help institutions learn to see lore produce knowledge" (135). Adapting the existing framework of placement essay evaluation procedures can facilitate new knowledge production, and it can disrupt the practice-evaluation - central to our inscription in hegemonic power relations.

Like Harkin, Susan Miller foretells the need for revisionary practices in order for composition theory to maintain its vitality. In her specific arguments for a methodology, Miller explains well the link between transformative pedagogy for students and transformative methods for the discipline:

We will need systematically to examine the situations in which readers read specifically identifiable kinds of writing, including our own reading of student texts, so that readers' expectations, requirements, and cultural or idiosyncratic prejudices become visible to student writers. We will need to account for evaluations of writing not in terms of its meaning or correctness, nor by gauging its expressiveness, but by investigating the actual results that a specific piece of writing - however well or ill formed it may be-has when both intended and accidental readers read it. (79)

Because the specific instance of placement essay evaluation that I've described constructs students as "accidental" readers, their responses to those essays disrupt the readings of the intended audience and make visible that audience's expectations. The exercise I suggest further requires that we and students investigate "actual results" of specific pieces of writing. In order to resist co-optation by the values derived from institutional social order, however, even the kinds of investigations that Miller describes must also disrupt disciplinary practice.

My proposal for letting students in on those practices - sketchy though it may be-is one of the few that offers such decentering. It supplies at least some of what Miller calls for, namely, multiple perspectives on how members of the "intended" actual audience read student writing. It's a method that can demonstrate not just the existence of an Author/student binary, but also how that opposition works in the academy and how one might combat its effects. It initiates bi-lateral negotiations between students and teachers by making our evaluations of students' academic discourse-our practices and thus our 
authority - negotiable. Especially if and when students' evaluations actually "count" as legitimate scores in the placement essay grading process, it fosters students' theorizing about and evaluation of "our" language. Consequently, my proposed method can also improve the status of our own theorizing and better enable us to see ourselves in what we do.

Susan Miller argues that such vision is crucial to the future of composition theory, for as of yet "the object that is theorized in composition studies remains fairly opaque because it still resides in the unarticulated but indomitable categories of 'high' and 'low' that first defined all academic textual studies" (76). "In its current configurations," she continues,

writing is a slippery, overdetermined signification. Its "authorship" results from resistances among competing and already articulated ideas, a writer's specific access and reaction to them, a specific motive and occasion for writing, and the constraints of language itself as a writer encounters them. Like government documents and some academic publications, a text may be written to have been written, not to record, develop, or express a thought, and not to be closely, or even casually, read.

Despite our insistent and naïve professions to the contrary, students are usually well aware that we often require a text be written simply for it to have been written; likewise they all too rapidly notice if and when their written texts are not closely or even casually read.

Our students' persistent and consistent recognition of this situatedness of the texts we evaluate speaks of their pervasive and subversive discernment of discursive authority. In fact, conceptually, they may well be better equipped - because differently located - than we are to recognize the situated-ness of academic writing. As the next section demonstrates, it's sometimes uncanny how - given the chance to witness and then theorize about our discursive practices - student writers even at developmental levels can divine the theories of some of our most respected scholars.

\section{How the Sharper Blade Cuts}

In order to determine the effects of including students in the practices of evaluation and placement, I piloted this approach twice. I wanted evidence, of course, that such a project could help students realize, emulate, and critique those features of good writing that composition teachers look for. Though I didn't set out to discover how students' perspectives on my own and other teachers' evaluations 
would affect my own practices of inventing academic discourse, that discovery plays a major role in what I see as the project's success.

But before describing those effects, let me contextualize my "experiment." During two different semesters of basic writing instruction-representing three sections of approximately twenty-five students each $-\mathrm{I}$ incorporated placement exam training sessions into the last month of the semester. I emulated as closely as possible the process for placing incoming, first-year students into a composition course appropriate to their writing ability. At the university where the students and I were located that process is called the FPE (Freshman Placement Exam) grading session. At the outset of the process, graders of the essay exam are introduced to a rubric which lists the characteristics of writing that correspond to each of the four possible holistic scores a grader can assign. Next comes a norming session during which the fifteen to twenty graders (usually, but not always, graduate teaching assistants) read specially selected sample essays, assign a tentative score to each ( 1 the lowest, 4 the highest), and then discuss aloud their justifications for each score. In this way, the graders calibrate before the next step of actually scoring hundreds of placement exams. Finally, the administrative staff on site computes the average of two graders' scores and then assigns the FPE writer to the composition course (honors, "regular," developmental) indicated. In certain situations (for instance, when the same essay receives the lowest and the highest possible score from two independent readers), the administrative staff requests a third reading of an essay.

These training sessions are very effective, I am told, because their holistic scores are "reliable," meaning that the graders generate very few $1 / 4$ splits and that the course grades that the student writers ultimately receive almost always illustrate a "match" between the FPEassigned course and students' writing abilities. Further, as an essential aspect of training first-year graduate students to be composition instructors, this calibration process promotes instructors' internalizing the standards of the department and - to a certain extent - of the discipline and the university. These are precisely the reasons why I chose to include this practice as an essential element of my first-year composition course.

In order to get to the point more quickly, I won't detail here my method for arranging the approximately month-long unit wherein I trained basic writing students to grade FPEs. (Those interested in the nuts and bolts can refer to Appendix A.) Instead, I'll simply list, in the chronological order of their distribution, the materials I provided for each student:

- the instructions, including the writing prompt, given to the students who took the Freshman Placement Exam (FPE), 
- the rubric that explains criteria for each possible score,

- several sample student essays all written in response to one FPE prompt, including an essay that each student grader had written herself on the first day of class,

- access to the teacher-assigned scores on the sample essays (provided only after the student graders had assigned scores of their own),

- a synopsis of teacher comments on individual essays (again provided only after student graders had assigned their own scores),

- a questionnaire [Appendix B] which facilitated students' theorizing about the placement process and the nature of academic writing and to which student graders responded in their journals.

What I do want to detail for you here are those aspects of this teaching practice that were most engaging and useful, primarily from the students' point of view but also from mine.

One useful but not unexpected yield of the session was its evidence that the students had no trouble at all identifying the middle ground of "satisfactory" academic writing. Rarely, if ever, did their scores of " 2 " or " 3 " differ from the scores teachers assigned. I found it quite surprising, however, that students generated a plethora of $1 / 4$ splits between their own and teachers' assessments. These splits occurred only on papers that the teacher-readers had perceived to be "honors" essays (" 4 ") but that my students perceived as "developmental" ("1" ) essays. Such splits accounted for well over half of my students' responses to the scored honors essays.

The persistence of this discrepancy indicates a particularly rich resource for revealing teachers' inscription in and students' exclusion from a hidden cooperation of privilege and exclusion in academic discursive practices. And sure enough, our classroom discussion of these 1 / 4 splits made disturbingly clear to me the mysterious (to students) ideologies informing instructors' evaluations of "honors" level academic texts. Students' generally "common sense" and unanimous explanations justified the low scores they assigned to the essays that the teachers perceived as honors essays. As far as my students were concerned, essay writers who used movies or personal experiences or "opinions" to support their arguments were not writing good essays because they weren't relying on "facts." My students took particular issue with an essay written in response to a prompt for evidence to support the claim that feminism "still had far to go; " the writer substantiated that claim by using evidence from Die Hard. My students found the essay "stupid . . . because it just talked about movies and 
movies aren't real in the first place." The teachers, on the other hand, agreed that the writer's analysis of a popular movie had given clever and articulate evidence of persistent sexist attitudes in American culture.

Clearly, before encountering the views of the teacher-graders, my student-graders had not yet recognized that an academic writer's "authority is not established through his presence but through his ... ability ... to speak as a god-like source beyond the limitations of any particular social or historical moment" ("Inventing" 155). If they could not see the worth of that authority in another's essay, little wonder that they could not make in their own writing the "imperial gesture" essential to appropriating academic discourse. Neither did these students - as writers or evaluators - know how to "read" movies as texts available to be analyzed nor know that teachers might consider a movie's evidence "real."

To put this argument in other terms, I'll say that my students didn't recognize an important "subject position" available to them. "Purveyor and critic of pop culture's artifacts" is an inscription that we teachers recognize and generally favor. Lester Faigley has shown us several other, primarily self-reflective, expressive, and confessional subject positions that composition teachers tend to prefer. Like those other examples, the "Die Hard" essay's accounting for the pervasive sexism in the film inscribes a definitive subject position English professors often embody; it's disdain for the unsophisticated attitudes prevalent in popular (read "low") culture's texts also critiques "common" attitudes that many of my basic writing students hold. Yet, in reading through students' eyes the essay writer's scorn (condescension even), I discover what Faigley did in reading his samples of teacherdefined excellence in student writing:

I'm struck by how similar student and teacher sound ... I'm also struck by how ... the truths 'exposed' and 'revealed' in the essay are a series of recognitions for a college English teacher. (124-5)

These recognitions, Faigley contends, constitute teacher-defined "authentic voice." As we all know, that definitive characteristic of "authentic voice" crops up in most grading rubrics and is usually described as a factor that distinguishes "excellent" from "good" or from "average" examples of student writing.

Trying to decipher this concept of "genuine voice" bewildered my students more than any other task involved in learning the terms on the grading rubric. Among themselves, they defined the term as "the quality that made you sure what someone's opinion was, the way that you could hear the personality of the writer." They wondered 
why teachers would want someone to have this quality. For them the clearest example of a "genuine" or "natural" voice spoke in an essay in which the writer was, they said, "obviously a jerk because he showed he was a sexist and didn't think [i.e., realize] that female teachers would be reading and grading his paper." For them, this writer had an opinion-occupied a subject position-clearly unacceptable to English teachers; they apparently assumed, then, that a writer with an easily identifiable "voice" was one who had no good sense of her audience. Thus, to them, having "voice" meant "letting your opinions slip out" (especially your "negative" opinions); sounding "natural" meant "sounding like yourself," a reverberation that, they also assumed, English teachers would NOT appreciate. Common-sensical and unsophisticated as they may be, these assessments of our attitudes toward "genuine voice" are disturbingly accurate: English teachers would definitely not, I'd wager, author-ize the subject position of "uncritical and sincere appreciator of Bruce Willis movies and the attitudes they display," at least not publicly.

Now imagine, if you will, a grading session wherein instructors like you and students like these must mediate these conflicting definitions and criteria for excellence. Granted, such a session would be less efficient-much less - than ones wherein all graders are trained writing instructors and/or new graduate teaching assistants. But the calibration that would occur during the training would help mediate the discrepancies in teachers' and students' negotiations of meaning and the criteria for excellence. For my students, I did little if anything to "justify" the teachers' opinions of excellence (or lack) in the essays. I did, however, tell them that I had been one of the teacher/graders myself, and I often did "report" what teachers had said about an essay during our grading session when I also reported the scores that the teachers had assigned. In addition, I regularly made comments something like this: "Yes, I can see what you mean that this concept of 'genuine' voice is confusing. I don't really know why teachers call it that. I can see how your definition makes sense too."

Since that time, however, their comments have prompted me to search for more sophisticated theories explaining why "genuine" is a term we teachers often attach to voice. In that prompting lies some of students' capacity to invent academic discourse for me; from their perspectives emerges the power of this contact zone of professional practice. Granted, explicit purchase in this contact zone between students and teachers does not of itself equalize the disproportionate power relations, but it does de-stabilize them to some extent. More importantly, it demystifies some of our ideological assumptions because - at the very least-it holds us accountable for them. Can we deny the value in such mediations?

If you think we can, then consider the students' perspectives 
on this process we underwent. In responding to my queries about the worth of the unit in our class, students unanimously agreed that it was helpful, most wished we'd done this work at the beginning rather than at the end of the semester, and many wanted to have spent more time on this section. Michelle's evaluation echoed many others':

I am glad we did this unit because I think that until students become aware of this they are in the dark and left out of what is really necessary to succeed as a writer at the university.

Amy's explanation of the value of our study speaks most to me:

I felt this unit was beneficial because all my teachers before made a 'game' out of writing and trying to figure out what they wanted on paper. It always seemed like I figured the secret out when it was too late. With this unit we went directly to what is expected and wanted and studied why.

Including students in the process of placement and evaluation has further value because it improves their writing in several ways. First, it facilitates the metacognitive awareness that makes for better revision, helps students to travel the terrain of global issues like planning and organizing and to avoid the tourist traps of excessive attention to grammar errors and other localized oddities. My students' reflections on their work with the placement process demonstrates that they were developing this awareness. For instance, when I asked them to compare their own FPE essays (written on the first day of our semester together and in response to the same prompt and time constraints as the essays they later "graded") with the other student essays they graded, Karen reflected,

I realize/remember now that I did not have a plan for my essay ... a student who can manipulate a topic so that he can incorporate what he knows into an essay is a student with 'good writing'ability.

Angie realized that

The essays I thought were 1's were [really] 4's because of their creativity. Grammar wasn't most important.

Our study also improved students' writing abilities by revealing to them the complexity of the writing task, a task inextricably linked to making meaning and to negotiating the constraints of a particular context. For example, Lorena claimed that 
The most surprising thing I learned was that I could manipulate a topic question and use it to my advantage; which I never thought of.

\section{Jeff reflected that}

The essay I wrote is almost identical to the other essay I read; they both lack what is needed to be placed in English 101 [the "regular" as opposed to the developmental course] and that is style, creativity and imagination. We both wrote what we thought the teacher expected us to write and that is the basic boring facts and statistics on feminism [the topic of the FPE] .... My assignment to this class isn't just involved in writing; it's also involved with thinking and imagination.

As these comments indicate, our study of the practices of evaluating placement exams also facilitated students' seeing that and how academic writing complicates the commonplace:

An honors placement is one that is complex enough to go over my head. ... [T] his particular writer rather than taking the subject as one large spectrum, like I would have chosen to do, picked one instance or situation which she was close to or related with and shared this experience with his/her readers .... When I said essay \# $x$ was boring because she was telling us things we already knew, I realized my essay is just the same. (Jeanette)

Interestingly, many students' explanations of what constitutes good academic writing parallel the concepts and even the wording of Bartholomae's descriptions of what basic writers need to learn. For illustration, consider these students' written responses to my questions: "What kinds of rules does the group [of people who use academic discourse] have about what students should or shouldn't say?" and "How does the group keep outsiders out?"

If a student can make a teacher think or view a topic from a different perspective, the student has succeeded. (Lorena)

I think this "group" [teachers] is implying not to be stereotypical or be one sided on debatable issues.... The one whose voice isn't respected is the one who's stereotypical. (Karen)

The group thinks that a writer's personality and style should 
be unique ... [but] most outsiders don't know what is meant by "mature content" [a term on the grading rubric]. (Gladys)

Similarly, students' answers to my question "Who has authority to speak in this academic discourse community?" exemplify Bartholomae's definitions of academic specialization:

The kind of writing that the university wants is writing that shows a lot of knowledge in one area not a lot of knowledge on everything. (Troy)

Finally, and perhaps most important as evidence of the interventionary edge of my proposed approach to basic writing instruction, my students' responses to the practice reveal their growing awareness of the power relations that pervade academic discourse. They began to recognize the kinds of gestures that authorize our discourse. They realized that

The person who is most qualified to talk or have a say-so is the person who has the confidence to talk either because he or she has an experience or knows vocabulary or has the right conception or belief.... The voice that is not likely to be respected is a person's voice who has little experiences in talking, has limited vocabulary, has limited exposure to certain concepts and beliefs. This can be the kind of person the group is trying to shut out. This can be also a person who isn't familiar to this kind of language use and refrained to [use it] and as a result chose to be silenced in which he or she has no control over the language use the group uses. (Gladys)

As Gladys intimates in her recognition that the "voice" NOT respected is the one with only limited exposure to "certain concepts and beliefs," these basic writing students are certainly capable of critique of the systemic practices that keep them in their place. They see how teachers' practice (their uses rather than their theories) of academic discourse and discursive authority belies their typically-professed, egalitarian values and beliefs. Gladys' and other students' critiques demonstrate their nascent realization that the subject position(s) that teachers recognize and often embody is elitist, self-authorized, and often self-congratulatory. Consider these responses to my request that students theorize about the ways members of the academy use language as a means for uncovering the values and beliefs academics might have:

They also value honesty and uniqueness, an individualist. I think their view of the world is one that's very competitive. 
Their specialized language gives them a label-a group of individuals with a place in society, a career and status. Being that they view the world as competitive, they play in the game. They use this language because it sets them apart. (Michelle)

This group probably views the world as a dull and fairly uneducated place. The effect on "mainstream" people who hear these people use this language is a sort of hostility. "Why do they think they're so good" may be the question. (Angie)

In total, these students' responses indicate at least three advantages to this proposed approach to writing instruction: students find it useful; it facilitates their understanding and production of the kind of writing that the academy expects of them; and it accords them the opportunity to reflect on and theorize about the nature of language and power relations in the university. Thus, it supports students' learning how to "poise themselves in a hesitant and tenuous relationship to the language and methods of the university," to see that successful writers' - indeed, even teachers' - authority is of their own construction.

What I see as another essential aspect of this approach to writing instruction is that it facilitates our learning, not just students'. It helps us to utilize practitioner "lore" to de-center the hegemonic authority of our discursive practices. It capitalizes on that "post-disciplinary," experiential, we-use-it-because-it-works local knowledge. It sanctions our classrooms as a site for expanding the horizons of our disciplinary knowledge and for resisting institutional appropriation of liberatory pedagogy. Inviting students to collaborate in our evaluation procedures disturbs the status quo: since, as Evan Watkins' contends, evaluations are the cultural capital - the abstract labor - that English professors circulate into capitalist society, disrupting the production of that surplus capital is definitely one means by which we might perpetuate our counter-hegemonic project and effect change.

Furthermore, if - as Bizzell believes - the process of changing a discourse "begins when change in the material world impinges more frequently or urgently than before," then this student intervention in professors' evaluative practice is fruitful because it provides just the material change needed to reconstruct the "institutional structure of the discipline" (216). Students' deconstructive analyses of how our academic language works present me-and, I hope, you too-with insights; they can challenge us to recognize our discursive inscriptions and our positions not as gods or wizards but simply as local examples of professionals whose

specialized language gives them a label - a group of individuals with a place in society, a career and status. Being that they 
view the world as competitive, they play in the game. They use this language because it sets them apart. (Gladys)

The pedagogical approach that I've proposed here provides a way for not only our students but also us professors of English to know and locate our places as writers in the institution, for us professors to step to the side of our own practice and keep a watchful eye on our often unconscious or inadvertent choices about where to locate ourselves and, by implication, our students.

Van Slyck argues, in "Repositioning Ourselves in the Contact Zone," that it's we teachers who must

help students see that unreflective group consensus does not constitute an ethical position and that sometimes becoming an individual means standing apart from one's community and questioning its practices. (156)

I see an additional responsibility, and that is to allow students to help us see the benefit of questioning our practices. As compositionists, as members of a community committed to teaching for social change, we can facilitate students' and therefore our own reflection on our ethical positions and fulfill our objective of intervention in hegemonic power relations. Students' critique and reflection on academic discourse can bring us the "largeness of mind" that Clifford Geertz advocates:

... [I]t is from the far more difficult achievement of seeing ourselves amongst others, as a local example of the forms human life has locally taken, a case among cases, a world among worlds that the largeness of mind, without which objectivity is self-congratulation and tolerance a sham, comes. (16)

As Geertz entreats anthropologists, I entreat us to remember that our mission "is to keep reteaching this fugitive truth" (16).

\section{Note}

1. In the "mock" sessions I have conducted, students evaluated actual placement essays generated in earlier testing sessions and then compared their scores to the "actual" scores and comments assigned by authorized graders. Hence, my students' evaluations didn't "count" in the sense that their scores did not assign any physical person to a material site. As you shall see, my students clearly realized that their scores weren't "real." Nonetheless, they were eager to participate in a practice that illuminated how teachers learn the criteria for judging 
writing and earn their positions as authorized graders; having to assume responsibility for assigning their peers to a specific writing location may well make students even more eager to participate. I firmly believe that many - maybe even most - of these students are quite capable of success in "norming" practices and thus of earning their own positions as authorized graders. Of course, permitting students' evaluations to have such material effect in grading sessions would more powerfully and politically authorize them and their critiques, more effectively de-center the hegemonic authority of the evaluation process. No institutional reality that I've witnessed has yet permitted that degree of intervention. The potential for such reality inspires my persistence.

\section{Works Cited}

Bartholomae, David. "Inventing the University." When a Writer Can't Write: Studies in Writer's Block and Other Composing Process Problems. Ed. Mike Rose. New York: Guilford Press, 1985: 134-165.

---. "Writing on the Margins: The Concept of Literacy in Higher Education." A Sourcebook for Basic Writing Teachers. Theresa Enos, Ed. New York: Random House,'1987: 66-83.

Bartholomae, David, and Petrosky, Anthony R. "Facts, Artifacts, and Counterfacts: A Basic Reading and Writing Course for the College Curriculum." Rptd. in A Sourcebook for Basic Writing Teachers. Theresa Enos, Ed. New York: Random House, 1987: 275-306.

Bizzell, Patricia. Academic Discourse and Critical Consciousness. Pittsburgh, PA: U of Pittsburgh P, 1992.

Bourdieu, Pierre. Outline of a Theory of Practice. Trans. Richard Nice. Cambridge: Cambridge UP, 1977.

Elbow, Peter. "Reflections on Academic Discourse: How It Relates to Freshman and Colleagues." College English 53 (1991): 135-55.

Faigley, Lester. Fragments of Rationality: Postmodernity and the Subject of Composition. Pittsburgh, PA: U of Pittsburgh P, 1992.

Geertz, Clifford. Local Knowledge: Further Essays in Interpretive Anthropology. New York: Basic Books, 1983.

Harkin, Patricia. "The Postdisciplinary Politics of Lore." Contending with Words: Composition and Rhetoric in a Postmodern Age. Ed. Harkin, Patricia and John Schlib. New York: MLA, 1991: 124-138.

Hindman, Jane E. "Reinventing the University: Finding the Place for Basic Writers." Journal of Basic Writing 12 (1993): 55-76.

Horner, Bruce. "Rethinking the 'Sociality' of Error: Teaching Editing as Negotiation." Rhetoric Review 11 (Fall 1992): 172-199.

---. "Students, Authorship, and the Work of Composition." College English 59 (1997): 505-529. 
Jarratt, Susan C. "'Feminism and Composition: The Case for Conflict." Contending with Words: Composition and Rhetoric in a Postmodern Age. Ed. Harkin, Patricia and John Schlib. New York: MLA, 1991: 103-123.

Lu, Min-Zhan. "Professing Multiculturalism: The Politics of Style in the Contact Zone." College Composition and Communication 45 (December 1994): 442-458.

---. "Redefining the Legacy of Mina Shaughnessy: A Critique of the Politics of Linguistic Innocence." JBW 10 (Spring 1991). Rpt. in The Writing Teacher's Sourcebook. Oxford: Oxford UP, 1994: 327337.

Miller, Susan. "Writing Theory: Theory Writing." Methods and Methodology in Composition Research. Ed. Gesa Kirsch and Patricia Sullivan. Carbondale: Southern Illinois UP, 1992: 62-83.

North, Stephen M. The Making of Knowledge in Composition: Portrait of an Emerging Field. Portsmouth, NH: Boynton/Cook, 1987.

Pratt, Mary Louise. "Arts of the Contact Zone." Profession 1991: 3340.

Van Slyck, Phyllis. "Repositioning Ourselves in the Contact Zone." College English 59 (1997): 149-170.

Watkins, Evan. Work Time: English Departments and the Circulation of Cultural Value. Stanford, CA: Stanford UP, 1989. 


\section{Appendix I}

Outline for my Basic Writing Unit (approximately 4 weeks) wherein students emulate the process of evaluating Freshmen Placement Exams (FPEs)

\section{Preparation of Materials}

Using a prompt that had been retired from actual FPE exam settings, I asked the instructors of two sections each of English 100 (basic writing first year composition course), 101 ("mainstream" first year composition course), and 103 (honors composition course) to have their students write responses to the prompt. All students were given the same time period ( 30 minutes) and instructions given in an actual FPE exam. A group of four experienced FPE graders scored the approximately 150 exams generated. Each exam was assigned at least two scores; I then read and scored all exams myself. Thus, I had access to at least three teacher evaluations for each of the sample FPE exams.

\section{Initial In-Class Preparation}

On the first day of English 100 class, students wrote a diagnostic essay in response to the same prompt and with the same instructions as those given to the students who wrote the materials described above. I told them that I would read their essays to make sure that they had been placed appropriately and that we would be referring to their essays later on during the semester.

\section{In-Class Work with FPE Exams}

During the last month of English 100, we spent about four weeks on a unit dedicated to examining "academic discourse." During this time, we read sections of Mike Rose's Lives on the Boundary, in particular sections about the "academic club" and academic writing (Chapters 6 and 7). In addition, we enacted the graders' "calibration" process as follows:

a. Students read and studied the rubric for grading FPEs. In addition, they read eight FPE essays, evaluated and assigned a holistic grade to each, and wrote their justifications for the scores they gave.

b. During class, we all talked about the scores the students had assigned and compared the students' scores with the instructors'. We discussed at length any discrepancies between the students' evaluations and the instructors' and reviewed carefully the justifications each group gave for the scores.

c. Each student read two other placement exams assigned only to her 
and then also read the one she herself had written on the first day of class. Students wrote about the similarities and differences in their exams and the others they scored and about the ways that their writing had improved since the beginning of the semester; we discussed their responses to these assignments.

d. Students wrote a letter to someone they knew back at home who might be going to college soon. In the letter, students were to explain in their own language what it is that they think English teachers are looking for when they score placement exams.

e. Students wrote out answers to the questions on a handout I gave them. The questions require students to think about the language that teachers at the university use, to theorize about the nature of academic discourse, and to reflect on their experiences during the process of grading FPEs. (See Appendix II)

\section{Appendix II}

Questionnaire Basic Writing Students Completed at the end of the FPE Unit

By reading the rubric for grading Freshman Placement Exams and by seeing what kinds of scores the teachers gave certain exams, you've had the opportunity in the last few days to examine the language that teachers use. Mike Rose calls this group (teachers and students who do well in these teachers' eyes) the "academic club." Other people (like the teachers themselves) call their language "academic discourse" and say that academic discourse is the language that people use at the university. What I want you to do is think and write about these questions. By doing this, you will be "theorizing" (creating a philosophy or hypothesis) about the nature of "academic discourse."

1. What kind of "rules" does this group (i.e. teachers who grade these exams and students who do well on them) have about what students should or shouldn't say? Are there specific words or topics that the group considers forbidden? Does the group have any special words that only insiders understand? What words? What phrases? Do they ever use these special words as a "secret code" that's meant to keep outsiders out? How would you define these words/phrases for "outsiders"?

2. Who is most qualified to talk or have a say-so, according to this group's "rules" for using language? In other words, whose voice is 
respected the most? What will that voice sound like? Whose voice is not respected in the group? What kind of person or sounds will the group try to shut out? Why? How does a person get the authority to speak in this group?

3. Based on the language that people in this group use, what other things can we notice that they also value? What sort of view of the world (a safe place, a hostile place, a dull place, a competitive place, etc.) does this group have? How does the group members' specialized language reflect their lifestyles and beliefs? Why do you think they use this language? What effect(s) does this language use have on more "mainstream" people?

4. Do you think all teachers in the university prefer the kind of language that's valued in the placement exam grading sessions? Why or why not? What teachers in specific might think differently? What kind of language or writing would those teachers value? If all teachers at the university don't agree, then why would English teachers be the ones who are in charge of this exam and of shaping the way you write?

5. What was the most surprising thing that you heard, learned, realized, read while we were working with the freshman placement exam essays and materials?

6. What was the most useful thing you learned while reading the placement exam rubric and the sample placement essays? Why is it useful?

7. Are you glad we did this unit in our class? Why or why not? If you were teaching new English 100 students, would you do this exercise? Would you use more class time, less time, or about the same amount of time to discuss these placement exam essays? What would you add or leave out of the lesson? 


\section{Laurie Grobman}

\section{BUILDING BRIDGES TO ACADEMIC DISCOURSE: THE PEER GROUP LEADER IN BASIC WRITING PEER RESPONSE GROUPS}

ABSTRACT: The academic discourse paradigm locates the basic writer outside academic discourse, lacking the authority academic writers possess. This exclusion is manifested in peer response groups, where basic writers often shy away from critiquing substantive issues of content or organization in each other's work. This article describes a study of writing groups which attempted to build the bridges between basic writers and academic writers by incorporating a peer group leader - a sophomore student who guides basic writers - into peer response sessions. The peer group leader straddles the roles of the two primary types of peer collaboration in basic writing-peer response in basic writing classrooms and peer tutorials in Writing Centers - and thus draws from the advantages of both. This article analyzes the strengths and weaknesses of this project and its implications for the further use of peer group leaders in basic writing.

David Bartholomae's landmark essays "Inventing the University" and "Writing on the Margins: The Concept of Literacy in Higher Education" locate the basic writer outside academic discourse, lacking the authority academic writers possess. This exclusion is manifested, among other ways, in peer response groups, where basic writers often shy away from critiquing substantive issues of content or organization in each other's work. Their hesitancy is understandable, given that the university has told them (by virtue of their placement in a "remedial" writing course) that they do not know how to write. In this article, I will describe a study of writing groups in which I attempted to build the bridges between basic writers and academic writers by incorporating a peer group leader - a sophomore student who guides basic writers during peer response sessions - in an electronic classroom with online

Laurie Grobman is an Assistant Professor of English at Penn State University, Berks-Lehigh Valley College. Her research and teaching interests include basic writing, composition, professional writing, and multicultural studies. She has published in Journal of Basic Writing, Journal of Business and Technical Communication, Confluencia: Revista Hispanica de Cultural y Literatura, Studies in American Jewish Literature, and Diversity: A Journal of Multicultural Issues. She also has articles forthcoming in MELUS: The Journal of the Society for the Study of the Multi-Ethnic Literatures of the United States and MAWA Review. 
peer response sessions. ${ }^{1}$ I hypothesized that efficacy of peer response would increase, expecting that the peer group leader would be able to provide a bridge between basic writers' and academic communities, enabling basic writers to model academic discourse as they authorize themselves as participants.

The theoretical support for peer response groups in composition is by now well known: social theories of language and learning suggest that students should construct meaning not in isolation but within the context of social interaction. Although the use of peer response groups is common practice in writing classrooms, research on peer response groups offers mixed reviews, largely because students typically lack the skills and knowledge for peer response (see $\mathrm{Zhu}$ ). Indeed, much of the research on writing groups focuses on ways to promote more effective, substantive response in students (see Zhu) and on the causes and characteristics of successful and unsuccessful peer response groups (see Bishop). Furthermore, a great deal of this research focuses on composition rather than basic writing students.

Nevertheless, Bartholomae's work with basic writers has led many researchers and instructors, including myself, to use peer response groups as a way to empower basic writers (Weaver 31). Basic writing pedagogy emerging from social constructivist views of writing encourages students to see their written texts as part of academic discourse, a larger conversation taking place in writing. This approach presupposes, as do I, that developmental writers can produce intelligent writing if instructors challenge them with serious content and enable them to enter academic conversations. Peer response groups are one means through which students can potentially enter these conversations.

However, Wei Zhu notes that the opportunities for peer interaction offered by peer response groups often go unfulfilled (517). Though many factors influence peer response group efficacy and inefficacy, group members' lack of confidence in peers' expertise and members' fear in offering criticism are among the most salient characteristics of peer response group failure (Bishop 121). Clearly, these problems are more pronounced for basic writers, whose reluctance and/or inability to offer substantive critique hinders meaningful learning from knowledgeable peers. Basic writers' precarious position as outsiders in the academic community and subsequent lack of confidence in their own writing abilities lead these students to shy away from assuming any measure of authority in offering meaningful response. Basic writers tend to resist honest and authoritative critique, even in electronic classrooms which otherwise contribute to community-building (see Gay; Varone).

Zhu points out that while a significant amount of research on peer response centers on its benefits to students, less research examines the factors that influence peer interaction (518). My project incor- 
porating a peer group leader in basic writing peer response groups sought to examine such conditions. I attempted to make writing groups more effective in basic writing classrooms based on what I knew of the research in this area as well as my experiences with writing groups and basic writers. Rather than give in to what Sandra Lawrence and Elizabeth Sommers conclude about instructors' doubts about the value of peer response groups for inexperienced writers, I sought to find ways to make this experience meaningful and valuable. Moreover, I sought to promote writing groups in which basic writers, like their composition counterparts, reconceptualize substantive issues in their writing, countering Joan Wauters' claim that for basic writers, "there is an excellent rationale for offering only positive reinforcement, if the goal is to encourage confidence on the part of reluctant writers" (157). Basic writers should be treated as intellectuals learning a new discourse, and peer response sessions should reflect such academic work. By making academic discourse visible through the use of a peer group leader, I could help students in their understanding and appropriation of academic discourse. ${ }^{2}$

This article describes and analyzes how I used a peer group leader to provide a bridge between basic writers and academic discourse. I strongly believe in the potential of peer group leaders in basic writing classrooms. In this article, I hope to convey that potential by identifying the strengths and weaknesses of what happened in my classroom in the context of peer collaboration research and theory. While my study can not cover the range and variety of basic writing classroom situations and dynamics, it does raise significant issues that beg further research and practice. In the remainder of the article, I discuss the theoretical basis for the use of peer group leaders, turn next to the experiences in my classroom, and end with my conclusions about the present and future of peer group leaders in basic writing.

\section{Building Bridges in Peer Collaboration Research: Peer Group Leaders in Basic Writing}

Using limited funds from an internal grant, I selected one student as the peer group leader for my basic writing class. ${ }^{3}$ I theorized that peer group leaders, who have only recently become academic writers themselves, could constitute a bridge between basic writers' and academic communities. David Bartholomae and Anthony Petrosky suggest we "engage students in a process whereby they discover academic discourse from the inside" (36). Peer group leaders make academic discourse's inside visible, so basic writing students do not have to invent it blindly. At once insiders and outsiders, peer group leaders provide a vital link between writer and audience, writer and academic 
discourse. As James Gee argues, discourses are mastered by "enculturation into social practices through scaffolded and supported interaction with people who have already mastered the Discourse" (qtd. in Zhu 518). Straddling the fence somewhere between academic and basic writers' communities, this young woman could, I hoped, provide the scaffolding and supported interaction upon and through which basic writers would enter academic discourse. In so doing, peer group leaders provide what Kenneth Bruffee would call a "conversation" to model or what subscribers to the competing model of academic authority would see as a means to challenge it. In both cases, peer group leaders could aid basic writers' appropriation of academic discourse.

I chose a student I had known from my basic writing class a year earlier. She was among the strongest writers in my class (and I knew she had been successful in English Composition), but more importantly, I felt she had characteristics that would suit the peer group leader role: leadership, integrity, maturity, and sensitivity. Tyisha, the peer group leader, attended my class during peer response sessions, joining one or two groups and guiding them through and participating in response. ${ }^{4}$ I instructed her to be descriptive and to pay attention to global issues of meaning, content, and organization rather than mechanical issues in students' writing. I expected Tyisha to model these responses for students as well as guide them to suitable modes of critique. Additionally, I informed students that they could seek the peer group leader's help outside of class as well, through email or phone calls.

The peer group leader thus straddled the roles of the two primary types of peer collaboration in basic writing: peer response in basic writing classrooms and peer tutorials in Writing Centers. I envisioned the peer group leader as a mediary between peers in a peer response group and tutors in Writing Center tutorials, and I believed that by bringing the peer tutor into not only the classroom, but the peer response group, I would be able to draw at once from the advantages of both peer response groups and peer tutorials. Of course, there is a flip side as well, for peer group leaders have the potential to degrade the collaboration of peers in peer response groups.

Muriel Harris' widely-known and respected work on the similarities and differences between peer tutorials and peer response, though now seven years old, remains a significant contribution to the study and practice of these important collaborative methods in basic writing classrooms. Harris asserts that both writing center tutorials and peer response groups are "collaborative learning about writing" ("Collaboration" 369) in which "one writer claims ownership and makes all final decisions" (370); moreover, the goal of the tutor and peer group members is the same: "all are working toward more effective writing abilities and heightened awareness of general writing concerns" (373). 
Bringing peer group leaders into peer response sessions leaves these important general similarities unchanged.

It is the distinctions Harris makes, however, which interest me more in the context of peer group leaders, particularly in terms of how the peer group leader can take advantage of these distinctions and become a force in basic writers' peer response sessions and meaningful learning in collaboration with knowledgeable peers. Among the most significant of these differences is the widely-accepted view that peer tutors in writing tutorials become "neither a teacher nor a peer" as they assist writers with writing issues beyond "fixing" a particular paper under consideration while peer response readers focus on and critique a specific draft (371). Peer tutors explain issues and problems and give instructional assistance. As Stephen North notes, the tutor's job "is to produce better writers, not just better writing" (qtd. in Harris 372). In tutorials, tutors individualize and personalize the concerns, while in peer response groups, readers offer mutual assistance in a back-and-forth interaction that deals with general skills (373).

Peer group leaders take on both roles, neither teachers, peer tutors, nor peers, straddling multiple communities as they join the peer response group. In their unique role, peer group leaders can bring individualization to peer response groups since they do not have writing to be critiqued and do not seek mutual assistance. This difference from other members of the peer response group allows for an additional layer of instruction in peer response groups, beyond a focus on the writing under scrutiny to more general writing concerns, including instructional assistance on how to respond to peers' writing, which the tutorial lacks. Learning the nuances of critique can in and of itself lead to improved writing abilities. Thus, Harris' assertion that peer tutors' methods and concerns for uncovering writers' problems are not appropriate for peer response groups no longer holds when we introduce peer group leaders into peer response groups. Peer group leaders can individualize response, and, more importantly, can lead students away from purely directive response.

Harris' distinction in terms of collaboration is important in this context. She argues that peer response groups are closer to collaborative writing (i.e. joint authorship) than writing tutorials, for peer response group work emphasizes informing, while writing tutorials emphasize the student's own discovery ("Collaboration" 377). On first glance, it may seem that using a peer group leader might move the peer response group away from collaborative writing, since peer group leaders do emphasize students' own discovery. However, peer group leaders can simultaneously increase the level and quality of informative modes. Peer group leaders raise peer response beyond simple informing on specific issues, a goal of many instructors who use peer response groups, despite Harris' claim that these groups tend to be 
prescriptive (see Benesch; Zhu; Bishop). Peer group leaders guide group members into larger, substantive issues and thus students' own discovery of the writing process. Moreover, unlike tutorials, peer response groups with peer group leaders also facilitate students' discovery of group processes; that is, peer group leaders guide and model peer group response and critique, so students discover not only their own writing issues, but how to benefit from and contribute to peer response. In peer response work with peer group leaders, basic writing students not only attempt to critique their peers' draft but themselves learn about the possibilities for revision in the process. Therefore, despite the potential to undermine collaboration among peers, peer group leaders can enhance it by raising the efficacy of peer group members' informing and multiple layers of discovery.

In their multiple roles, peer group leaders thus provide a bridge between what Thomas Newkirk calls peers' and instructors' distinct "evaluative communities" (309). His study suggests that peer response groups may reinforce students' abilities to write for their peers but not the academic community, and, subsequently, that "students need practice applying the criteria that they are now learning" and should be viewed as "apprentices, attempting to learn and apply criteria appropriate to an academic audience" (310). Newkirk argues for teachers' active role in peer response; however, I believe peer group leaders can more effectively "mak[e] the norms of that community clear and plausible-even appealing" (310). Ideally, peer response enables students to enter academic discourse through working with knowledgeable peers, breaking free from one evaluative community to enter another, and it empowers students who do not see themselves as academic writers. However, in practice, students' crossover is more problematic. Peer group leaders can expose students to the conventions-appealing and not-so-appealing - of academic discourse. Peer group leaders, though, do not impose on students what Benesch calls the "teacher's code," but instead allow them to respond to writing issues in "their own language" (90), since peer group leaders have, in Harris' words, "a foot in each discourse community" (380). With the use of peer group leaders, therefore, basic writers develop this language more independently of the teacher and in collaboration with peers.

Using peer group leaders in peer response groups also bridges what Tim Hacker describes as the two main approaches to peer response: the broad categories of "teacher-directed" and "modeling." The former category includes teacher intervention in the form of worksheets (a set of heuristics for approaching an essay) and/or instructions on how to proceed, while "modeling" consists of teacher intervention prior to actual student-directed peer response sessions through teaching students how to evaluate and critique their peers' essays before peer response sessions. Using peer group leaders, how- 
ever, reduces the need for teacher intervention in either model. ${ }^{5}$ That is, with peer group leaders, students can "model" effective response, but they do so in-process, and they do not need a set of heuristics provided by the instructor. Moreover, with peer group leaders, more authentic collaboration occurs because peer response groups remain decentered. Students cannot blindly invent the language of academic discourse, but peer group leaders make its inside visible. With peer group leaders as facilitators, basic writers take on a more active role in the invention of academic discourse. Like peer tutors, peer group leaders can empower student writers who "want to have power over their environment, to be in control of what happens to them, ... and manipulate language the way their teachers do before they will be able to play the academic game the way the insiders do" (Hawkins 64).

Harris makes the further point that students in peer tutorials typically trust peer tutors and have confidence in their skills and knowledge. Students' perception of the peer group leader is also an important component of the peer group leader's usefulness in peer response groups. For peer response to work, peer group members must have confidence in their peers' knowledge. However, for basic writers especially, trust in peers' knowledge is suspect, mainly because they have been designated as underprepared for college writing. Peer group leaders can play a significant role in leading basic writers to see themselves and their peers as knowledgeable, skilled writers. Moreover, because peer group leaders can pass their knowledge to basic writing students, they more evenly distribute knowledge in the classroom. As a result, the classroom becomes a more authentic decentered, collaborative learning environment, in practice as well as in theory.

While peer group leaders can bring the advantages of both peer response groups and peer tutorials to their roles in peer response sessions, they may also degrade peer response. Harris points out that because peer tutors are more acquainted with academic discourse than the tutees, "the further they are from being peers in a collaborative relationship" ("Collaboration" 379). Students come to them seeking prescriptives, thereby making it difficult for tutors to remain collaborators rather than co-authors and frustrating both student and tutor (379). Certainly the potential exists as well when we bring peer group leaders to peer response groups. Peer group leaders, straddling both the basic writers' and academic communities, are not completely "equal" to other peer group members. Without writing of their own "out there" and under scrutiny, peer group leaders have less at stake than the other peer group members. Harris makes the point that the peer tutor's unique position as interpreter of academic jargon is in peril if the tutor, "enamored of the jargon of the field, moves too far into the teacher's world" (380). Clearly, this risk of co-authoring and co-opting student writing exists with peer group leaders in peer response groups, 
but can be minimized with effective training and guidance.

Relatedly, peer group leaders may interfere with what Harris identifies as peer response groups' give-and-take process of negotiation that leads to consensus about how the group will undertake peer response (374). With the peer group leader's participation in peer response, the negotiation between students will likely be less democratic, for part of the peer group leader's role is to help guide students to specific kinds of response. Moreover, as in tutorials, the tutor's and students' goals may often conflict, since students want particular papers fixed while the tutor attempts to address larger issues (374-75). Clearly, if students have the goal of fixing a particular piece of writing in their peer response group, they may find themselves in conflict with the peer group leader who will be guiding them to more global issues as well. On the other hand, since peer response groups with peer group leaders can effectively address both specific and general writing concerns, the conflicts between students and peer group leader are likely to be reduced.

Harris' identification of the tutor's "unique advantage of being both a nonjudgmental, non-evaluative helper - a collaborator in whom the writer can confide" (376) - cannot be ignored when we bring the peer group leader into peer response. Arguably, the peer group leader may face difficult hurdles in getting group members to perceive him/ her as non-evaluative and non-judgmental, given the peer group leader's connection to the instructor. Instructors can make it clear to students that the peer group leader is there to offer assistance, not to evaluate or judge them. Instructors can also inform students that even though they will consult with the peer group leader throughout the semester (much like peer tutors in Writing Centers confer with instructors), the peer group leader will not be involved in grading the students in any way. In my class, students' participation in peer response did influence their grades to some degree, but it was my assessment of the logged transcripts of the sessions, not anything the peer group leader told me, that affected my evaluation of students' participation in this process. Although I do not think I was able to completely overcome my students' association of the peer group leader with myself, I believe they did come to see her as non-evaluative, enabling her to evoke honest and authoritative response.

\section{Building Bridges to Academic Discourse: The Peer Group Leader in Basic Writing}

How well did using a peer group leader work in my class? What advantages and/or disadvantages did this young woman bring to basic writers' peer response groups? In the following pages, I offer my 
analyses of the peer group sessions. Since most of our response sessions occurred online, I was able to use these transcripts to monitor and assess the peer group leader's effectiveness in leading students to substantive response. ${ }^{6}$ I hope to suggest, finally, that this study has significant implications for further research and practice using peer group leaders as a bridge to academic discourse for basic writers.

In the basic writing class under study, I challenged students with difficult work, connecting content with methodology as we studied varied aspects and definitions of literacy, each assignment building off the others so that the writing assignments, as Berthoff suggests, "encourage conscientization, the discovery of the mind in action" so students "learn ... how meanings make future meanings possible, how form finds further form" (755). Moreover, class content, focused on academic literacy itself, wedded content with methodology and put discourse at the center of analysis. Thus, course content and methodology began the process through which basic writers could enter academic discourse. The peer group leader helped these students make this difficult leap, as the following examples demonstrate. At the same time, however, her work illuminates some of the potential perils of peer group leaders in basic writers' peer response.

One strength of the peer group leader was her ability to both inform and model. In the following example, Tyisha, the peer group leader, guides students away from mechanical issues, without specifically instructing them not to consider such surface features.
Stan: yo Paul i guess you read my review
Paul: yup
Paul: it was good
Stan: good content
Paul: yes
Stan: i found it very interesting
Paul: but I found a lot of little mistakes
Paul: did you catch any?
Tyisha: I liked your paper also Stan, it was really good, Paul is there anything in his paper that you thought he could work on, besides a few spelling mistakes.

Tyisha's language effectively downplays "a few spelling mistakes" and re-focuses students' attention to more substantive issues, without specifying what these should be. This exchange demonstrates Tyisha's ability to simultaneously focus on the essay under consideration while leading students to discovery.

In the next example, Tyisha successfully keeps the group focused and elicits effective critique. 
Tyisha: what can he do about that 5th paragraph

Stan: break it up

Tyisha: It is too big- break it up how?

Stan: hold on $i$ have to read it again to get that answer

Paul: I think I could break it up at the word people

Larry: LEHIGH IS BETTER THAN BERK

Paul: yea yea

Tyisha: Larry we're having a discussion

Paul: Larry is the man

Stan: ok i just want to get to main sooooooooooo i don't really care

Stan: but berks has more that one building and we have a guy

Paul: that really doesn't bother me

Tyisha: Anyways, what can we do with this para. lets get back on track

Tyisha: just 5 more minutes

Paul: I could break it up at the word "people"

Tyisha: Good and from there what could he do Stan

Stan: that is what $i$ was just about to say

Stan: back up the ideas in greater detail

Tyisha: should he change the intro. sentence to that paragraph or keep it the same.

Stan: just make sure you have good transition between the two paragraphs

Paul: ok

Stan: yep.......change the intro

When Larry interrupts Paul's and Stan's academic conversation, Tyisha takes a leadership role, trying to get them back on track. Though Stan momentarily gives in to Larry's disruptions, he does re-focus his attention on the task. This is an important example of the peer group leader's potential role, for all too often, basic writers get off track - and stay there. Although Tim Hacker claims that students in writing groups tend to take on the role of teacher, I rarely see this occur with basic writers. It is difficult for these students to get back on track on their own, perhaps afraid to take on such a leadership role, questioning their own authority as writers.

Furthermore, the above exchange also illuminates the ways in which the peer group leader can simultaneously focus on a particular piece of writing and more global writing instruction. Even though Tyisha and the peer group members are discussing Paul's essay, Tyisha's comments are directed at Stan, the responder. Paul's comment that "I could break it up at the word 'people" and Stan's comment that "that is what I was just about to say" indicate their understanding of both how to "fix" this particular paragraph and its appli- 
cability to issues of paragraphing generally.

Similarly, the following exchange also illuminates the peer group leader's ability to straddle the roles of tutor and peer, focusing on specific and general concerns.

Sara: In some of the papers I write, I start out with a question Tyisha: so how does this help Joes paper

Tyisha: what idea do you have for Joe that he could use with a question in his paper

Sara: He could have started out with "What is Technical Literacy?"

Tyisha: and then what could he have done in his intro to support this?

Joe: why would I want to start with a question that I don't know the answer to?

..

Sara: Explain how many definitions it had and use each definition to start a new paragraph

Tyisha: good point how would you answer that, you went right to the point in your starting paragraph.

Sara: Joe what do you say?

Joe: The point that I am attempting to say is that I do not know the exact definitions.

Sara: Did you try looking them up?

Joe: no, because we are suppose to find our own.

Sara begins this exchange over Joe's introductory paragraph by pointing to her own strategy for introductions. Tyisha then pushes her to apply it to Joe's essay. Despite Joe's disagreement, Tyisha effectively guides these students to consider not only Joe's essay but a particular rhetorical strategy more generally. Sara and Joe debate the issue in academic terms, Joe responding that "looking it up" is not what academic discourse is about. Instead, Joe realizes the role he must play as a knowledge-maker.

The following example demonstrates an impressive interchange of substantive ideas between Tyisha, Jennifer, and Stan that occurred fairly late in the semester. Jennifer begins by asking both her peer and the peer group leader for response:

Jennifer: Tyisha, do you think I stay on track or do I drift off my topic?

Jennifer: Also, do you think my thesis is okay, or more like what do you think my thesis is?

Jennifer: Stan, give me some input. What do I need to change? 
Remember I did this late last night.

Stan: well you talk about culture and beliefs and than you jump to standard english. It just needs something to blend the idea that even though a person likes to keep their beliefs that they still need standard english.

Tyisha: Your paper is very good however, Stan can you identify Jennifers thesis, and does it go along with her paper.

Tyisha directs Jennifer and Stan to consider a particular problem in Jennifer's essay, the lack of a clear thesis/focus, specifically responding to Jennifer's request for help but in the process guiding Stan to respond. The discussion continues:

Stan: well I think it can be improved upon. I really did not understand what the article was going to be about when I read it.

Jennifer: I think I am still talking about Standard English. I throw in culture and beliefs because that is why people stray from Standard English, it is so they can keep close to their culture.

Tyisha: Okay, so then how does all this information tie in to Rachel Jones facing disadvantages-what do you think Stan. Jennifer: I don't understand. Didn't I introduce my thesis in the opening? I thought I made it clear what I was talking about, but I could be wrong.

Tyisha: Your thesis should be in the introductory paragraph last sentence before you get into your supporting paragraphs. Jennifer: I used Rachel Jones because I like how she expresses that people are faced with disadvantages without speaking Standard English.

Tyisha presses Stan to help Jennifer with this problem of purpose and simultaneously propels Jennifer into thoughtful consideration of her rhetorical choices. Even though Jennifer notes, as a writer questioning her own authority, that "I could be wrong," she continues to explain the reasoning behind her own understanding of her thesis and its placement in the essay. Tyisha's presence has helped this basic writer gain confidence in her own and her peer's knowledge and writing. The conversation concludes this way:

Stan: try adding something like this; Standard english pulls from cultural independence. Some people feel that without there cultural distinction they will be lost. For a person to truly accelerate in our society they must have a little of both. Cultural diversity is not acceptable in todays world and for a per- 
son to not understand or use standard english they will be lost.

Jennifer: so, she was my spark for this paper. I am responding and giving my idea of her views.

Tyisha: It's good you used Jones however, what is your thesis, is it that last sentence, because if so then you could talk about the things SHE FACED, I think it could be the $2^{\text {nd }}$ and $3^{\text {rd }}$ sentences combined, how do you feel Stan.

Stan: well I wrote what I think it should be

Jennifer: thanks Stan, I like that response you gave me previously. I wrote it down because I like it a lot.

Tyisha's membership in the academic community is evidenced by her stronger, more nuanced reading of Rachel Jones' essay, "What's Wrong With Black English?" and her clearer sense of how to respond to an outside reading in one's essay. She prods Jennifer into a deeper reading in a way that both models and guides Jennifer and Stan in the conventions of academic discourse. Benesch argues that peer response is often disconnected - that is, utterances are left suspended, other comments are raised, and an emerging conversation rarely materializes (93). With the aid of Tyisha, we see a substantive conversation emerge (temporarily interrupted by the lag time inherent in online synchronous conversations) because Tyisha enables them to "enter imperfectly into peer group conversations" (Benesch 93, emphasis mine), as Stan's misstatement that "Cultural diversity is not acceptable" indicates. Indeed, Stan's rewriting of Jennifer's introductory paragraph (which shows his own sense of authority as a knowledgeable peer) illuminates the perils of peer response generally. I would like to believe that peer group leaders could lessen the impact of such difficulties, though admittedly, Tyisha did not "catch" it this time.

The above examples and analysis point to the strengths of peer group leaders in basic writers' peer response, but there were some pitfalls as well. Mainly, these occurred when the peer group leader became overly prescriptive, as the following two examples demonstrate:

Stan: overall the paper was good. Some things that need to be worked on is unity. Also what is that delta 9 stuff about.

Stan: is that the code for the tetrahydrocannabinal

Paul: yea

Tyisha: define cannabis in your paper so your reader knows what it is.

Paul: ok 
Tyisha: what can Joe do to make his first sentence sound interesting?

Tom: Joe could tell the reader what his point of view is

Tyisha: yes or he could also do what

Tyisha: where are you Joe

Tom: he could state what the controversy is

Joe: I don't want to include my opinion in the beginning because I was writing from a non-bias point of viewpoint

Tyisha: Tom, do you think you would pick up an article like Joe's why or why not?

Tom: I would because in reading the first sentence I want to know what the controversy is

Tyisha: Joe your paper is good, just work on making the introductory sentence sound appealing to the reader, by having a sentence like, As I looked into the subject of cultural diversity, I noticed how it was such a controversial topic.

There are probably a number of reasons why instances such as these occurred, beginning with Harris' identification of peer tutors' tendency to become "enamored of" their more authoritative role (380). There were times when I observed Tyisha reveling in her role as more knowledgeable, and why not? She was a former basic writer, and her work as a peer group leader by its very nature indicated how far she had come. At the same time, like peer tutors, Tyisha was still very much a part of her peers' community, only one year ahead of them in school, as her comments from various peer response sessions reveal: "what can Paul do to make his paper more personal to his audience"; "Maybe in your intro you could mention that there are bad effects of weed"; "Let's flip to Paul's [essay]"; and "you're a nut Paul." In the first comment, Tyisha uses academic terminology ("audience"), though somewhat awkwardly. In the second sentence, her use of the word "weed," rather than the more formal "marijuana" (as I would call it), discloses her ties to basic writers' community. The final two comments also reveal her connection-as-peer with the basic writers in my class.

I also believe that Tyisha was genuinely concerned about the writers in my class, and she wanted to help them improve their essays and get good grades, perhaps losing sight of her alternate roles. Her impulse to jump in with ways to "fix" their essays may have been a result of this concern. Moreover, there were times when she probably became frustrated with students in her group, as she prodded and pushed them to areas they did not want to go.

Relatedly, Harris' identification of the conflict over objectives of tutor and tutee may also explain some of the difficulties I experienced 
with the peer group leader. In the impressive exchange between Tyisha, Stan, and Jennifer previously discussed (I reproduce it below), there are also some signs of discontent.

Stan: try adding something like this; Standard english pulls from cultural independence. Some people feel that without there cultural distinction they will be lost. For a person to truly accelerate in our society they must have a little of both. Cultural diversity is not acceptable in todays world and for a person to not understand or use standard english they will be lost Jennifer: Also, she was my spark for this paper. I am responding and giving my idea of her views.

Tyisha: It's good you used Jones however, what is your thesis, is it that last sentence, because if so then you could talk about the things SHE FACED, I think it could be the $2^{\text {nd }}$ and $3^{\text {rd }}$ sentences combined, how do you feel Stan

Stan: well I write what I think it should be Jennifer: thanks Stan, I like that response you gave me previously. I wrote it down because I like it a lot.

The transcript itself shows less of the conflict than did Tyisha's comments to me after class. Tyisha felt that Jennifer was defensive, rejecting Tyisha's input and guidance, though I wonder whether some of this was not a misperception on her part. Nevertheless, I do believe the dialogue highlights two of Harris' points. First, it is possible that Jennifer saw Tyisha as judgmental, since Jennifer clearly felt strongly about her essay. The fact that the peer group leader does not have writing to be mutually critiqued alters the dynamic of peer collaboration and may have led Jennifer to feel defensive about her writing. Secondly, I think it is conceivable that Jennifer wanted what Stan gave her: a more direct answer to her questions about the thesis. Indeed, Stan rewrites the paragraph for her. Tyisha, on the other hand, prods Jennifer into making the discovery for herself, which may have been frustrating for Jennifer. Moreover, Tyisha's use of capital letters when she wrote "'it's good you used Jones however, what is your thesis, is it that last sentence, because if so then you could talk about the things SHE FACED," may have been offensive to Jennifer, although I think Tyisha only meant to emphasize the point she was trying to get across. Jennifer's "thank you" to Stan at the end of the discussion, absent one to Tyisha, may be further evidence of the conflict Tyisha sensed. 


\section{The Future of Peer Group Leaders in Basic Writing}

This study of the peer group leader in basic writing has significant implications for further research and practice. Above all else, it points to how peer group leaders can aid basic writers' appropriation of academic discourse. The benefits of peer response groups for writers include cognitive, global issues like "better sense of audience" and "motivation to revise," specific task-oriented activities like increased effectiveness in proofreading and editing, and emotional benefits such as offering emotional support and developing a sense of community (Harris, "Collaboration" 372). I have shown how Tyisha contributed to each of these areas in her work with my basic writers.

This study also identifies areas of concern in using peer group leaders, but I do not think the concerns are unsolvable. Rather, I think there are ways to lessen their impact, and I will suggest some of them here. Indeed, I am using peer group leaders again in my current basic writing classes, and I have made many of these changes in my own classes. First, I believe peer group leaders need more training and integration into the basic writing class than the project under study allowed. Tyisha had only one day of training at the beginning of the semester (due to limited funds as well as my inexperience). Moreover, although she and I discussed issues as they arose for her throughout the semester, our conversations were informal and spontaneous. I suggest incorporating more training time, including structured, formal supervision and guidance throughout the semester. I also believe the research on selection and training of peer tutors in Writing Centers can inform this work (see Cobb and Elledge).

Currently, I am using three peer group leaders in my basic writing classes, and I have spent more time with ongoing assessment and adjustment of their work with students as well as with their initial training. It is very difficult for peer group leaders to walk that fine line between offering help and solving the problem for the basic writers with whom they work, an issue tutors in writing centers also face. Indeed, these students' recent roles as peer responders in peer response groups (in English Composition last semester) make the multiplicity of their new roles even more challenging. Thus, their ongoing training centers on these issues.

My current peer group leaders began the semester by reading Richard Straub's "Responding - Really Responding - to Other Students' Writing" and excerpts from Muriel Harris' Teaching One-to-One: The Writing Conference. They participated in a mock peer group session, and they attended class on the date I introduced peer response groups to my basic writing students. Additionally, we continue to discuss and assess their work with students, and two of the three peer 
group leaders are co-presenting their experiences as peer group leaders at this year's National Conference on Peer Tutoring in Writing. They will also attend other panels at the conference to learn more about writing center tutorials and the distinctiveness of their roles as peer group leaders.

Furthermore, I suggest that peer group leaders be more integrated into the class than my initial study allowed. Due to limited funding, Tyisha attended class only on peer response days, which lessened the opportunity for students and tutor to bond. Subsequently, the trust that is so important between tutor and student may have been curtailed. ${ }^{7}$ At the same time, I believe Tyisha's sense of investment in the class could have been stronger (I am a bit suspect about whether she read all the assignments), although I do think she cared about the students with whom she worked. Attending more classes would have also helped her to feel like part of the class rather than an intruder on peer response days.

Again, I have begun to address some of these problems in my current work with peer group leaders. These students (all were in my English Composition classes last fall, and one was also a former basic writer in the class under study) are attending the basic writing classes an average of two out of three class meetings per week, including the dates when we discuss the readings. ${ }^{8}$ Moreover, the peer group leaders attend class and work with students during workshop classes when students are working on prewriting, drafting, and/or revision. I am attempting to find additional ways to expand their role as peer leaders in the class, though again I am somewhat limited by financial constraints.

I also think it would have been helpful for Tyisha to attend class when we discussed the readings in order to obtain a more sophisticated understanding of them. Though more advanced with academic discourse than the basic writers, she still was, after all, a sophomore, and I do not think all her difficulties with the readings were because she did not read them. Relatedly, Tyisha's performance also raises the issue of peer group leaders' age and maturity. I foresee many benefits of using older students as peer group leaders, such as more serious investment in academic work, greater reliability, and higher skill levels in reading difficult texts. ${ }^{9}$ However, these benefits might be offset by older students' distance from first-year basic writers and the potential for degradation of peer collaboration.

Additionally, I think it is important to use more peer group leaders in a basic writing classroom. Ideally, each writing group should have a peer group leader. Tyisha's potential to help the students was undermined by the fact that there was only one of her to go around. Subsequently, she had less opportunity to get to really know the students with whom she worked and individualize instruction based on 
specific needs. Additionally, I felt somewhat uncomfortable about the fairness of having her work with some students rather than others. In designing the project, I had expected that Tyisha could work with all the students over the course of the semester by working with two or three groups during each peer response class. However, during the first class I learned that she could not go from one group to another because doing so disrupted conversations-in-progress.

Currently, I am using two peer group leaders in one class and one in the other, still less-than-ideal situations. ${ }^{10}$ Clearly, funding is a potentially serious obstacle to maximizing the benefits of using peer group leaders in basic writing. As a result, I have begun to think about other ways to support peer group leaders. For example, I am beginning discussions with the Honors Coordinator at my college about finding ways to integrate using peer group leaders with our Honors program. Other possibilities include for-credit internships, community service, and/or senior capstone experiences. Currently, I am involved in designing a major in Writing and Rhetoric for our college, and this major might offer opportunities to integrate the peer group leader experience with students' course of study.

Finally, my study also raises issues related to computer-mediated-communication (CMC) and online peer response sessions. I chose to conduct my peer response sessions online for a number of reasons, but primarily because I have experienced the ways in which "technology can help build a sense of community and change basic writing dynamics" (Varone 213). Because electronic forums challenge teachercentered pedagogies and provide students with the means to question academic (and other) authority, online peer groups potentially foster basic writers' meaningful participation in the review process. Research on online forums and collaborative writing suggests that students respond well to this less-threatening atmosphere, especially for students who perceive differences in status or knowledge, and engage more collaboratively and intensely with writing (see Schriner and Rice).

In this study, I chose not to focus on CMC issues largely because I was mainly concerned with the use of the peer group leader. I also believe that the implications of peer group leaders hold for both traditional and electronic classrooms, though I expect that there are advantages and disadvantages to each. As I continue to use peer group leaders in my basic writing classes, I will look more closely at the convergences and divergences of electronic and traditional classrooms, including CMC-specific issues such as lag time, space, and anonymity. Indeed, in my current basic writing classes using peer group leaders, I have chosen to conduct peer response sessions face-to-face, even though I hold class in a computer classroom two out of three days per week. Clearly, the specific dynamics of peer group leaders and online peer response is an area ripe for research. 
Bishop asserts that teachers who use peer writing groups must be researchers in the sense that they monitor and evaluate the process. They must be "willing to experiment, to redefine group failures as steps in a larger process that leads to success, and to have realistic expectations for this holistic teaching method. Before long, those expectations will be met and hopefully surpassed" (124). I am one of these teachers, eager to continue working with peer group leaders to help basic writers cross the bridge to the academic community. When they cross that bridge and appropriate academic discourse, they will have the opportunity to make their mark on the world.

\section{Notes}

1. I thank my collegue Candace Spigelman for the term, "peer group leader."

2. Margaret Weaver rightfully acknowledges the debate over authority and peer response groups in basic writing research. That is, some theorists advocate consensus, that peer response enables students to join our conversations, while others advocate dissent, that peer response groups enable basic writers to resist academic discourse (though she perhaps creates a false dichotomy). Nevertheless, because I believe the use of peer group leaders can facilitate both dissensus and consensus, debating the issue itself is beyond the scope of this essay.

3. I received this grant in conjunction with a colleague, Claudine Keenan. Claudine used a peer group leader in her basic writing class at the Lehigh Valley Campus of Penn State University, Berks-Lehigh Valley College, but I am writing only about my class at the Berks Campus.

4. Throughout this article, I am using pseudonyms for both the peer group leader and the basic writers.

5. I am not encouraging teachers to disappear completely, however. Indeed, I introduced a writing rubric to my students, one that closely resembled my own set of writing assessment criteria with greater emphasis on content and meaning than mechanics, and throughout the semester, we circled back to these issues in numerous ways. However, my attention to rhetorical issues had more to do with my general approach to teaching academic discourse, rather than specifically focused on modeling for peer response groups. 
6. I have edited the transcripts to make them legible (students writing online tend to rush and transcripts can be difficult to read), but I have been very careful not to appropriate their words or language.

7. Students will offer more critical and high-quality response in an atmosphere of support and sharing. That is, group members need to gain some sense of group identity, have a sense of shared goals, and feel invested in their peers' work. Robert Brooke, Ruth Mirtz, and Rick Evans' study of student writing groups stress that for groups that worked well together, "a significant number of students describe their small groups as friendly and family-like in their unconditional acceptance" (34). Similarly, groups fail when students do not feel comfortable with their group members and do not get along.

8. Thus far, the peer group leaders have only listened to, rather than participated in, class discussions of the readings. I am currently weighing the advantages and disadvantages of allowing them to be more involved in this aspect of the class, especially when students work in groups to analyze and interpret the difficult reading selections. Clearly, the peer group leaders' participation in this aspect of the class raises issues both similar to and different from their participation in writing groups.

9. Penn State University, Berks-Lehigh Valley College, was only in its second full year as a four-year college when I undertook this project. Therefore, I had few juniors and seniors from which to choose. I expect a greater pool of potential peer group leaders as our college grows.

10. I received funding for two peer group leaders per class, but unfortunately I received the funding so close to the start of the semester that I was unable to find a fourth student whose schedule met my needs.

\section{Works Cited}

Bartholomae, David. "Inventing the University." Journal of Basic Writing 3.1 (1986): 4-23.

-. "Writing on the Margins: The Concept of Literacy in Higher Education." A Sourcebook for Basic Writing Teachers. Ed. Theresa Enos. New York: Random House, 1987. 66-83.

Bartholomae, David, and Anthony R. Petrosky. Facts, Artifacts, and Counterfacts: 'Theory and Method for a Reading and Writing Course. Upper Montclair, NJ: Boynton/Cook, 1986.

Benesch, Sarah. "Improving Peer Response: Collaboration Between Teachers and Students." Journal of Teaching Writing 4.1 (1985): 87- 
94.

Berthoff, Ann E. “Is Teaching Still Possible?" College English 46.6 (1984): 743-55.

Bishop, Wendy. "Helping Peer Writing Groups Succeed." Teaching English in the Two-Year College 15.2 (1988): 120-25.

Brooke, Robert, Ruth Mirtz, and Rick Evans. Small Groups in Writing Workshops: Invitations to a Writer's Life. Urbana: NCTE, 1994.

Bruffee, Kenneth. "Collaborative Learning and 'The Conversation of Mankind.'" College English 46.7 (1984): 635-52.

Cobb, Loretta, and Elaine K. Elledge. "Peer Tutors as a Source of Power for Basic Writers." Teaching English in the Two-Year College 9.2 (1983): 135-39.

Gay, Pamela. "Questions and Issues in Basic Writing and Computing." Computers and Composition 8.3 (1991): 63-81.

Hacker, Tim. "The Effect of Teacher Conferences on Peer Response Discourse." Teaching English in the Two-Year College 23.2 (1996): 11226.

Harris, Muriel. "Collaboration Is Not Collaboration Is Not Collaboration: Writing Center Tutorials vs. Peer-Response Groups." College Composition and Communication 43.3 (1992): 369-83.

---. Teaching One-to-One: The Writing Conference. Urbana: NCTE, 1989.

Hawkins, Thom. "Intimacy and Audience: The Relationship Between Revision and the Social Dimension of Peer Tutoring." College English 42.1 (1980): 64-68.

Jones, Rachel L. "What's Wrong with Black English." Encountering Cultures: Reading and Writing in a Changing World. Ed. Richard Holeton. Englewood Cliffs: Blair, 1992. 17-19.

Lawrence, Sandra M., and Elizabeth Sommers. "From the Park Bench to the (Writing) Workshop Table: Encouraging Collaboration among Inexperienced Writers." Teaching English in the Two-Year College 23.2 (1996): 101-11.

Newkirk, Thomas. "Direction and Misdirection in Peer Response." CCC 35.3 (1984): 300-11.

Schriner, Delores K., and William C. Rice. "Computer Conferencing and Collaborative Learning: A Discourse Community at Work." CCC 40.4 (1989): 472-78.

Straub, Richard. "Responding - Really Responding - to Other Students' Writing." The Subject is Writing: Essays by Teachers and Students. Ed. Wendy Bishop. $2^{\text {nd }}$ ed. Portsmouth: Boynton/Cook, 1999. 136-46.

Varone, Sandy. "Voices From the Computer Classroom: Novice Writers and Peer Response To Writing." Teaching English in the TwoYear College 23.3 (1996): 213-18.

Wauters, Joan K. “Non-Confrontational Critiquing Pairs: An Alternative to Verbal Peer Response Groups." Writing Instructor 7.3-4 (1988): 156-66. 
Weaver, Margaret E. “Using Peer Response in the Classroom: Students' Perspectives." Research and Teaching in Developmental Education 12.1 (1995): 31-37.

Zhu, Wei. "Effects of Training for Peer Response on Students' Comments and Interaction." Written Communication 12.4 (1995): 492528. 


\section{JUST WRITING, BASICALLY: BASIC WRITERS ON BASIC WRITING}

ABSTRACT: This article explores three salient findings from interviews with basic writing students at the University of Michigan-Dearborn: students' definition of "basic writing," their understanding of writing and reading expectations in other courses, and their conceptualization of writing. It suggests that these findings cast new light on the responsibilities that we have toward basic writers, both as teachers and as representatives of the institutions where we teach. Ultimately, the article suggests that we must help students understand what it means to be a basic writer in their particular institutions by providing more thorough information before placement procedures; it also suggests that we can help writers contest and refute their labels as basic writers through the curricula in our courses.

\section{Introduction}

As an area of focus within composition studies, basic writing has come a long way since the publication of Errors and Expectations. We have our own journal, JBW; we have our own Special Interest Group within the CCCC, the Conference on Basic Writing. Basic writing regularly appears as a submission category in the CCCC call for proposals. In essence, since the late 1970s, basic writing has begun to move through the same kind of professional growth that other fields (including composition) have experienced as they move toward legitimacy as fields. If one were inclined to define the development of basic writing as a linear progressive narrative, these developments could be seen as important signs that the sub-field was moving toward such legitimacy, at least within the broader discipline of composition.

As it has moved through this process, scholarship in basic writing has also become more complex. Our research has moved well beyond simply identifying who are basic writers and what are their defining characteristics. Instead, the focus has shifted, broadly, to three areas. The first encompasses studies examining the construction of basic writers and/or basic writing classes and, perhaps, questioning

Linda Adler-Kassner is Assistant Professor of Composition at the University of MichiganDearborm. She has published articles in JBW, CCC, TETYC, and elsewhere. This article represents part of an ongoing study conducted with Susanmarie Harrington of basic writing and basic writers in the contemporary academy. 
the legitimacy of those constructions based on the analysis of them (for example, Adams; Bartholomae, "Tidy House;" Scott; Stygall). Next are those studies describing and/or analyzing pedagogies used for working with basic writers, including assessment methods within those pedagogies (these might include deBeaugrande and Olson; Lu; Perl, "Composing,"; Shaughnessy, Errors, "Diving In"). Third are studies examining basic writers in action - those focusing on writers' cognitive processes (like Hull, Rose, et al.; Hull and Rose; Rose), and those examining their actual writing or revising processes (Perl; GrayRosendale). More important than serving as a testament to our growth as a sub-field, these studies have enriched our understandings of basic writing and basic writers immeasurably. Yet, as our focus broadens, we have left behind some of the early questions that once captivated researchers.

\section{Back to Basics: Defining Basic Writers}

Among these questions is one that Susanmarie Harrington and I have suggested must regain their centrality to our work: Who are basic writers? In "The Dilemma That Still Counts," we examined the ways in which basic writers (and basic writing) has been defined through twenty-odd years of basic writing research. We argued that while "basic writing" remains an essential concept in the academy, we must work to clarify what the term means in order to act upon it, particularly in light of political actions like those recently taken within the CUNY system. Among the issues we posed for further investigation in our article was learning more about how basic writers (or, more appropriately, students labeled basic writers within particular institutions) defined themselves. How do they understand their experiences with writing and reading? Do they find particular features in their writing to be problematic? Do they contest their labeling as "basic writers?" Do they perceive their skills and challenges differently than the university does?

In order to find out how basic writers at my institution answered these questions, my colleague Randy Woodland and I interviewed 16 students chosen randomly from the 80 who placed into our basic writing course during the fall semester of 1998 . The questions that we asked students in our interviews reflected the two approaches which Susanmarie and I presented as widely prevalent in basic writing research in "The Dilemma That Still Counts." Cognitively-based studies, we wrote, were concerned with writers' individual processes as they wrote and read. The processes which writers bring to producing or decoding texts are the subjects of study. Thus, in designing this current study Randy and I asked students to bring in examples of past 
writing that they particularly liked and to talk with us about them, and asked questions that prompted students to reflect on their composing processes. Susanmarie and I also suggested that a later trend in basic writing scholarship is toward culturally-based studies, which examine the writer in relationship to larger cultures (like the academy). In this light, a writer is seen as within a broader matrix of literate processes, some or all of which might come into play during their encounters with academic texts. This approach is reflected in questions directed to UM-D students about their writing and reading histories and those about their perceptions of writing and reading requirements that they will encounter in college. ${ }^{1}$ The interview protocol was divided into three basic areas (questions are included in Appendix A):

I. Existing writing. In the letter inviting students to talk with us, we asked if they had a paper (or several papers) that they particularly liked, and if they would bring those with them to the interview so that we could talk with them about the essays.

II. Experiences with and ideas about writing and reading. These included questions about students' families and family histories with writing and reading; students' histories with writing and reading inside and outside of school; students present writing and reading habits; students' experiences with writing and reading in school; about connections between writing and reading outside and inside of the classroom; and about how students defined key terms related to writing and reading.

III. Expectations for college. Here, we asked students if they had a planned major and, if they did, what it was. Additionally, if they had a major in mind, we asked what they expected would be required of them in courses in their major.

IV. Conceptualizations of and expectations for writing. Questions here fell into two general areas: those related to the basic writing course (including "what is a basic writer?"), and the specific writing and reading expectations in their proposed or prospective majors.

Students' responses to these questions have helped us develop a better understanding about how they approach post-secondary education, how they imagine the role of writing in that education, and how they see themselves in relation to what they imagine the academy to be. They also provide the foundation for a compelling argument about the responsibilities that institutions (and the teachers who are a part of them) have toward students who are identified as basic writers. Helping students to contest and, ideally, to overcome their status as basic writers is an implied goal of most basic writing courses. ${ }^{2}$ But these interviews suggest that to really help students develop a sense of that definition and the means to overcome it, we need to do more than 
imply. In fact, we need to explicitly help students understand and act on what all of this means in our specific institutional contexts. We might even make the questions "what does it mean to be a basic writer here, and what does it take to not be one?" part of the "subject" of our basic writing courses.

To illustrate these findings, I'll ground the discussion in portions of interviews with two writers, Tom and Susan. ${ }^{3}$ In some ways, these two writers are typical of UM-D's basic writing population. Like most of our students, they came from inner-ring suburbs of Detroit and commuted to UM-D from homes where they lived with two parents or guardians. Both came from homes where some writing and reading took place, although writing and reading was not a main focus in either home. Tom was unusual in that neither of his parents had completed a two- or four-year degree, but was typical in that at least one of his parents had attended (if not completed) community college. ${ }^{4}$ Both described themselves as fairly good students. ${ }^{5}$ Neither writer professed a great love of writing or reading outside of the classroom (although Tom said he enjoyed science fiction novels); in this respect, they were also quite representative of the other students whom we interviewed.

After taking the UM-Dearborn placement exam, both Tom and Susan received two scores of 2 (out of a possible score of 6 ) on the exam. According to the scoring guidelines, a " 2 " essay

has significant weakness of one or more kinds: Development of ideas may be weak with few specific details to support main ideas. Paragraphs may be relatively short and loosely organized with inadequate transitions. The overall organizational pattern may be loose or not apparent. There may be a pattern of major grammatical errors or numerous misspellings.

Most writers who take basic writing at UM-D receive scores of " 2 " on their exams, and in this light Tom and Susan were also fairly representative. Their responses to questions about writing in college were also fairly typical of the basic writers whom we interviewed, and they nicely foreground some of the most interesting findings to emerge from our discussions with basic writing students.

\section{Tom's and Susan's Interviews}

\section{Tom}

Like the vast majority of students on our commuter campus, Tom still lived at home. His father was recently retired from "Ford's"; ${ }^{6}$ his mother worked at the Kmart Headquarters in Troy, Michigan. Tom 
said neither he nor anyone in his family did a lot of writing or reading outside of school, although he did enjoy "making up a story and writing about it" and he liked science fiction. Once, in school, he got to write a science-fiction story as a paper, which he enjoyed. But most of his high school writing and reading he found tedious - reading a book and writing reports, and doing "analyzing." Tom could name only one book he enjoyed reading in high school, To Kill a Mockingbird.

At UM-D, Tom planned to major in Computer Information Systems, a major housed in the College of Engineering and Computer Science. When I asked Tom if he thought he'd have to do a lot of writing or reading for his major, he said, "I don't believe so," although he hadn't talked to anyone to get a sense of whether his impression was correct. He did think he'd have to do a lot of math, "and ... research with the books and the computer books and stuff," but since he was "into computers," he didn't think he would be "handed a book and [told,] 'Here, read this."'

When I asked him to describe his writing, Tom said, "I can get creative, but it's mostly just like science fiction stuff that I like to come up with." As a writer, he said, "I'm only doing it 'cause I have to, and I have to get a good grade on it." Tom thought he would learn "how to write essays, you know, essays, papers," in basic writing. Additionally, he thought he'd learn to

try to keep focus on certain points and use proper grammar, which I was never really good with anyways, but ... actually, it's the grammar that I don't really care for. I learned a lot of it, but I just can't remember.

\section{Susan}

Susan also graduated from an inner-ring suburban high school. Susan's dad was "kind of self-employed," and her mother was a nurse. She said her family did some reading and writing - her mom "[wrote] e-mails a lot and read magazines a lot," and her stepfather read the newspaper. She didn't do a lot of writing or reading. She had a creative writing class in school that she liked, but they didn't do a lot of writing the first semester, and had "a journal" in the second. "It wasn't really a writing class. It ended up being a relationship class." She liked her ninth grade English teacher, who "really pushed you, and made you understand [reading in the class]."

Susan thought she would major in business at UM-D, but wasn't really sure. Susan expected to write papers in college, and that those papers would be "so much different [from high school] ... everything [in college] is just more intellectual and you have to think more and go, you know, deeper into things and explain yourself . . . and just 
have things to back it up."

When I asked her if she thought of herself as a good student she didn't answer directly. Instead, she said, "I know what I want to do and I know what I have to do, so...." As a writer, Susan said "I think I have a lot to say .... but I don't know how to write it. I don't know how to put my words together and write it down and make it flow good and make it sound right. I can't do that." She said her writing now was

really shaky ... 'cause I'll have to sit there and I'll have to write something over and over again 'cause it just doesn't flow right and it doesn't make any sense the first time I write it, so I have to sit there and I have to really work at it.

I asked her if it came out, but it wasn't what she was thinking, and she said,

Exactly ... . Afterwards, when I look at it . . I'm, like, that wasn't what I was trying to say at all. And I try to put it in different words or I'll just try to rewrite it out later on and it just doesn't work and I'll have to sit there and I'll have to work at it for a while.

Sometimes she continued to work at it; sometimes, she gave up because she found it frustrating. "Being a writer," Susan said, was "being creative about what you say and being able to write it down; having it make sense and come together and having people read it and understand it and know what you're talking about.... The thoughts [in your head] come out right." "Learning to write" meant "just developing the skills that you need to get all your words down, all your thoughts out and get them out properly, and just brainstorming and putting it all together and writing it down." In the basic writing course, Susan hoped to learn "better writing techniques, how to get everything out properly, and how to write it down and make everything flow."

Included in Tom's and Susan's responses are three compelling issues that came up with most of the writers whom we interviewed: their understanding of the term "basic writing," their expectations for writing and reading in other college courses, and their conceptualizations of writing. For those who have worked in basic writing for any length of time and/or those versed with basic writing literature, these issues may sound familiar. However, hearing them expressed from students' perspectives led me to think carefully about the responsibilities that we have toward basic writers as teachers and as representatives of the institutions where we teach. 


\section{Issue \#1}

\section{Basic Writers on "Basic Writers": What's in a Name?}

Teachers often label students "remedial," "marginal," at risk," "basic," or "illiterate": labels given by the judges, not the judged.

Alan Purves, "Clothing the Emperor"

\section{What do the words "basic writer" mean to you?}

Just writing simple. Just well, yeah, that's important for jobs and communicating with other people, that's the same thing there.

\section{Tom}

Basic writer. I guess just a person who writes, probably someone who just, you know, writes things just... like their given assignment and they'll just write it down. But I think a writer is actually somebody who does writing and writes a lot.

Susan

Among the questions that Susanmarie and I raised in "The Dilemma That Still Counts" is whether basic writers contest the label that had been attached to them as a result of their performance on some kind of assessment measure (like our composition placement exam). But Tom and Susan, like every other writer we interviewed for this study, don't know what "basic writer" means. I don't mean that they don't know what it means to be a basic writer - they certainly know that they're not taking first-year composition. But they don't know that they are called basic writers, or that the course they're in (ours is called "Writing Techniques") is spoken of in the field as a "basic" (or "developmental") writing course.

I think that this is a dilemma for several reasons. In a recent essay, Peter Mortenson raised questions about the ethics of using subjects anonymously in our research. I see this as an extension of that problem - here, the issue of "basic writing" itself is anonymous, at least (as Tom, Susan, and Alan Purves suggest) to the people who are labeled that way. In fact, many basic writing researchers and teachers have worked long and hard to help erase the stigma that we think students must feel when they are placed in basic writing courses. Some researchers, for instance, attempt to identify the ways in which basic 
writers are multiply literate, despite the labels that have been affixed to them based on performance on a measure like a placement exam. Their positions are clear: these writers have abilities outside of the classroom; their performance in the classroom is affected by the ways that they approach their work (and those approaches, in turn, are affected by any number of internal and external circumstances).

We have taken these more complex labels into the classroom, as well. Many basic writing instructors (and I include myself here) have been shaped by the ideas of Mina Shaughnessy and her intellectual descendants (Perl, Hull, Rose, Bartholomae, and so on). We have developed a number of skillful ways to talk about literacy (or literacies) so that students don't feel they are failures, don't see their experiences as isolated, and don't feel that the literacies that they bring to the academy are "bad." In the mythic story of basic writing, we say that this different way of talking about basic writers and their abilities works against the deficit model that has framed writing instruction since the end of the nineteenth century, pointing to the creation of English A at Harvard University while gnashing our teeth and wringing our hands.

Sometimes, as in some of my own classes, we use texts (like Lives on the Boundary) with which we hope basic writers will identify - that they will read and say, "Aha! That person's experience is like mine!" Because the texts are always carefully chosen (again, like Lives), the hope is that students will then understand that they bring something different - not bad, but different - to their learning, and need to find ways to fit that "difference" into writing in this context. But this approach, which certainly isn't one that only I use, still elides the question of what it means to be a basic writer in the specific context in which these writers find themselves. In a sense, it asks students to participate in a system of values that surrounds a particular "reading" of Lives on the Boundary. Yet one of the tenets of recent culturally-based approaches to basic writing work is the notion that these writers do not share (some) of the same values reflected in academic discourse. Thus, the logic here is inconsistent: Shared interpretation, to some degree, is based on shared culture. And basic writing scholarship has suggested that these writers do not participate in this culture. Therefore, they might not share interpretations held by members of this culture. ${ }^{7}$ (Additionally, imagine the dizzying connections between these things! Is one academic institution like another? Yes, in some ways. Is UM-Dearborn in 1999 like Loyola or UCLA in the mid-1960s and early 1970 s? In some ways yes, and in some no. But why should we expect students to make the rather abstract connections that we might see between that circumstance and theirs?) Since we - since I - sometimes don't tell basic writers exactly what it means to be a basic writer (in this time and place), these students are left to their own devices to figure out what basic writing is, and what makes them basic writers. 
Meanwhile, while we talk with students about their multiple literacies inside the classroom, we're talking about them as "basic writers" outside of it, as in this article. I'm a member of the Conference on Basic Writing. I subscribe to the Journal of Basic Writing. But the idea of the "basic writer" and all of the characteristics associated with it are invisible to the students themselves.

One could make the argument that I'm quibbling over issues of mere semantics, but I don't think I am. After all, how can basic writers contest their labeling as basic writers (and then refute it as well) if they don't know that this is what they're called? Certainly, they can tell us that they know more than they have been labeled as knowing; they might say that they're better at writing in different contexts - they can say a lot of things. But if language is power (and I believe that it is), not giving students the language to talk about themselves (or, at least, their labels) and their situations seems to me an act of withholding power.

\section{Issue \#2}

\section{Why Writing? Tom on the Role of Writing and Reading in the Academy}

Another issue that we were interested in investigating was what writing and reading expectations these writers thought they would face as they moved through college. In fact, it was a remark about just these expectations made by a student in my fall 1997 basic writing course that led me to want to talk with these writers about their experiences with writing and reading, their perceptions of themselves, and what they thought they'd have to do in future courses. In the eighth or ninth week of the semester, just as we were working through the final chapters of Lives on the Boundary, my student said, "Why do we have to do all of this reading and writing, anyway? I mean, I'm not going to have to do any of this stuff in my major. I'm going to get all my reading from the computer."

Like this former student of mine, Tom also thought that writing and reading was something that would be necessary mostly in "English" courses like this one, not in courses like the ones he would have to take. His reply to a question about whether he thought he would have to do much reading and/or writing in his major appears above: "I don't believe so." He did think he'd have to do a lot of math, but as he said, "since I'm into computers, I probably ... won't be as much being handed a book and [told,] 'Here, read this.'”

This is a response that many of us have heard before. But pointing to it as an isolated issue affecting only the student who utters it 
neglects a larger problem associated with the belief that writing and reading happens only in writing courses. To illustrate this, I'll cite something that many of us have heard before: "Our students can't write, and it's your [i.e., "the writing program's"] fault." Of course, we can take issue with the key points in the complaint. And of course, we know it's not exclusively our fault: we can tell students like Tom and my former student that they will have to read and write in their majors, and (in some cases) they still won't believe us. We also know that composition research that has long made the point that writing skills appropriate for all students in all disciplines for the rest of their academic careers cannot be fully developed in the two or three courses they take with us. But when basic writers (or any writers) believe that they won't really need these things they're learning in our classes anyway, it makes what we can do all the more difficult.

\section{Issue \#3}

\section{We Have Seen the Enemy . . Basic Writers on Themselves}

At the heart of "The Dilemma That Still Counts" was a question that Susanmarie and I felt was vital for basic writing to address as a field: who are basic writers? We quickly found what researchers before us had discovered: there is no easy answer. However, after an examination of basic writing scholarship written during the last twenty years, we did find that the common feature uniting these writers (as they were represented in scholarship) was error - not just the sentencelevel mistakes that students make on their papers, but errors of conceptualization that lead to errors in content and form as well as surface-level error. Within more cognitively-based approaches, we found that some researchers suggested that these errors resulted from what I'll call a non-deficit approach. Embedded here is the principle that, despite assumptions to the contrary, there is not necessarily a misconnection between writers' processes and what comes out in their writing. Instead, to use Shaughnessy's term, there is an internally consistent "logic" in their texts that reflect cognitive processes at work, rather than flawed ones (e.g., Shaughnessy, Perl, Rose, Hull and Rose). The result is a text that is perceived as flawed because it doesn't match or incorporate the conventions of the discourse it seeks to reproduce. Other cognitively-based studies, though, suggested that basic writers do have cognitive deficits, or they do have issues that affect the cognitive processes that they bring to their writing that reflect in the production of errors. ${ }^{8}$ These include studies suggesting that writers carry with them a hefty case of anxiety, sometimes linked with low self-esteem (e.g., Sheridan-Rabideau and Brossell, Slattery, Adams). Basic 
writing scholars whose work is situated within a cultural framework see the error in students' work resulting from the interaction between writer and institutional contexts. They suggest that writers don't negotiate this movement fluidly, and thus their writing does not reflect what is understood as "correct" or "good" (in terms of content and/or form) in the academic context (or among academic discourse communities).

In our interviews with basic writers, we were interested in learning about what features of their writing they thought marked them as not ready for first-year composition - would they identify either lack of familiarity with grammatical or discourse conventions as the defining hallmark in their writing? We expected to hear a fair amount about making grammatical mistakes, some claims that these writers just didn't know what to say, and some people talking about the bad cases of nerves they brought with them to any writing situation.

But what we expected and what we heard were two different things, at least on some levels. A few of our interviewees did mention grammar as the "problem" in their writing. But most of them defined "the problem" as what I've come to call "unsuccessful information transfer," an issue that reflects elements of the deficit model described earlier. Susan's response to my question about how she would describe her writing illustrates what I mean by this. She said, "It's really shaky. ... After I read it, .. I' $m$, like, that wasn't what I was trying to say at all." Earlier in the conversation, she described what happened during a typical paper: "It always just seems like when I would get it down, it doesn't sound right. ... Usually, I'll, like, think of it, and ... I could ... say it out loud what I want to write. But then when I start writing, either I'll forget it or it just doesn't come out the same."

Susan's expectation that what is in her mind should come out on paper just as it's conceptualized is what I mean by "information transfer." It's in the brain one moment, and is quickly moved to paper the next. Susan described this kind of process when I asked her what " being a writer" meant:

[It's] being creative about what you say and being able to write it down; having it make sense and come together and having people read it and understand it and know what you're talking about. ... The thoughts [in your head] come out right.

Learning to write, Susan said, was about perfecting this transfer: it was "just developing the skills you need to get all your words down, all your thoughts out and get them out properly, and just brainstorming and putting it all together and writing it down." Other students echoed this conception of writing, too. Sam described "being a writer" as "being able just to pick any topic out of your pocket, you know, and 
be able to write a page or two on it. It makes sense...." Irene said that "being a writer" was "Having [your writing] make sense and come together and having other people read it and understand it and know what you're talking about.... The thoughts come out and they come out right." It's in the brain one moment; it's on the page the next. Hank's response also typified this approach to writing:

It always just seems like when I would get [my opinion] down [in an essay], it doesn't sound right. ... Usually I'll ... think of [what I want to say], and, you know, I could say it out loud what I want to write. But then when I start writing, either I'll forget it or it just doesn't come out the same.

Sharon said, "I know what I want to say, I just can't put it on paper. And that's the problem I have." In fact, for Susan, Sam, Irene, Hank, Sharon, and three other writers whom we interviewed (eight of the sixteen), "incorrectly" moving ideas from their heads on to the paper was what they thought was "wrong" with their writing.

The notion of writing as "information transfer" isn't a phenomenon unique to this group, of course. In fact, the idea that ideas should come out on to the page wholly formed is a tenet of current-traditional approaches to writing. It reflects the belief that writing is a mechanism for recording on paper ideas that have been clearly conceptualized before they are written; writing is a vehicle for those clearly conceptualized ideas to be clearly expressed. As Sharon Crowley has argued, this approach "tacitly assume[s] that any thinking student should be able to get her writing right on the first go-round" (147). Here, writing isn't a process, it's a product of ideas that are already in the mind, and if they don't come out right, that's where the problem lies. As Crowley and composition historians like James Berlin and Robert Connors have demonstrated so persuasively, this conceptualization of writing is one which is fairly prevalent in American higher education. And given what we know about the way that writing is taught in many high schools, it seems a relatively common model there, as well. ${ }^{9}$

Returning to the deficit/non-deficit distinctions made earlier, these students do see themselves as having a deficit. As far as they are concerned, though, the "deficit" has little to do with the kind of writing they are doing or the situation in which they are writing. To them, it has to do with what writing is - here or anywhere else. To them, it is about performance - producing so many paragraphs of so many sentences of so many words, doing so in a short period, and seeing that the ideas in those so many paragraphs (etc.) replicate ideas that writers already have. When this doesn't happen correctly the writing is "wrong" and needs to be "fixed." 


\section{Another Dilemma That Still Counts: What We Want; What We Get}

There are certainly some college-level basic writing instructors who think of writing as the expression of clear ideas, clearly expressed. But many of us bring to our courses an alternative conception of writing that frames as it a process that helps writers think, that facilitates communication, that mediates among communities. From this alternative perspective, it's easy to look at what students say about not producing "successful information transfer," gnash our teeth, wring our hands, and think about one more conceptualization that we must dispel in our courses before students can see writing as a medium for developing ideas and thinking through issues over a period of time. This reaction certainly perpetuates the myth of the basic writing instructor that Jeanne Gunner has recently suggested is associated with the "iconic teacher-figure" descended from Mina Shaughnessy. As Gunner describes her, this teacher

occupies a position of honor. The teacher is constructed as a kind of hero, one who identifies with and champions basic writers, and who enacts a Virgilian role of guide into academic discourse or a Wordsworthian validator of expressivism. Like Dante's Virgil or Wordsworth's Romantic poet, this teacher is positioned as a kind of outsider - as one who is outside the institutional hierarchy and the traditional academic values that have been seen as hostile and unwelcoming to basic writers. The primary credential of such a teacher is individual commitment, a sense of mission to teach, initiate, inspire, and defend basic writers. (31)

But to come to this familiar, comforting conclusion would be to let ourselves off several hooks, absolving ourselves of complicity in issues that we need to confront when we discuss the goals of our basic writing courses. First, there is the issue of course design discussed earlier - we have constructed entire curricula around helping writers develop alternative conceptions of themselves. As empowering as such a curriculum might be, it also elides the issue of what it means to be a basic writer here and now, in this institution and this place. I will return to this issue of curriculum later in this article. First, though, it's necessary to look at what comes before that curriculum.

When students arrive on our campus the first writing-related assignment that students face is a placement exam. At UM-Dearborn, students write this analytic/response essay even before they have en- 
rolled for a single class, as part of their day-long orientation. Students have two hours to read a short (two-page) passage and respond to a question that asks them to interpret the reading and respond to it using concrete evidence (including their own experiences) to ground their analyses. The exam that Tom and Susan took, for instance, involved reading a portion of Paule Marshall's "The Poets in the Kitchen," an essay about how language helped the author's mother and her friends also employed in domestic service to create a community. The instructions accompanying the exam suggest that students do some "process work" before they write, brainstorming and perhaps making an outline or a cluster to guide their final essays. The instructions also encourage students to use this as an opportunity to consider their own experiences through writing about an idea, and to use evidence from those experiences in their response.

But, in the end, the quality of the evidence in the essay is, at best, no more important than the form that the response takes. A student who produced a perfectly formed, relatively superficial exam that demonstrated some development, some fluency with the language, and some understanding of structure and surface conventions in their response to the question about this excerpt would be placed in first year composition, not basic writing. In other words, if a student had a successful information transfer session on this exam, they wouldn't be labeled a "basic writer." Similarly, an exam that had some great ideas but was jumbled up and hard to follow - one where the information transfer wasn't as successful - would land a student in basic writing.

The placement process that we use certainly is not unique - there are many campuses that use measures like the timed exams to assess students' writing. And the reasons why we (and, doubtless, other campuses) use the placement process that we do are probably all too familiar - it's the best we can do with what we have. Our current placement exam replaced one that contained approximately 70 questions about grammar, punctuation, spelling, and word usage that were to be answered on a Scantron form. At the end of the exam, there was a short essay question. Given the current balance of time and resources available for writing assessment, then, the current strategy seemed to be the best option. But neither our good intentions nor the institutional realities that result in this approach to placement testing change the net result here: the first "college writing task" that students face privileges a conception of writing, a performance model, that we know doesn't work for students (our research shows it), and which students say doesn't work for them, either. Additionally, this isn't an approach that many of us endorse, and for that reason it also is not one that basic writers are likely to encounter when they get to some of our basic writing courses.

Once students are placed in basic writing courses, they face a range 
of experiences in their courses. But regardless of what their particular class is like, they probably won't learn much more about what "basic writing" means for them in this institution in these classes. They also don't spend much time trying to figure out why they're "doing all of this writing and/or reading" either. In fact, I would argue that on each of these issues, we rarely fulfill our responsibility to these students: helping them develop the language and strategies that they can use to contest their labeling as "basic writers" and, perhaps, free themselves of it. But just because some of us have not done this doesn't mean that we cannot begin to do so.

\section{Conclusion: A Modest Proposal}

Reflecting on the implications discussed here may, I think, provide possible solutions to some of the issues raised in these student interviews. These solutions begin with some slight modifications to placement procedures, then move into curricular change.

The first part of this proposal involves telling basic writers what we mean when we identify them as such. For instance, we might start by naming courses what they are, rather than using polite euphemisms for them. (Again, our basic writing course is called "Writing Techniques.") But of course, "basic writing" is itself another term that is laden with meaning that needs to be unpacked. Thus, we might accompany these modified names with descriptions of the courses (particularly of their goals), and distribute these to students before they take the exams that affect their placements. While many institutions may do this, many others (including my own) rely on other people to do it for them - admissions officers, orientation coordinators, or counselors. But rather than hand over this small but significant responsibility, I would argue that we should do it ourselves.

Of course, this small action still doesn't help students confront the much larger question of what it means to be labeled a "basic writer." What was it about these students' writing that was seen as problematic? What does it mean, within the context of the institution, to be in basic writing? At my own institution, why are these students - many of whom earned high marks in their high school English classes - in basic writing? One way to begin addressing this, and perhaps to concomitantly help students develop the language they need to contest their definitions as basic writers (if they want to, of course) is to begin basic writing courses with the documents that landed students in the course in the first place. We might ask students to re-read these documents, and then to write about why and how they wrote what they did. We might also ask those who rated the essays to write back to students about their readings, providing a basis for a discussion about 
these responses within the context of the academic writing situation where students could really begin to think about the issue of what is a "basic writer," and whether they thought they were one or not.

In the basic writing course I'm teaching this semester, I've designed a curriculum (stemming from these interviews) that I hope will help students develop additional answers to these and other questions, as well. In their first paper, students define a problem or issue related to education and literacy that they want to investigate, write about what, in their experience, makes them interested in it, and consider how they might investigate the problem or issue. Remaining true to my basic writing roots, I have students read the first two chapters of Lives on the Boundary as they write this paper. This time, though, I'm not asking them to empathize with Rose's experience as an underprepared student. Instead, I'm asking students to participate in the same kind of intellectual inquiry that Rose does as a researcher, identifying the methods that he used for his investigation and considering whether they might be appropriate for their own.

So far, students have identified some problems that they feel strongly about: How does the placement process work? Why are students placed in basic writing courses? How do high schools prepare students for college-level English and math? Who decides what classes students should take, why, and how? (Certainly, to readers of this essay, these questions may sound familiar. But in my own defense let me say that I helped primarily with shaping, not defining, them.) When it comes time for students to write their third paper of the term, they'll return to these first essays. They'll read through them and choose a problem or issue that they want to investigate, conduct the investigation (individually or in groups), and write up their results. Then they'll use that writing as the basis for another piece of writing - a public document intended for (and distributed to) an audience whom they feel can learn from the results of their investigation.

Ultimately, I hope that this approach will accomplish three goals. First, of course, I hope that students will develop as writers - that they will build strategies that they can carry with them to other courses, that they might discover that writing can help them think and is a medium for communicating ideas between writers and readers. Second, I hope to rectify some of the issues I've raised here by creating an environment where students can learn more about the issues related to education and literacy that they have defined and, in the process, more about what it really means to be a basic writer here, ultimately developing their skills and thinking so that they can move beyond that classification. Finally, I hope that this approach will raise questions within the institution about basic writers and basic writing. While I don't agree with the notion in some "abolitionist" arguments that basic writing exists as a self-perpetuating enterprise, I do agree that insti- 
tutions must be aware of, and accountable to, basic writers - particularly when we ask them to enroll in classes that carry "additive" (or, as Randy Woodland says, "fictional") credit.

There are other approaches that might be taken to these issues as well. For instance, it might be possible to design an assignment or a course around an ongoing investigation of "college level writing." This could start with the first piece of such writing students complete - the placement exam - and then move to the larger context of writing in our institutions. This part of the investigation might involve finding out more about the writing and reading practices in other disciplines like the ones that students planned to go into as majors. Such investigations would require support from colleagues, and would need to be carefully structured. But they also would help students understand the contexts in which they are writing (and writing toward), and give them a clearer sense of the writing and reading demands that they might encounter in those majors. This exploration might also be augmented by varying degrees of involvement by faculty members from different disciplines. They could come for a "one shot" talk about writing and reading practices; they might even co-teach a section of the course. Whatever shape this investigation takes - whether it's a single assignment, or a term-long focus - it may help students understand what reading and writing they will face and what shape those might take. Ultimately, such an investigation might also lead students to take their composition courses (basic writing and other ones) more seriously. Additionally, such an investigation could also be framed as part of the process of investigation into college-level writing, and could serve as an additional basis for students to reflect on the ideas of "basic writer" and "basic writing" in their institutional contexts.

Of course, this is only a beginning. And as a "modest proposal," it is not without its own complications. For instance, we need to decide to what degree we will formulate our courses according to students' responses to questions about writing. For instance, sometimes basic writers cite lack of interest in the subjects of their essays as a reason for the quality of the ideas and/or writing in them. Will students be interested in investigating the institutional contexts for their own writing, and that writing in those contexts? As a long veteran of reflexive courses that have approached some of the issues from perspectives somewhat similar to those raised here, my own experience says sometimes yes, sometimes no. I am certainly optimistic about the approach I am using in my own basic writing course that I described earlier, but that course is only three weeks old at the time of this writing. One word of caution, though: I would argue that we not use students' responses to questions about themselves and basic writing to design a typical "client" (or set of clients) to which we market. Instead, these responses can be the beginning of dialogue - and in this 
light, we have something to offer, as well.

Additionally, some basic writing instructors might look at this modest proposal and decide that it's not so modest - that asking students to investigate the reception of their writing, the institutional context surrounding that reception, and the role of writing and reading in different parts of that context is ambitious for such a course. Certainly, this proposal could be broken up into a series of smaller assignments; students might even focus on only one part of this proposal during a basic writing course. But in response to the charge that students cannot do this kind of work, I cite my favorite line from Lives on the Boundary: "Students will float to the mark you set" (26). In a carefully designed, carefully guided process where students can work together, in steps, on even a small part of this complex investigation, they will do good work.

Another problem with this modest proposal is that it remains an unfortunate fact that some of the materials associated with basic writing - like textbooks - still conceptualize writing as an act that is more about producing texts that look good. The alternative proposed here doesn't negate the possibility of dealing with surface-level errors, or making nice sentences, or any of the other elements of writing included in those texts. But it does move the idea of writing to the forefront of the basic writing course, and it does place basic writers in a situation where they will learn more about their own writing and the place of writing (and reading) in the academy. Doing so may ultimately help basic writers develop the language (and language/writing-related skills) to talk about themselves in the academy, and help basic writing courses (and programs) move closer to solving the dilemmas we face.

\section{Notes}

1. These questions were also shaped, in part, by Deborah Mutnick's outstanding study of basic writers described in Writing in an Alien World. Questions asking writers to define some terms ("basic writer," "learning to write," "being a writer") were asked by Mutnick, and were used in our study with her permission.

2. This notion of basic writing and basic writer is in some ways reflected in (and is a reflection of) the research in basic writing. Often, the pedagogy in basic writing courses is influenced by research which focuses on helping students work through issues that have resulted in their placement in basic writing courses. While the analysis in that research probably stems from specific institutional contexts (like this article's does), the ideas in it are meant to be generalizable (as the ideas in this article are). But we must ask ourselves: does the need to con- 
struct "basic writers" and "basic writing" as semi-homogenous categories lend credence to an avoidance of specifically defining those categories? While this issue is outside the scope of this article, it will be taken up by the larger study of which this research is a part.

3. These names, along with all other student names in this article, have been changed.

4. While we did not ask specifically about parents' education levels, most students told us something about their parents' educational backgrounds. Two students had at least one parent with an advanced degree; five had at least one parent with a four-year degree; four had at least one parent with a two-year degree; three had parents with no higher education. Among those who didn't specifically identify higher education experiences of their parents, three had at least one parent in what might typically be considered a "blue collar" job (e.g., working on the line in a stamping plant); three had at least one parent who worked in what might be considered a "white collar" job (e.g., nursing).

5. Admission to UM-Dearborn is quite competitive - generally, students are in the top ten percent of their high school classes. For this reason, it is not surprising that Tom and Susan described themselves as fairly good students.

6. Typically, blue-collar workers at Ford Motor Company (or those related to them) refer to the company as "Ford's"; employees in more "professional" position (e.g., managers or engineers) refer to it as "Ford."

7. Of course, this is a point raised in Glynda Hull and Mike Rose's article "This Wooden Shack Place: The Logic of an Unconventional Reading" as well.

8. For a thorough review of some of these early cognitive approaches, see Rose, "Narrowing the Mind: Remedial Writers and Cognitive Reductionism."

9. Certainly, Tom and Susan's high school grades reflect this interpretation. Tom reported that in classes devoted primarily to composition, he received two B's, and a "B or a C." Susan reported receiving a B and three A's. Yet, in citing these high school writing experiences, I don't want to lay blame entirely at the feet of high school writing instructors - like those of us in post-secondary education, their choices are affected by a number of factors that are not for us to judge. 


\section{Acknowledgments}

I'd like to thank Randy Woodland, Susanmarie Harrington, Steve Fox, and Mary Sauer. I'd also like to thank Tami Younis and Nelson Hamblin for transcription assistance. Finally, thanks to anonymous $J B W$ reviewers whose comments helped me to focus the analysis here. This research was supported by an Immersion Grant from the College of Arts, Sciences, and Letters of University of Michigan-Dearborn.

\section{Works Cited}

Adams, Peter Dow. "Basic Writing Reconsidered." Journal of Basic Writing 21.1(1993): 22-36.

Bartholomae, David. "Inventing the University." When A Writer Can't Write: Studies in Writer's Block and Other Composing-Process Problems. Ed. Mike Rose. New York: Guilford Press, 1985: 134-65

--.. "The Tidy House: Basic Writing in the American Curriculum." JBW 12(1): 4-21.

Berlin, James. Rhetoric and Reality. Carbondale: Southern Illinois University Press, 1987.

Connors, Robert. Composition-Rhetoric. Pittsburgh: University of Pittsburgh Press, 1997.

De Beaugrande, Robert, and Marjean Olson. "Using a 'Write-SpeakWrite' Approach for Basic Writers." JBW 10.2 (1991): 4-32.

Gray-Rosendale, Laura. "Revising the Political in Basic Writing Scholarship." JBW15.2 (1996): 24-49.

Gunner, Jeanne. "Iconic Discourse: The Troubling Legacy of Mina Shaughnessy." JBW 17.2 (1999): 25-42.

Harrington, Susanmarie and Linda Adler-Kassner. "The Dilemma that Still Counts: Basic Writing at a Political Crossroads." JBW 17.2 (1999): 1-24

Hull, Glynda and Mike Rose. "This Wooden Shack Place": The Logic of an Unconventional Reading. College Composition and Communication 41.3(1990): 287-298.

---, Mike Rose, K. Fraser, and M. Castellano. "Remediation as Social Construct: Perspectives from an Analysis of Classroom Discourse." CCC 42(1991): 299-329.

Mortenson, Peter. “Going Public." CCC 50 (1998): 182-205.

Mutnick, Deborah. Writing in an Alien World. Portsmouth: Boynton/ Cook, 1996.

Perl, Sondra. "A Look at Basic Writers in the Process of Composing." 
Basic Writing: Essays for Teachers, Teachers, and Administrators. Ed. Lawrence N. Kasden and Daniel R. Hoeber. Urbana IL: NCTE, 1980:13-32.

Purves, Alan. "Clothing the Emperor: Towards a Framework Relating Function and Form in Literacy." JBW 10.2 (1991): 33-53.

Rose, Mike. "Narrowing the Mind: Cognitive Reductionism and Remedial Writers." Cross-Talk in Comp Theory. Ed. Victor Villanueva. Urbana, IL: NCTE, 1997.

---. Lives on the Boundary: The Struggles and Achievements of America's Underprepared. New York: Penguin, 1989.

Shaughnessy, Mina. "Diving In," CCC 27.3 (1976): 234-39.

---. Errors and Expectations: A Guide for the Teacher of Basic Writing. New York: Oxford UP, 1977.

Sheridan-Rabideau, Mary P. and Gordon Brossell. "Finding Basic Writing's Place." JBW 14.1(1995): 21-26.

Slattery, Patrick J. "Applying Intellectual Development Theory to Composition." JBW 9.2 (1990): 54-64.

Stygall, Gail. "Resisting Privilege: Basic Writing and Foucault's Author Function." CCC 45.3(1994): 320-341.

\section{Appendix: Interview Questions}

\section{Existing Writing}

1. Why did you choose this paper? What did you like about it?

2. Show us the areas in the paper where you think you did something particularly well, and talk about why you think you did a good job in theseplaces.

3. Are there things in the paper you wish you might have done differently? If you had more time, what more might you like to do with this paper?

\section{Experiences with writing and reading}

1. Can you tell me a little about your family? (Where is your family from? Do you have brothers or sisters? Are they in college? Where do your parents work?)

2. Does your family do a lot of writing and/or reading? (If so: what kinds of things do different people in your family like to write and/or read? Do you know what you like about them?)

3. Do you like to read and/or write? What kinds of things do you enjoy?

4. Did you do much of the kind of reading or writing you like to do in school? (If yes - what kind? How were these things used? If no - what did you do instead? Did teachers know about the 
kinds of things you like to read/write? If so, what did they think about them?)

5. How do you define "being a writer"?

6. How would you define "learning to write"?

\section{Expectations of college careers}

1. What do you think you might want to major in? Why do you want to major in that?

2. Can you tell me a little bit about what you think will be required for that major? For example, will you have to know a lot about a particular area, or be academically strong in a particular subject?

\section{Expectations of college writing}

1. What do you think of taking 099, "Writing Techniques?" What kinds of things do you hope to learn there?

2. What do you think writing in college will be like? (Will it be like what you did in high school? Will it be different? Do you think you'll have to write longer/shorter/more/fewer papers, etc.)? What do you think college professors, especially writing professors, will be like?

3. Do you think you'll have to do a lot of writing and/or reading in your major? What kinds of writing and/or reading do you think you'll have to do there? 


\section{Susanmarie Harrington}

\section{THE REPRESENTATION OF BASIC WRITERS IN BASIC WRITING SCHOLARSHIP, OR WHO IS QUENTIN PIERCE?}

ABSTRACT: This essay argues that basic writing research has focused on teachers' expectations and students' errors, leaving a curious void in our understandings of students' needs. It reviews research trends, arguing that researchers who directly concern themselves directly with what students' voices can add to our knowledge of the field will fill an important gap in the literature.

\section{Introduction}

In 1993, Wendy Bishop suggested that much of the research composition teachers rely on to shape classroom techniques is "studentvacant," (93), which is to say it fails to incorporate the perspectives of those most directly affected by our classroom techniques: students. This oversight, Bishop argued, is caused in part by an emphasis on scientific study and in part by the need to create teacher narratives in which professional expertise and intervention are necessary to help inexperienced writers. While Bishop's subsequent work has been part of a rising interest in ethnography, scholarly attention to teacher-centered issues has maintained a "student-vacant" focus, and this is particularly true in the field of basic writing.

Even as I write that sentence, I want to object to my own analysis. After all, I say to myself, what field is more student-centered than basic writing? Isn't our collective concern a desire to nurture students who might otherwise likely fail? Doesn't the oft-repeated assertion that Shaughnessy's Errors and Expectations gave rise to basic writing scholarship ${ }^{1}$ illustrate a long concern for making students central in our work? A glance through any volume of JBW, any visit to a Confer-

Susanmarie Harrington is Director of Writing and Associate Professor of English at Indiana University Purdue University Indianapolis. She has published articles in JBW, Computers and Composition, and elsewhere. This article represents part of an ongoing study of basic writing and basic writers in the contemporary academy conducted with Linda Adler-Kassner. 
ence on Basic Writing meeting or any workshop for basic writing instructors reveals an incredible commitment to basic writing students. But despite the dedication of many basic writing teachers and researchers, there is a curious gap in the ways students are represented in basic writing scholarship.

This gap, I argue, is at odds with how the field of basic writing generally conceives its mission - to support students who need extra help to succeed in school. In many ways, the title of Errors and Expectations laid the groundwork for how we have approached that mission. Students have long been the subjects of our thoughtful analysis. We have looked at students' errors and teachers' expectations and practices; we have refined our techniques, explored the effects of technology on basic writers, structured and evaluated programs, and so on. And we have been fierce advocates of entering students' needs. Both in our scholarship and in our classrooms, we have carefully interpreted students' texts (and thereby the students who write them). But in many ways, we know very little about the students who take our courses. I don't mean to suggest that as teachers we run student-vacant classrooms. But as researchers, we know very little about our studentssomething that Howard Tinberg has recently suggested impedes our politicking in response to attacks on basic writing as well as our ability to respond to students in class. That we know little about students has, in some ways, driven the development of basic writing programs. We have built programs to serve students whose needs were not anticipated by traditional programs of study. This essay addresses the ways in which our work has succeeded, while examining what we have learned about students along the way.

\section{Searching for Quentin Pierce}

David Bartholomae's “The Tidy House: Basic Writing in the American Curriculum," an essay doubtless familiar to most readers of these pages, illustrates the way that students helped shape Bartholomae's early basic writing work. "Tidy House" seems worlds away from Errors and Expectations, although both are prominent pieces that arguably ushered in new trends in scholarship. While Errors guided many early developers of basic writing programs, "Tidy House" began a tradition of institutional critiques that have culminated both in curricular reforms and calls to eliminate basic writing programs. The political differences between the eras of Errors and "Tidy House" are many. But however much changed in the political landscape, one thing did not: how students are represented.

Quentin Pierce, an early student of Bartholomae's, figures largely in the narrative portion of "Tidy House," which explains how Pierce 
got Bartholomae into the basic writing business. Bartholomae reflected on his interactions with Pierce in order to make a larger point: "I want to cast this moment as more than an isolated incident. I want it to be representative" (5). And it is a representative moment-many readers (including myself) read Bartholmae's dealings with Quentin Pierce and remember encounters with students that left us asking hard questions, questions which propelled us to teach or research differently. For Bartholmae, the moment in question concerned Pierce's submission of a difficult essay, written in response to the question, "If existence precedes essence, what is man?" As Bartholomae begins to tell us about Pierce's work, he pauses to parenthetically address us as fellow teachers: "(you can visualize the page - the handwriting is labored and there is much scratching out)" (6). Pierce's essay ended thus:

\section{I don't care. \\ I don't care.}

About man and good and evil I don't care about this shit fuck this shit, trash, and should be put in the trash can with this shit

\section{Thank you very much}

\section{I lose again (6)}

When Bartholomae got this essay, he "did not know how to read it. [He] could only ignore it" (6). He was plagued with difficult experiences that semester, and finally approached his department chair to say that he would rather become a lawyer than endure another such class. Fortunately, the chair offered him a job setting up a basic writing program; the following year Bartholomae moved on to Pitt, where the evolution of the basic writing curriculum is familiar to readers of Bartholomae and Petrosky's Facts, Artifacts, and Counterfacts and Ways of Reading. And the roots of a highly thoughtful, effective curriculum are evident in Bartholomae's early response to Pierce's work.

Bartholomae, for all he says he knew only how to ignore the essay at the time, read it quite sensitively:

I knew enough to know that the paper was, in a sense, a very skillful performance in words. I knew that it was written for me. I knew that it was probably wrong to read it as simply expressive (an expression of who Quentin Pierce 'really was'); I think I knew that it was not sufficient to read the essay simply as evidence that I had made the man a loser - since the 
document was also a dramatic and skillful way of saying 'Fuck you-I'm not the loser, you are.' I saw that the essay had an idea - and that the writer called for the moves that could enable its elaboration. (7).

This text (or was it this student?) helped Bartholomae embark on the work that has helped so many of us learn how to help students succeed. But "Tidy House," like Errors and Expectations, is the story of a teacher, not the story of a student (not suprising, given that it was originally delivered as a keynote address at the $4^{\text {th }}$ National Conference on Basic Writing). Bartholomae returns to some thoughts about Pierce at the end of "Tidy House," to address the question of what will serve students - and what served Pierce in particular:

Do I believe in the course represented in Facts, Artifacts, Counterfacts - do I believe it is a reasonable way to manage his work as a reader and writer? Yes. The point is that while I believe in the course, I am not sure I believe in its institutional position as a course that is necessarily prior to or lesser than the mainstream course. Do I believe Quentin is served by being called a basic writer and positioned in the curriculum in these terms? I'm not sure I do. (19-20)

Here we see the mind of David Bartholomae at work-reading the text, reading his response to the text, reading this encounter with a student in terms of what it meant then, what it means now, what it meant for him, what it means for us. We see someone with a long history in basic writing critically re-assessing the term. We see a reflective teacher continuing to puzzle over the meaning of a challenging encounter with a student-more than twenty years after the fact. But what we don't see is Quentin Pierce at work, except as represented through his teacher's reading.

The essay, to be sure, is Pierce's mind at work-but as Bartholomae noted in his initial response to the essay, it's hard to know what Pierce intended with his text. Pierce offered a representation of thinking that requires interpretation - not just by a teacher, but by the author. And the traditional way that scholarship is framed often prevents us from seeing what students intend with their texts. We focus instead on what we see in their texts. Would Bartholomae have established basic writing programs differently if he knew Quentin's interpretation of that essay or that course 27 years ago at Rutgers? We don't know, but such questions are essential if we are to move ahead with the current project of reconceiving basic writing in a time of political crisis. We need to reach out to students as we work to define our field, especially in the current political climate. 
My argument here is simple: in our research, we have largely represented students so we can represent ourselves. And we represent ourselves as creative, compassionate, flexible teachers and problem-posers - sometimes heroes, sometimes confused. This representation serves all sorts of good purposes, and it's an important element in the evolution of a field. But this representation has a cost: it elides space for students' voices to be heard.

\section{Looking Back: The Journal of Basic Writing, Vols. 1-17}

To look back at how our field has configured students, I turned to my library's collection of the Journal of Basic Writing. It's not my purpose here to do a history of $J B W$ or even a complete content analysis of work presented there. Rather, I describe broad trends in basic writing scholarship, using the work published here as one important indication of how the field of basic writing has shaped itself. In many ways, JBW institutionalizes basic writing. It's housed at CUNY, where Shaughnessy worked. In its history and its mailing address, JBW is allied with the tradition of open-access institutions. Its evolution from a newsletter-type publication into a more professional-looking refereed journal marks scholarly advancement in important ways. JBW has also had a close association with the Conference on Basic Writing (CBW), an increasingly large special interest group of the Conference on College Composition and Communication (which has recently transformed its own newsletter into a refereed online publication, Basic Writing e-Journal ${ }^{2}$ ). As JBW and CBW have matured, so has our field, and to take $J B W$ as a bellwether of our collective work both honors and interrogates our history.

As I began reading the stacks of JBWs, I approached this task with the general assumption that some articles would focus on classroom practices and others would treat broader issues. Other than that I did not bring a pre-formed set of categories to my reading. Rather, I wanted to group articles organically, letting connections among articles emerge as I started reading. Eventually, some major groupings appeared from my scribbled notes and diagrams. These categories allowed me to present the diversity of approaches in the first 17 volumes of $J B W$, while succinctly summarizing those approaches. I classified each article according to the following schema (cross-classifying articles when it was appropriate):

- Teaching Techniques. This is a rather broad category that refers to all aspects of the nuts and bolts of teaching-everything from curriculum or program design, vocabulary acquisition, teaching with technology, or teacher training, to specific teaching techniques or assign- 
ments. These articles are written to guide other teachers in developing similar approaches. They provide valuable resources for those developing and evaluating programs. Detailed analysis of curricular innovations (both successes and failures) has enabled curriculum and faculty development to improve. Articles such as Brosnahan and Neuleib's "Teaching Grammar to Basic Writers," Beyer and Brostoff's "An Approach to Integrating Writing into a History Course," or Mische and Winslow's "The Hero's Performance and Students' Quests for Meaning and Identity: A Humanities and Writing Course Design" are categorized here.

- Theory. This category includes keynote addresses intended to motivate teachers as well as pieces about the nature of basic writing as a field, broad descriptions of literacy and its acquisition, and meta-analyses of basic writing research. These articles are intended to provide perspective on the field, to illustrate past trends and urge future changes. These broad critiques urge basic writing teachers and scholars to consider the philosophical underpinnings of our work, and the emphasis here is on the major trend and big assumption, rather than on particular syllabi or assignments. Like the teaching articles, they are designed to affect practice, but usually not at the level of the individual classroom. Bizzell's "Power, Authority, and Critical Pedagogy," Purves' "Clothing the Emperor: Toward a New Framework Relating Function and Form in Literacy," and Bartholomae's "Tidy House" are representative here.

- Text Analysis. This category refers to studies, such as Epes' "Tracing Errors to their Sources," or Otte's "Computer-Adjusted Errors and Expectations" which have as their primary task the close reading of student texts in order to draw conclusions about students' needs or the efficacy of teaching techniques. In many respects, the text analysis articles are closely aligned with teaching technique articles, since in most cases the analysis is conducted in order to guide the development of classroom materials. Marinara's "When Working Class Students 'Do' the Academy: How We Negotiate with Alternative Literacies" is a good example of an article that uses detailed text analyses as a foundation for a careful description of a course plan.

- Student-Present. This category includes articles with a serious attention to student voices. Yorio's work, discussed below, is representative here. $J B W$ volume 11, number 2, contains a number of fine examples from this category: Agnew's "Basic Writers in the Workplace: Writing Adequately for Careers After College" and Carol Peterson Haviland and J. Milton Clark's "What Can Our Students Tell us About Essay Examination Designs and Practices" use methodologies that 
make students' perspectives on their writing experiences central to the analysis. In student-present scholarship, the focus is on how students experience broad curricular trends.

- Student-Qualities. This category includes work where the teacher or researcher analyze students' attitudes or other personal qualities. Students are important in both student-qualities and student-present research. I distinguish the two categories, though, by what drives the research question. In student-quality scholarship, the researcher's notion of what student attribute is important drives the work; in student-present research, the students' notion of what factors are important drives the analysis. Studies of writing apprehension (BuleyMeisssner's "Am I Really That Bad?") or other studies that examine students' affect (Wolcott and Burh's "Attitude as it Affects Developmental Writers' Essays") are representative here.

- Miscellaneous. This category includes mainly the tributes to Mina Shaughnessy that have been published over the years, such as volume 11, number two's special section, "Remembering Mina Shaughnessy," which included short tributes from Shaughnessy's colleagues and two short pieces by Shaughnessy; the excerpt from Maher's biography of Shaughnessy, and also other difficult-to-classify works as Alice Trillin's interview with Calvin Trillin are also included here.

I offer these categories to draw a broad picture of the field, recognizing that each category captures a wide range of scholarship within it. The categories themselves are heuristics, rather than fast labels, and there are overlapping relationships among the categories. One reviewer of this essay wondered whether these categories represented differences of degree rather than differences of kind. It's certainly the case that student-present and student-qualities might usefully be represented as different points of a continuum of research on students, and it is also true that virtually everything published in $J B W$ has as a general aim the improvement of instruction.

The text analysis category might itself be considered an extension or sub-set of the teaching techniques category. My analysis separated it from teaching techniques in order to highlight a method for reflecting on student learning. In this set of articles (only 12 over the volumes examined), teacher/researchers are closely reading students' texts, searching for patterns that will help improve instruction. The close reading is designed to elicit a deep description of the texts, either in form or content, and it introduces a carefully structured analysis of student performance into classroom assessment. While many articles in JBW include examples of student texts, I have used this category only for those articles where the formal description of the texts was an 
important aim of the author. "Tidy House," for instance, would not be included in this category, despite its close reading of Quentin Pierce's text, because Bartholmae's focus there was on his own reaction to the piece, rather than on features of the student text.

The emphasis on student text is important, for close readings of what students actually do when they write begin to offer a route for students' concerns to affect the development of curriculum. George Otte's "Computer-Adjusted Errors and Expectations" (the homage to Shaughnessy in the title will not be lost on most readers, indicating part of the history of this type of reading) is a text-analysis article which demonstrates a way of using student work to plan and evaluating teaching technique and curriculum. Otte focuses on what kinds of errors students produced in their texts, and what features of the texts changed (or didn't) over the course of the semester. He ends the article with reflections about what his students' writing experiences say about how to teach about error. Otte's approach to error and grammar uses students' texts as a lens, which is very different from Brosnahan's and Neulieb's broad discussion of why and how to teach grammar to teachers and students. Their discussion, while rooted in their teaching experience, does not offer a close view of students' performance in writing.

Overall, while the categories offered here may be broad or messy, they do offer a snapshot of basic writing research over time (for a broader recent review of basic writing literature, see Harrington and Adler-Kassner). The categorizing of articles is summarized in Tables 1 and 2 .

\section{Teaching and Theory}

\begin{tabular}{ll}
\hline Category & $\begin{array}{l}\text { Number } \\
\text { (Percent of Total) }\end{array}$ \\
\hline Teaching Techniques & $144(53 \%)$ \\
Theory & $72(26 \%)$ \\
Student-Present & $17(6 \%)$ \\
Text-Analysis & $12(4 \%)$ \\
Unknown* & $12(4 \%)$ \\
Student-Qualities & $10(4 \%)$ \\
Miscellaneous & $6 \quad(2 \%)$ \\
\hline Total & 273 \\
\hline
\end{tabular}

Table 1: JBW Articles, by Code

*unknown articles from missing issues in the library collection

Table 1 shows the total number of articles in each category, which shows the overall dominance of articles about teaching techniques. 144 of the 261 articles published between volumes 1 and 17 discuss teach- 
ing techniques - an appropriate focus, given the the overall mission of the journal and the field. JBWhas naturally had an interest in the classroom (curriculum, assignments, ways to teach particular skills). JBW has functioned a bit like a long-distance teachers' lounge, providing a space for the thoughtful consideration of what works in what contexts, what doesn't, and why. This teachers' lounge doesn't dismiss theory, however, and in dividing teaching technique and theory articles, I don't mean to divorce the two. $J B W$ 's own call for papers makes clear that good discussions of teaching practice must be rooted in pedagogical theory. $J B W$ 's teaching articles are different from the old CCC "Staffroom Interchange" in that the teaching techniques are described at length and grounded in theory. My distinction here merely highlights the immediate focus of the article.

\begin{tabular}{lllll}
\hline & Vols.1-4 & $5-9$ & $10-13$ & $14-17$ \\
\hline Teaching Techniques & 61 & 40 & 24 & 19 \\
Theory & 8 & 12 & 28 & 24 \\
Student-Present & 0 & 6 & 5 & 6 \\
Text Analysis & 2 & 6 & 1 & 3 \\
Unknown & 9 & 2 & 1 & 0 \\
Student-Qualities & 4 & 4 & 1 & 1 \\
Miscellaneous & 3 & 0 & 0 & 3 \\
\hline Total & 87 & 70 & 60 & 56 \\
\hline
\end{tabular}

\section{Table 2: JBW Articles by Volume and Code}

Taken together, the teaching technique and text analysis articleswhich comprise close to $60 \%$ of the total publications in JBW-offer a variety of approaches to basic writing instruction, and they model teacher reflection in myriad ways. Over time the percentage of publications in this categories has been falling, as illustrated in Table 2 . While most articles in the early volumes of $J B W$ addressed such concerns, in more recent years only about a third of articles have done so. This evolution mimics the progression of composition publication more generally, but the consistent attention to teaching-related concerns reflects the close connection between basic writing and teaching practice. Yet Table 2 demonstrates that in both volumes 10-13 and 14-17, theory articles edge out teaching technique articles in frequency. Theory articles have long been represented in $J B W$ : early volumes contained pieces like Smith and Hirsch's keynote addresses. The number of theoretical pieces is highest in volumes 10-13 (rather than the most recent volumes), something that surprised me given the professional rewards associated with theory rather than practice. On the whole, however, an increasing attention to theoretical concerns seems to have reduced somewhat the number of articles devoted to teaching techniques.

The turn toward the theoretical is important. As Jeanne Gunner 
notes, the field of basic writing has always been defined through theory. Theory first enabled the establishment of a paradigm (shaped by iconic visions of Shaughnessy and CUNY); more recently, Gunner argues, we are in the midst of a struggle to shift (or defend) that paradigm. Theorizing has also enabled us to establish professional legitimacy in the wider profession and to take a critical perspective on our common undertakings. But in that push toward the theoretical, basic writing students have become increasingly absent. As Linda Adler-Kassner and I have recently argued, it is widely acknowledged that basic writing students are a diverse lot - but that argument itself begins to backfire pragmatically. When basic writers are seen to be everywhere, they are also nowhere. If basic writers are constructed so that we understand them to be students who simply don't know academic conventions, then it is difficult to distinguish them from any other group of students - and that lack of definition itself makes it difficult to have coherent programs. A crucial element in our efforts to serve students in an increasingly politicized climate must be a concerted effort to find out more about who our students are.

\section{What Students Will Tell Us If We Will Only Ask}

Finding out who our students are is, in some ways, an easy task: we can ask them. We can ask students to tell us about their literacy experiences, about their schooling, about the ways they encounter written texts in their lives. Linda Adler-Kassner and I (working with other colleagues at IUPUI and the University of Michigan-Dearborn) have recently begun a research project that takes such questions out of the classroom and into a broader realm of scholarly discourse (see Adler-Kassner's essay in this volume for an early report of one facet of this project). To some extent, Adler-Kassner and I may be calling less for a change in practice than a change in public discourse among practitioners. As teachers, many of us already tap into our students' senses of identity.

I often begin the semester with an assignment that asks students to write me a letter about their previous writing experiences and their impressions of writers and writing. The profusion of work on literacy narratives (see Fox for one example) suggests that I'm not alone here. Many textbooks also have introductory exercises or even whole focuses on students' exploring their literacy backgrounds (for some examples, see the sections on assessing one's writing background in Gay, Developing Writers, and Rich). Other examples of such assignments can be found in JBW articles describing assignments about literacy. Morris Young, for example, uses his students' work to illustrate their "very personal connections with writing and its power in helping them 
enter the world of public discourse" (55). Using three students' work to explore issues of identity and public discourse, Young argues that these students - all participants in a University of Hawai'i bridge program for underprepared students - "theorize their roles as writers and their place in the Nation because they recognize that they are cultural workers and already live literate lives" (70).

In a very different vein, Eric Miraglia advocates bringing selfdiagnostic assessments into the basic writing course, as a way of implementing Ann Berthoff's advice to "Begin with where they are." The traditional diagnostic essay which teachers use at the start of the semester to gauge whether students are in the right course or not rests on various wrong assumptions about students and writing. Miraglia offers an elegant critique of these assignments, the most compelling being evident even in the term diagnostic. Nowhere else in writing assessment do we find the assumption that a one-shot assignment can lead to an accurate "diagnosis" of student needs in a situation that so clearly paints the student as suffering from some sort of disease that Dr. Teacher can cure. Simply asking students to assess their own writing abilities and needs leads to writing that can be evaluated in terms of both content (the students' areas of expertise) and form (the teacher's) (Miraglia 52). Miraglia-offering one form of student-present research - tested the students' writing samples against their own perceptions of their needs in interviews. ${ }^{3}$ In interviews, the students revealed more complicated goals than were explained in their samples. The work of Young and Miraglia demonstrates that individual teachers are, indeed, using their students' self-assessments to drive classroom techniques and teachers' analysis of student needs.

But how can we take this careful classroom work and use it to inform our programs and our scholarship? How can students' selfassessments of their positions in educational systems, and of their own writing, affect the way we teach? And how and when can we listen to students? In "Dialogizing Response," Pamela Gay argues that the move towards increasingly collaborative classroom approaches has not necessarily affected the way we talk to students about their work. Our responses and interactions with students still reinforce the notion that the teacher is the central authority figure in terms of curriculum and student work; student-teacher relationships are hampered by this exercise of institutional power. Gay quotes an Andrea Lunsford keynote address that urged "we've got to start looking at the 'between' - the relationship between teachers and students" (10). Gay elaborates: "We need to find various ways of dialogizing response - of de-privileging as best we can, teacher commentary - we need to find more ways of making the process of revising more interactive" (10). Gay's recent essay demonstrates how inviting students to respond to teacher response is one way of building dialogue into our classes, and it offers a 
way of building dialogue with students that does not depend on the content of a curriculum (many examples of exchanges with students about the nature of literacy come in courses where the curriculum makes literacy the subject matter studied, which is the case in Young's class). Even when our curriculum is not specifically about literacy and citizenship, we should draw upon students' assessments of their experiences, their abilities, and their goals. We must learn how to share what we learn from our students with each other.

\section{Student-Present Scholarship}

Student-present scholarship challenges us to address these issues. As is clear in tables 1 and 2, there are examples of student-present scholarship running through the history of $J B W$. The earliest example of such scholarship I noted was George Jensen's "The Reification of the Basic Writer" (in volume 5), which starts from the assumption that students' real needs can sometimes ignored by research that overdetermines views of students' deficiencies. Jensen responds to this problem with pedagogical practices, advocating use of the MeyersBriggs Personality inventory to identify different "types" of students in a class. Jensen sees the diversity of basic writers as something that should drive us to look at the individuals in our classrooms and tailor our curriculum to those specific students. At the classroom level, such flexibility is essential, but student-present research should have a broader agenda.

How can we approach the diversity of basic writers at a programmatic level? How can we come to understand "basic writers" in order to best design curriculum and to demarcate a field of scholarly inquiry? There is little evidence that students' perceptions of themselves drive how textbooks are written, or how writing programs are constructed. Instead, there is a preponderance of evidence that suggests we paternally or maternally assume we know what's good for students - often because we have carefully looked the situation over, using our broad experiences to guide our analysis - and then figured out how to deliver the curriculum. We study students, but we rarely ask students to evaluate our programs in any meaningful way. And in so doing, we have condoned the very characterizations of students that we say we fight against. If our program assessments and our curricula are not designed to permit students' voices to interact with our materials, we promote a stultifying position for student writers in our classes. This is not to say that students' voices are always right, but student voices deserve more of a place in our discourse. 


\section{Case Studies and Student-Present Research}

Students' voices are clearly heard in one genre of basic writing research: the case study. This genre has allowed basic writing teachers to pursue the stories of challenging students. In Hull and Rose's "That Wooden Shack Place," for instance, we meet Robert, whose unconventional reading of a poem drives his teachers' analysis of curriculum. Sally Barr Reagan's "Warning: Writers at Work" introduces Javier, a student with a troubled relationship to school, and Vivian Zamel's "Through Students' Eyes" takes us inside the minds of ESL writers. Zamel's case study followed three students over two semesters, in their basic writing and first-year composition courses. Zamel's work looked at the ways in which the very different philosophies of two writing teachers led to very different classrooms. Her careful research into the students' attitudes and experiences created a rich portrait of their experiences, and raised interesting questions about the ways two different teachers' assumptions created different learning environments for students. Zamel, unlike Bartholmae in telling of Quentin, cautions about broader interpretations of the case study:

Thus, while the "stories" of Carlos, Mohammed, and Nham may not have been representative, may even have been idiosyncratic, the significance of this study lies in the realization that, as teachers, we are always dealing with the unique and individual realities and interpretations of students and must take these into account. (94)

Exploring the mismatches between our goals and our students will help alleviate some of the frustrations these students described.

Another excellent case study explores the relationship between student and teacher action. Gesa Kirsch's study of Eugene's revising habits in "Students' Interpretations of Writing Tasks" illustrates the ways in which students themselves are effective guides to their work. Kirsch's thorough study of one student's work over the course of the semester created an equally thorough picture of her own work. She focused on the ways in which Gene interpreted writing tasks:

Only when Gene broadened his interpretation of writing tasks did he learn to expand his repertoire of writing strategies, his depth of analysis, and ultimately, his ways of knowing. While Gene's drastic change in interpreting writing tasks is not typical of most freshmen writers, it does suggest a potential for growth that lies dormant in many students until they master the skill of interpreting writing tasks and assume authority over their writing. (83) 
Kirsch explores the ways her discussion of teacherly authority helped Gene find ways to take risks with his writing, and thus interpret tasks in ways that explored his own authority as a writer. Journals, selfassessment, and conferences helped him achieve this growth.

As thorough as these case studies are, though, they are limited by their genre: as Zamel noted, it's difficult to generalize from them. How can we move beyond the case study to acknowledge the wide diversity of our students in a theoretically sound and pragmatically meaningful way as we set up programs and classrooms? If a case study is always idiosyncratic, valuable for what it teaches us about one individual (or a small group of individuals), how can we learn to generalize about basic writers in meaningful ways?

Such questions were anticipated by Carlos Yorio in studies he did with students at CUNY's Lehmann College and the University of Michigan. Yorio, the first to raise questions about the ways students are absent in our research, opens his story with Alice's encounter with the talking flowers in Wonderland - the flowers which told Alice what they thought about all sorts of things. Yorio noted:

Our students, like Alice's flowers, can talk; they have opinions about what we do and what we make them do. Like Alice's flowers, our students will not always agree with each other and may not always be right or even sensible. But, I will argue, they cannot be ignored. Native language, culture, social behavior, and previous experiences both in educational and noneducational settings have shaped them as people and as learned. They are not a tabula rasa. . . . At some level, we know all this. And yet, over and over again, my own students and those of other colleagues amaze me with comments, questions, and complaints which clearly show that some of them, at least, do not agree with what we are doing and feel a terrible sense of frustration in classes where techniques are used which they consider a waste of time. (33)

Yorio's work focused on ESL students' perceptions of teaching techniques. His work demonstrates that students have plenty to say, if they are asked. All told, in one survey Yorio describes, 711 respondents chose "I don't know" less than $2 \%$ of the time (in more than 17,000 total questions) (34). Yorio concluded that we need to tell our students more about why we do what we do, since students were not perceiving common teaching elements - group work, homework-as very important. In using a survey of students, and repeating his questions at multiple institutions, Yorio was able to illustrate both the indi- 
viduality of students and some common features in response.

Howard Tinberg recently illustrated the ways in which reflections from one class of basic writing students provided him with evidence of how much they were eager for challenging academic experiences. Both Tinberg and Yorio, using very different methodologies, suggest that students' perspectives on literacy and learning are essential to teachers and administrators seeking to define and protect programs. Linda Adler-Kassner's essay analyzes the ways basic writers' understanding of the composing process can be usefully incorporated into curriculum revision. Our students are the chief audience for our writing programs, and for our programs to be rhetorically effective, they must understand their audience. Adler-Kassner's interviews with the basic writers at University of Michigan-Dearborn suggest that the students' assumptions about writing and the curriculum's assumptions about writing have not always been in line with each other; addressing this disjunction should make instruction more effective.

I would end this essay by urging further attention to our students' voices, particularly in projects that enable us to make meaningful comparisons between student populations. Only by looking carefully at our local context, and then comparing local contexts, can we build a discourse about students that celebrates their diversity, without allowing that very diversity to turn the students as a group invisible. Such research will allow us to come to know the Quentin Pierces in our classrooms, and to use our acquaintance with Pierce and his colleagues to meaningfully discuss basic writers as a group. In this political climate, we need the anecdotal, deep knowledge from individual classrooms and case studies, but we also need broader alliances. Research that brings students into our research will help serve that purpose.

\section{Notes}

1. There is a strand of basic writing scholarship that problematizes the consistent association of the birth of basic writing with Errors and Expectations, CUNY, and Mina Shaughnessy. See, for example, Gunner, "Iconic Discourse" or Horner.

2. The Basic Writing e-Journal (as well as more information about the Conference on Basic Writing)is available at http:/ / www.asu.edu/clas / english/composition/cbw/.

3. He also interviewed teachers to look at their perceptions of students' needs. 


\section{Works Cited}

Adler-Kassner, Linda. "Just Writing, Basically: Basic Writers on Basic Writing." Journal of Basic Writing 18.2 (1999) 69-90.

Agnew, Eleanor. "Basic Writers in the Workplace: Writing Adequately for Careers after College." JBW11.2 (1992): 28-45.

Bartholomae, David. "The Tidy House: Basic Writing in the American Curriculum." Journal of Basic Writing 12.1(1993): 4-21.

Bartholomae, David and Anthony Petrosky. Facts, artifacts, and counterfacts : theory and method for a reading and writing course. Upper Montclair, N.J. : Boynton/Cook Publishers, 1986.

- - Ways of Reading: An Anthology for Writers, $3^{\text {rd }}$ ed. Boston: Bedford Books, 1993.

Beyer, Barry K. and Anita Brostoff. "An Approach to Integrating Writing into a History Course." JBW2.1 (1980): 36-52.

Bishop, Wendy. "Students' Stories and the Variable Gaze of Composition Research." Writing Ourselves into the Story: Unheard Voices from Composition Studies. Ed. Sheryl Fontaine and Susan Hunter. Carbondale IL: Southern Illinois UP, 1993. 197-214.

Bizzell, Patricia. "Power, Authority, and Critical Pedagogy," JBW10.2 (1991): 54-70.

Brosnahan, Irene and Janice Neuleib. "Teaching Grammar to Writers." JBW6.1 (1987): 28-35.

Buley-Meissner, Mary Louise. "'Am I Really That Bad?' Writing Apprehension and Basic Writers." JBW 8.2 (1989): 3-20.

Epes, Mary. "Tracing Errors to their Sources: A Study of the Encoding Processes of Adult Basic Writers." JBW 4.1(1985): 4-33.

Fox, Stephen L. "Memories of Play, Dreams of Success: Literacy Autobiographies of First-Year College Students." English in Texas 28.2 (1997): 17-26.

Gunner, Jeanne. "Iconic Discourse: The Troubling Legacy of Mina Shaughnessy." JBW17.2 (1998): 25-42.

Gay, Pamela. Developing Writers: A Dialogic Approach. Belmont CA: Wadsworth Publishing Company, 1995.

- -. "Dialogizing Response in the Writing Classroom: Students Answer Back." JBW17.1 (1998): 3-17.

Harrington, Susanmarie, and Linda Adler-Kassner. "'The Dilemma that Still Counts': Basic Writing at a Political Crossroads." JBW17.2 (1998): 1-24.

Haviland, Carol Peterson and J. Milton Clark. "What can our Students Tell Us about Essay Examination Designs and Practices." JBW11.2 (1992): 47-60.

Hirsch, E.D. "Culture and Literacy." JBW3.1(1980): 27-47.

Horner, Bruce. "The 'Birth' of 'Basic Writing.'” In Horner, Bruce, and Min-Zhan Lu, Representing the "Other": Basic Writers and the Teach- 
ing of Basic Writing. Urbana IL: NCTE, 1999. 3-19.

Hull, Glenda, and Mike Rose. "This Wooden Shack Place": The logic of an Unconventional Reading." College Composition and Communication 41.3(1990): 287-298

Jensen, George. "The Reification of the Basic Writer." JBW 7.1 (1986): 52-64.

Kirsch, Gesa. "Students' Interpretations of Writing Tasks: A Case Study." JBW7.2 (1988): 81-90.

Maher, Jane. "A Full and Good World from Mina P. Shaughnessy: Her Life and Work." JBW15.2 (1996): 3-23.

Marinara, Martha. "When Working Class Students 'Do' the Academy: How We Negotiate with Alternative Literacies." JBW16.2 (1997): 3-16.

Martinez, Joseph G.R. and Nancy C. Martinez. "Who is Alien in the Developmental Classroom? A Comparison of some Student/ Teacher Values." JBW 8.2 (1989): 99-112.

Miraglia, Eric. "A Self-Diagnostic Assessment in the Basic Writing Course." JBW14.2 (1995): 48-67.

Mische, Monica and Rosemary Winslow. "The Hero's Performance and Students' Quest for Meaning and Identity: A Humanities and Writing Course Design." JBW 15.2 (1996): 76-94.

Otte, George. "Computer-Adjusted Errors and Expectations." JBW10.2 (1991): 71-86.

Purves, Alan. "Clothing the Emperor: Toward a New Framework Relating Function and Form in Literacy." JBW 10.2 (1991): 33-53.

Reagan, Sally Barr. "Warning: Basic Writers at risk - The case of Javier." JBW10.2 (1991): 115.

Rich, Susanna. The Flexible Writer: A Basic Guide, $3^{\text {rd }}$ ed. Boston: Allyn and Bacon, 1998.

Shaughnessy, Mina P. Errors and Expectations: A Guide for the Teacher of Basic Writing. New York: Oxford UP, 1977.

Smith, Virginia B. "Keynote Address." First Shaughnessy Memorial Conference, April 3, 1980. JBW3.1 (1980): 41-49.

Tinberg, Howard. "Teaching in the Spaces Between: What Basic Writing Students Can Teach Us." JBW 17.2(1998): 76-90.

Trillin, Alice. "A Writer's Process: A Conversation with Calvin Trillin." JBW3.3 (1981): 5-18.

Wolcott, Willa and Diane Burh. "Attitude as it Affects Developmental Writers' Essays." JBW6.2 (1987): 3-15.

Yorio, Carlos. "The Other Side of the Looking Glass." JBW 8.1(1989): 32-45.

Young, Morris. "Narratives of Identity: Theorizing the Writer and the Nation." JBW15.2 (1996): 50-75.

Zamel, Vivian. "Through Students' Eyes: The Experiences of Three ESL Writers." JBW 9.2 (1990): 83-97. 


\section{Laura Gray-Rosendale}

\section{INVESTIGATING OUR DISCUR- SIVE HISTORY: $J B W$ AND THE CONSTRUCTION OF THE "BASIC WRITER'S" IDENTITY}

ABSTRACT: This paper offers a brief Foucauldian archaeological and discursive history of the Journal of Basic Writing because of its central place in the history of our scholarship. In doing so, this paper attempts to accomplish the following: 1) describe some of the broad historical features of the construction of Basic Writers' identities, 2) examine instances that appear within the journal in which critical disruptions and overlaps of such constructions occur in unexpected, telling ways, and 3) explore what such discursive moments reveal about trends and tendencies within the scholarship and history of Basic Writing itself. Thus the paper attempts to provide an altemative, metanarrative-resisting history of the journal itself, suggesting the values as well as problems within the current state of the construction of Basic Writers' identities in our scholarship, and presenting some speculations about future constructions of Basic Writers' identities.

Drawing upon Michel Foucault's view that the formation of identities and practices are themselves a function of historically specific discourses, this paper charts a history of constructions of "Basic Writer" student identities in Basic Writing and the Journal of Basic Writing from 1975 to the present. For Foucault, such history writing is archaeological, bringing "to light the epistemological field, the episteme in which knowledge, envisaged apart from all criteria having reference to its rational value or to its objective forms, grounds its positivity and thereby manifests a history which is not that of its growing perfection, but rather that of its conditions of possibility" (1970, xxii). Such historical research aims to advance critiques of the present era, to show the historical constitution of present modes of social domination, to identify historical continuities and discontinuities, progressive and

Laura Gray-Rosendale is Assistant Professor of Rhetoric and Composition and Chair of Northern Arizona University's Commission on the Status of Women. She teaches graduate and undergraduate classes in cultural studies, the history of rhetoric, gender studies, and basic writing. Her work has appeared in Signs: A Journal of Women and Culture, the Journal of Basic Writing, Concerns, as well as Composition Forum, and can be found in anthologies such as Getting a Life: Autobiography and Postmodemism, Miss Grundy Doesn't Teach Here Anymore: How Popular Culture Has Changed the Composition Classroom, and The Personal Narrative: Writing Ourselves as Teachers and Scholars. She is coediting Alternative Rhetorics for SUNY Press with Sibylle Gruber. Her book Rethinking Basic Writing: Exploring Identity, Politics, and Community in Interaction is published with Lawrence Erlbaum Associates.

DOI: 10.37514/JBW-J.1999.18.2.07 108 
regressive features of history, and the forces of domination and liberation therein. In doing so, it attempts to resist the construction of history as a metanarrative, instead offering readings of specific historical texts and their disruptive effects. As Foucault argues, some discourses have shaped and created meaning systems that have gained the status and currency of "truth," dominating how we define and organize both ourselves and our social world. In Foucault's definition, normative conditions and truths "are established between institutions, economic and social processes, behavioral patterns, systems of norms, techniques, types of classification, modes of characterization" $(1972,45)$ such that other alternative discourses can become marginalized and subjugated. Yet these discourses also potentially offer sites where hegemonic practices can be contested, challenged, and even resisted.

Utilizing Joseph Harris's ${ }^{1}$ discussion of the main metaphors that have dominated Basic Writing scholarship, growth, initiation and conflict, this paper investigates Basic Writing scholarship's tendency to form discursive relationships that have shaped student identity along those particular lines. In keeping with this kind of historical inquiry, I look not only to those texts which adhere to these metaphors, constituting the Basic Writer student identity as fixed or stable, but also to texts which fail to settle the Basic Writer student identity in this way and have therefore sometimes remained the "unread" of Basic Writing scholarship. I have decided to turn to this particular journal as the source for this disciplinary history for two reasons: 1) Basic Writing or the Journal of Basic Writing has historically been the main organ of the Basic Writing movement, and therefore it provides by and large a sustained view of such changes, and 2) placed within this journal this history may offer the opportunity for self-reflection, a recognition of where we've come from, the paths we've taken, and the adventures upon which we have yet to embark. While there are many texts which one might select, I point specifically to three: a 1978 text by Louise Yelin, the Myra Kogen/Janice Hays debate of the 1980s, and a series of texts that utilize the conflict model. All histories are invested with ideological, cultural, and social interests, and this one is no different. However, this history does attempt to provide an examination of these texts so as to reveal how previous conceptions of Basic Writer student identity may be contested and new conceptions might be formed.

\section{The "Growing" Basic Writing Student Identity}

Error may seem to be an old place to begin a new discussion about teaching writing. It is, after all, a subject English teachers already know about. Some people would claim that it is the English teacher's obsession with error that has killed writing for generations of stu- 
dents. Yet error- the unintentional deviation from expected patternsdominates the writing of many of the new students, inhibiting them and their readers from concentrating on what is being said.

Mina Shaughnessy, 1975

"Introduction" to the inaugural issue of Basic Writing

Certainly illustrations adhering to what Harris terms the "growth" metaphor (and its related metaphoric incarnations such as "developmental" 2 and "maturing") can be detected throughout many of the articles within the early printings of Basic Writing. In its most fundamental form, this construction of the Basic Writer's student identity relied in part upon these respective hypotheses: 1) the Basic Writer was perceived as incapable of propelling her/himself to the next "cognitive" or neurological level alone, requiring instead the teacher/ scholar's aid in order to accomplish this feat, 2) the Basic Writer was helpless to move to generalizations and abstractions "naturally" like other students, and therefore had to be led through a series of steps in order to arrive there, and 3) the Basic Writer's writing, while logical in its errors, needed to be purged of such errors. Relatively disconnected from the context within which the Basic Writer was actually writing, the Basic Writer's student identity was inscribed first and foremost by the necessity to become more cognitively advanced and more developmentally mature. Equally importantly, however, there have been attempts historically to challenge the predominance of this metaphoric allegiance that eventually led to its loss of power. After tracing a few representative examples of how and to what ends this metaphor has been deployed, I will then expose how one oft neglected text within Basic Writing history offered contradictory conceptions of this metaphor's utility, undermining and finally working to disrupt it.

When one turns to the first years of Basic Writing (1975 to the present), ${ }^{3}$ this focus on developmental concerns seems to pervade the journal. The first issue, "Error" (1975), was concerned with sustaining Shaughnessy's project of looking at the logic of students' errors developmentally. ${ }^{4}$ Shaughnessy's introduction to the first issue, directed to an audience of English teachers, relayed the predicament of the new teacher encountering students who were struggling in their writing, and indicated that no one "way" or "formula" could be found in books which would resolve the dilemma of how best to teach them. Rather, the journal was designed to be a location for teachers to "confront more questions than they will ever be able to answer and to abandon more strategies than they will ever finally accept" (3). In this introduction, Shaughnessy implied that the focus on the subject of error as the first topic in the journal was not a result of a need to center on that issue alone, but as a result of the need to uncover additional ways to inves- 
tigate the matter of error which may be more socially and pedagogically feasible. Contributors to this issue centered mainly upon this developmental or growth model.

The second issue, Fall/Winter 1976, took a slightly different approach than the first edition, complicating the developmental model a bit while it also continued to reproduce a rather comparable Basic Writing student identity, shaped as it was by many of the same scholarly forces. In this issue Shaughnessy claimed that "as yet, the teaching of writing to underprepared college freshmen is too loose and unstudied an experience to allow for uniformity within programs, let alone among them" (1). She pointed out the varying ways in which "basic" itself was defined institutionally and the diversities within budgets for programs and teacher-training. In this volume she invited "teachers to submit course descriptions" in order to "document the diversity of outlook and design that seems to characterize basic writing teaching" and to "find individual accounts of courses that would themselves be useful to all teachers" (1). Importantly, Shaughnessy recommended that "while the remedial situation dictates that we reduce the universe of writing to 'basic' subskills, the skill of writing seems to defy such reduction, impressing us again and again with its subtle involvement of various faculties and skills" (3). Urging teachers not to elaborate a "uniform system of teaching basic writing," this volume was entirely devoted to very different course designs within Basic Writing programs, while it was also calculated to bestow issues of reasoning and logic upon Basic Writing curricula and developmentally designed courses. This signaled a complication in the developmental model as well as a slight move away from it.

\section{Disruptions Within the Developmentalist Metaphor}

During this time period (1975 to 1979), however, there were a number of important scholarly attempts to alter this construction. These contributions, many of which appeared in the Fall/Winter 1978 issue titled "Applications: Theory Into Practice," disrupted and challenged the allegiance to the "growth" metaphor, suggesting that there were other possibilities for understanding how to construct the Basic Writer's identity. As then editor Marylea Meyersohn suggested in the prefatory note, "this issue is something of a departure from our earlier, more 'concrete' issues, and some readers may be surprised at its ideological intention: To demonstrate the uses of so-called 'high brow' literary criticism in the teaching of Basic Writing." Meyersohn explained that while readers might balk at this new strategy, the "diversity will stimulate instructors of writing to suspend disbelief about what helps students and to look more widely for sources of aid" (1). Such early attempts, 
though suppressed, signaled future directions for Basic Writing scholarship. A new, radical, construction of Basic Writer's student identity as not outside philosophical or theoretical issues but integral to them, however, could not be readily sustained at this historical point since there was little support for it within the larger sets of theories then operational within Composition Studies.

This issue included texts by Andrea Lunsford ${ }^{5}$ on Aristotelian rhetoric, Thomas Farrell on literacy and writing, and Marilyn Schauer Samuels on Norman Holland's theoretical models for the teaching of writing. While all of these texts contested the trajectory of Basic Writing scholarship thus far in particular ways, I will look at only one such text in detail here which pushes this disruption farthest. Louise Yelin's "Deciphering the Academic Hieroglyph: Marxist Literary Theory and the Practice of Basic Writing" stands out among the texts within this 1978 issue. Hers was perhaps the earliest attempt within the journal to bring a sustained understanding of social criticism to bear upon the Basic Writer's situation. Moreover, this was the first piece of meta-theoretical criticism published on Basic Writing scholarship itself. Finally, it was among the first texts to interweave conceptions of the Basic Writer identity as developmental, initiated into academic discourse, as well as socially constituted, three perspectives which would later come to be seen as somewhat incompatible.

\section{Yelin's Text}

Beginning with the question "What does a Marxist theory of literature and culture have to offer the teacher of Basic Writing?," Yelin argued that the practice of Basic Writing simply cannot be isolated from broader questions of literacy. In this piece she was quick to call attention to the fact that Marxist theory should not simply be applied to the Basic Writer's situation. Rather, the two should mutually inform each other. As she made her argument, Yelin's rhetorical tactics were as groundbreaking for her own day as much as they might be for an audience of today. Yelin began by judiciously crediting Shaughnessy with a "respect for Basic Writing students" and giving her a sense of both what she could reasonably expect from her students and from herself. Yelin turned away from Errors and Expectations not because of any kind of conservatism she saw in its political perspective but because "when I attempted to put Shaughnessy's suggestions into practice, the results were rarely as I would have wished" (14). Once she realized that this was the case, Yelin looked for a rationale. What she found was that Basic Writing's "respect for the individual" is premised upon a kind of liberalism which fosters a problematic "concomitant optimism about what can be accomplished." As such Shaughnessy's work and much Basic Writing scholarship could not canvass Basic 
Writing Programs as "part of a web of cultural, political, and economic structures, and institutions" (15). Despite its democratic focus, Yelin indicated, Basic Writing programs were in danger of fostering a vocational education which, often despite its own assertions, reinforced social stratification. As such, Yelin argued that Basic Writing embodied a contradiction "between the liberal ideal of equal opportunity and the economic realities of American capitalism" (16). Not willing to toss the growth model away, however, Yelin claimed that we might usefully employ the developmental model in conjunction with presenting Standard English as a "social and historical phenomenon and as a system of linguistic forms and structures" (23).

In taking up a variety of metaphoric investments, Yelin was understandably cautious throughout her discussion. The topic of Basic Writers' social situations, to her mind, should not overshadow the overarching goal, that they become fluent in the conventions of Standard English. However, Yelin did assert that the "activity of writing (and therefore the practice of Basic Writing) cannot be isolated from broader questions of literacy" (26). Also indicating her fears about initiating Basic Writers into an academic community, Yelin elucidated that Basic Writing could not and should not skirt the issue of the extent to which there is an institutional separation between "insiders" (academic experts) and "outsiders" (Basic Writers) and the extent to which it is both problematic and yet necessary to introduce Basic Writers to the codes and dominant values of American public life. However, Yelin did not leave the question of "initiation" there. She argued that these categories of "insiders" and "outsiders" are themselves myths which obscure real relations of domination. This led Yelin to assert firmly that we could no longer endeavor to exploit Basic Writing programs in order to conceal the relations of domination and subordination which existed within them. The sometimes expressivist and oftentimes politically-motivated call for students to "find their own voices" can in fact "patronize students in the name of 'creativity"' (24). In doing so, however, Yelin also importantly referenced the dangers of social theories which "romanticize" Basic Writers as a "culture of the oppressed" '" and sought to undermine this. Instead, Yelin called for a dialectical approach to Basic Writing as itself a cultural project worthy of critical investigation.

In making such claims, Yelin's composition strategically exposed some potential problems within the developmental, initiation, and conflict models themselves. In the case of the developmental allegiance, though its intentions were good, Yelin suggested that it ended up at moments being internally conflicted and contradictory. While desiring to help the Basic Writer, Yelin indicated, it too often took focus away from Basic Writers' social and rhetorical situations, resting attention almost exclusively upon their cognitive development. In the 
case of the initiation model, while it recognized the institutional construction of "insiders" and "outsiders" and debated how to supply the necessary academic codes to Basic Writers so that they might tip the scales, Yelin implied it did not call attention to the construction of these categories themselves or what oppressive social relations they helped to maintain. Lastly, and most curiously, while citing thinkers such as Karl Marx and Raymond Williams throughout her text, Yelin also offered an implicit criticism of what have come to be understood as "conflict" approaches which celebrate difference and diversity. In doing so, Yelin warned scholars and teachers about the potentials of romanticizing the position of the "oppressed" student, or focusing on issues of victimization to the exclusion of other issues. In doing so, Yelin's text defied easy categorization and exposed all of the main metaphoric attempts made to construct Basic Writing student identity as potentially problematic.

\section{Initiating the Basic Writer}

The student has to appropriate (or be appropriated by) a specialized discourse, and he has to do this as though he were easily and comfortably one with his audience, as though he were a member of the academy or an historian or an anthropologist or an economist, he has to invent the university by assembling and mimicking its language ...

. David Bartholomae, 1986

"Inventing the University"

By 1979, the journal moved closer to its previous format, this time with a convergence upon concerns related to the daily issues of teaching Basic Writing, "Programs." Nevertheless, this preliminary disruptive shift in 1978 to theoretical frameworks over pragmatic ones unquestionably signaled a scholarly change which was beginning to transpire within the journal itself, within the field of Basic Writing, and within the fabrication of Basic Writing student identities altogether. Developmental or cognitive constructions of Basic Writers' identities did not diminish entirely, of course, but gradually commenced to have less prominence within the journal, signaling what was a paradigm shift in how Basic Writing students' identities would be constructed. Basic Writers came to be seen not purely in developmentalist terms. Instead, they were perceived as more in line with the argument Yelin articulated, as social beings, impacted acutely by academic discourses and their rhetorical effects. This launched the gradual shift to "initiation" models (and related, patterned metaphors of "invention" and phrases such as "entering a discourse community") over and against concerns of "growth." This new Basic Writing student identity was 
predicated upon the following presumptions: 1) the Basic Writer was not immature, powerless to clear cognitive hurdles and make generalizations, but instead a novice to the conventions of academic discourse and the codes of academic life, 2) the Basic Writer's writing did not only divulge a logic of errors, but meaningful rhetorical attempts to "invent" a language $\mathrm{s} /$ he thought approximated academic discourse, and 3) the role of scholars and teachers within Basic Writing classes should be to "initiate" Basic Writers into the mainstream of academic discourse.

In this section I will first trace the new construction of the "Basic Writer" as "initiated." Then I will point to a text which revealed this construction's internal disruptions, finally helping to dismantle it. Now the Basic Writer's student identity involved an amateur status much like the beginner who had emerged before. This new framework, however, afforded a value to academic discourse and rhetorical thinking as discrete entities in themselves which might transfigure the Basic Writer.

The 1979 volume included David Bartholomae's "Teaching Basic Writing: An Alternative to Teaching Basic Skills." On its surface this text produced a self-study of the University of Pittsburgh Program. However, Bartholomae's text was radically distinct in the Basic Writing student identity it assembled. Bartholomae indicated further that the intent of his program was "to produce writers" who "gather new information, attempt new perspectives, re-formulate, re-see, and, in general, develop a command of a subject" (85). Taking issue with the developmentalist paradigm directly, Bartholomae argued in favor of a "responsible pedagogy," which, he contended, "begins by making the soundest possible speculation about the syllabus built into the learner, rather than imposing upon a learner a sequence serving the convenience of teachers or administrators" (89). Bartholomae finally took direct issue with the cognitive psychological assumptions which had driven this previous methodology as well as its metaphoric allegiances and its construction of Basic Writer identity, arguing instead on behalf of a more rhetorically-based approach:

much attention is being paid to research in cognitive psychology, presumably in hopes of finding a key to the mechanism that triggers generalization. A response more in keeping with our own training, however, is to acknowledge the motive in such an utterance and to redirect the writer by asking him to re-imagine both his audience and his reason for writing. (93)

Bartholomae's text gestured towards the fading power of the developmentalist construction of Basic Writer student identity. After the publication of this article, developmentalist paradigms would still 
surely be debated heatedly within the journal, but the model itself began waning distinctly in its influences. In its place, the initiation model, gained more control in the attempt to fix the Basic Writer's identity. The Spring/Summer 1981 issue took up the task of training teachers in Basic Writing theory and practice with pieces such as Harvey Wiener's "Preparing the Teacher of Writing," John Brereton's "The Doctorate Program in Composition at Wayne State," and Charles Moran's "A Model for Teacher Training Programs in the Field of Writing." Many of these texts broadened out into concerns about the profession of rhetoric and composition, discussing appropriate reading lists, dissertation topics, and qualifying examinations in the discipline, and in Basic Writing specifically. The Fall/Winter 1981 issue centered on revision, including pieces such as Ann Berthoff's "Recognition, Representation, and Revision," Donald Murray's "Making Meaning Clear: The Logic of Revision," Nancy Sommers' "Intentions and Revisions," and Linda Flower's "Revising Reader-based Prose." In her introduction to this issue, Sarah D'Eloia Fortune details the ways in which revision is being redefined no longer in terms of clarity and correctness, the province of style and arrangement, but "as the means and sometimes the substance of invention" (1). Moving between philosophies of revision, teaching strategies for revision, and students' own revising techniques, the texts in this issue took revision out of the realm of the fixed and static, seeing it as part of the rhetorical situation which was constantly changing and evolving.

The journal was not published from 1981 to 1985. As a result, there is much about the initiation metaphor's predominance in the journal that is difficult to fully understand. Clearly, though, as is demonstrated in the 1981 issues of the journal, rhetorical situation and context were shaping both how scholars viewed the profession as well as the site of revision. It would not be long before such views came to be applied to the construction of the Basic Writer's student identity itself. The 1985 issue signaled a brief recursive return to cognitive psychology and social science research which would shortly be dominated by more rhetorically-based, initiation models. As Fortune suggested in her introduction to the Spring issue, this was meant a return to the journal's inaugural issue, the "problem of persistent error in writing: its sources, its effects on readers and writers, and strategies for addressing it" (1). Part One of these two theme-driven issues would offer a return to issues of developmentalism and cognition, including Mary Epes" "Tracing Errors to Their Sources: A Study of the Encoding Processes of Adult Basic Writers," Marilyn Goldberg's "Overfamiliarity: A Cognitive Barrier in Teaching Composition," and Irvin Hashimoto's "Adult Learning and Composition Instruction." The Fall 1985 issue, while it also worked to address social science research, inaugurated other sorts of changes which forecasted what was to come. In this is- 
sue new editor Lynn Quitman Trokya offered a preview for 1986 which would involve two new policies: all articles would be refereed and there would be a move away from single-themed issues so as to publish material in a more timely fashion. Responses to previously published essays were also welcomed, indicating that the growing sense of rhetoric and composition as a profession was impacting the journal's structure and practices.

\section{The Kogen/Hays Debate}

By 1986 Troyka, drawing attention to the professionalization of Composition Studies altogether and Basic Writing scholarship specifically, had renamed the periodical the Journal of Basic Writing, and instated the changes she had forecasted within the preceding issue. Now funded by a short term grant from Exxon, the Spring issue included works by those who criticized the developmentalist/cognitivist strain within previous research much more overtly in favor of the "initiation" strain. This issue contained essays such as David Bartholomae's "Inventing the University," Andrea Lunsford's "Assignments for Basic Writers: Unresolved Issues and Needed Research," Myra Kogen's "The Conventions of Expository Writing" as well as George Jensen's "The Reification of the Basic Writer," the last of which specifically utilized the Myers-Briggs personality indicator tests to suggest that the conception of the homogeneous Basic Writing student was flawed.

Here I will focus upon the Kogen/Hays debate, not only because it galvanized a position against developmentalism as the governing metaphor, but because of the resistances and disruptions that developed within their discussion and within the field as a result. In this particular volume, Kogen's essay, "The Conventions of Expository Writing," provided the most sustained blow to the prominence of the growth metaphor within Basic Writing scholarship that any scholar had yet waged in the journal's history. In this article, Kogen argued convincingly that cognitive and developmentalist models failed to acknowledge that students already had the ability to think and reason logically but simply weren't familiar with academic discourse's conventions. She overtly denounced the previous work of developmentalist theorist Janice Hays which accepted and supported the "growth" metaphor, saying, "Hays is asserting that poor writers have not developed the ability to think abstractly" (34). She combated Hays' assumed claim, remarking that "freshmen writers certainly can think abstractly but they have not yet learned to present their ideas in accordance with conventional expectations" (34), pushing the notion of the Basic Writer student identity as "initiated" that much further. While this seemed an only slight deviation from earlier developmentalist approaches, this slight difference would indeed make all the difference. Kogen went on 
to advise that this propensity to emphasize the student's lack of cognitive maturity constructed a rendition of Basic Writing student identity which was itself fundamentally "demeaning" (36), calling instead for a rejection of this model and an acceptance of the student's introduction into academic discourse as the new model.

The publication of this piece resulted understandably in a significant and historic "dialogue" which tackled these concerns. At the center of this controversy was the new definition of the Basic Writer's student identity and the attempt to solidify or fix it finally as either thoroughly developmental or entirely initiated. The first rejoinder to Kogen's article came from Hays in a Spring 1987 article titled "Models of Intellectual Development and Writing: A Response to Myra Kogen et al.." Here Hays argued very specifically against Kogen in favor of William Perry's developmental model for the purposes of teaching Basic Writers, announcing that adult development was widely demonstrated as accurate, developmentalists were not maturationists, and developmentalists were not anti-context in focus as Kogen's argument had indeed implied. Hays made clear that the metaphoric investments Kogen herself ("academic discourse" and "initiation") held had opened Hays to criticism that may not have been warranted:

It is ironic that such charges are being leveled against developmentalists when they are the very ones who have championed student-centered learning, individualized teaching, respect for differences between students, the use of smallgroup work, and constructionist activity in the classroom. (17)

Hays, like Kogen, saw one of the Basic Writer's primary problems to be "awareness of the reader's perspective" but attributed this less to academic conventions alone and more to an inability to imagine multiple viewpoints due to a lack of the cognitive prerequisite - "mature thought." The second overt response to Kogen's essay then came from Joseph G.R. and Nancy C. Martinez during Fall 1987 in "Reconsidering Cognition and the Basic Writer: A Response to Myra Kogen." In this essay, waged against Hays' assertions, the authors maintained that Kogen's claims could even be defended from the perspective of cognitive psychology itself, suggesting that there were "qualitative differences between children's and adult's cognition" which Hays' application of this theory indeed overlooked. They also criticized Hays' use of Perry's scheme, proposing it was too "culture bound" (80). Lastly, they contended that Hays' examination of student essays alone was not enough in order to assess students' thought processes fully. According to their logic, the writers argued, one must also look at "affective and situational factors such as motivation and familiarity with a task" (80), or other social concerns which might impact Basic Writers' stu- 
dent learning.

Due in large part to the way in which her work was received, Hays wrote a later piece which took up many of the questions and issues her disputants had raised. Hays in fact heeded this call to the social and to the current developments within Basic Writing students' identities quite plainly. Hays' own Fall 1988 answer to Kogen's and the Martinez' essays, "Socio-Cognitive Development and Argumentative Writing: Issues and Implications From One Research Project" indeed reflected her willingness to recognize that academic socialization and other cultural forces also modified Basic Writers' writing behavior in substantial ways. Hays' willingness to concede the possibilities of initiation into academic discourse and rhetoricality also demarcated how the battle to solidify the Basic Writing student identity was being temporarily won. The Basic Writer student identity within our scholarship could no longer be seen outside of social and historical forces without raising criticisms about whether its premises rested upon the developmentalist models which reigned previously, or conceptions of student identity which treated the Basic Writer as a "child" who lacked adequate cognitive development. What we see when we look at this debate is the final dismantling of one conception of student identity and the need to delimit a new conception of student identity that would be followed in the journal's subsequent pages - despite the obvious commonalties and overlaps of the values and arguments within the two perspectives. This debate echoed larger concerns within the discipline of rhetoric and composition, particularly the ways in which growth in WAC and WID as well as rhetoric of inquiry models were impacting and changing the predominance of cognitive research. As Hays suggests, developmentalist did not necessarily mean "anti-context" but it did suggest a primary focus on cognition, neurology, and development. In doing so, it was not giving context primacy, primacy that those who held to the "academic discourse" notion felt it deserved. Disrupting the very notions of what developmentalist and initiation models encompassed, these texts destabilized the terms and their meanings themselves. No longer was the question of "Who is the Basic Writer?" paramount but rather how she or he was described (one's metaphoric investments) and what that description suggested. It was in part because of this debate and its concentration on social and cultural context that the very possibility of a construction based upon the "conflict" model was born.

\section{The Basic Writing Student Identity In and Out of Conflict}

The aim of this paper is to critique an essentialist assumption about language that is dominant in the teaching of basic writing. This assumption holds that the essence of meaning precedes and is indepen- 
dent of language, which serves merely as a vehicle to communicate that essence. According to this assumption, differences in discourse conventions have no effect on the essential meaning communicated. .. My critique is motivated by my alignment with various Marxist and poststructuralist theories of language. In one way or another, these theories have argued that language is best understood not as a neutral vehicle of communication but as a site of struggle among competing discourses.

Min- Zhan Lu, 1991

"Redefining the Legacy of Mina Shaughnessy: A Critique of the Politics of Linguistic Innocence"

Just as was the case for the metaphors of "developmentalism" and "initiation," the "conflict" model of the Basic Writer's student identity appears to have had no one birth, no one originary moment. Instead, perhaps even more than in the case of past metaphorical investments, the conflict metaphor seems to have occurred with slight differences and alterations in a wide number of texts at different historical moments. This metaphoric investment emerged concurrently within rhetoric and composition studies as poststructuralist, marxist, feminist, and postcolonial theory gained increased attention. I hope to trace some of the conflict model's construction of the Basic Writer's identity changes and alterations in this section, not by pointing to one specific debate as I have with previous metaphors but rather a series of texts which responded to the destabilization of the "developmentalist" and "initiation" metaphors. In the Spring of 1990, Kathleen Dixon's "Intellectual Development and the Place of Narrative in 'Basic' and Freshman Composition," appeared in the Journal of Basic Writing. It effectively recast the developmentalist constructions as well as the initiation constructions of Basic Writer student identities. Dixon used Luce Irigaray's Speculum of the Other Woman to argue that models of cognitive development constructed Basic Writers as 'others,' incapable of writing anything but narrative, and incapable of thinking that was not dualistic in its focus. She asserted importantly not that we should discount the critical research of Piaget, but that we must read Piaget "mythically," taking up Vygotsky additionally because of his social constructivist stance. Dixon's article also indicated what was to become a larger shift within Basic Writing scholarship, a shift which, we recall, had resulted earlier in the disruption of the predominance of the "growth" model: the application of high theory to the Basic Writer's situation. Importantly, also, this theoretical application was one that had long-lasting effects because of its social, psychological, and gender implications.

After what was a sustained period during which criticism of the 
"growth" model by the "initiation" model was in vogue, increasingly, as we have just witnessed, questions were raised about the initiation model's assimilationist, and even "paternalistic," tendencies. A new metaphor for Basic Writing student identities began to arise in Basic Writing scholarship within the Journal of Basic Writing around the Spring of 1991. This edition contained texts such as Rexford Brown's "Schooling and Thoughtfulness," Peter Rondinone's "Teacher Background and Student Needs," Rose Marie Kinder's "A Piece of the Streets," Pat Belanoff's "The Myth of Assessment," and Min-Zhan Lu's "Redefining the Legacy of Mina Shaughnessy: A Critique of the Politics of Linguistic Innocence." As previously mentioned, Harris significantly references this shift as the beginning of a "contact zone" or "conflict" metaphor, a phrase he adopts from Mary Louise Pratt's 1991 Profession article, "Arts of the Contact Zone." As I mentioned earlier, in that article Pratt claimed that classrooms ought to be places where conflicts between discourses were heightened and examined. Pratt discussed this thesis subsequently within her 1993 chapter "Criticism in the Contact Zone: Decentering Community and Nation" in Steven Bell, Albert LeMay, and Leonard Orr's Critical Theory, Cultural Politics, and Latin American Narrative. In this text she called for an even greater "focus on how social bonds operate across lines of difference, hierarchy, and unshared or conflicting assumptions ... such a 'contact perspective' would assume the heterogeneity of a social group and would place in the foreground the relationality of meaning" (88). Pratt also newly advocated the presence of "permeable borderlands" that were not anticipated to replace constructs of authenticity, autonomy, and community which often legitimate minority discourse, but rather relied upon a "transgressive, interruptive engagement with official categories" (101).

The Basic Writer student identity, previously carefully constructed in covert ways, often operating as a set of distinct composing traits, was now overtly perceived to itself be a construction: instead it was freshly conceived as an identity in flux, subject to and a subject of many historical and social forces which, scholars affirmed, had problematically created it. The stability of this new construction of the Basic Writing student identity as uncertain and flexible would both enable a new species of important, innovative pedagogical potentials as well as continue to dictate, in new terms, the kinds of constructions of Basic Writing student identity deemed allowable or conceivable within Basic Writing scholarship.

\section{Lu and Others}

Perhaps the first of the journal's articles to fully define this new 
Basic Writing student identity was Min- Zhan Lu's 1991 "Redefining the Legacy of Mina Shaughnessy: A Critique of the Politics of Linguistic Innocence." ${ }^{6}$ Here Lu argued that Shaughnessy's essentialist view of language denied the critical political dimensions of the linguistic choices that Basic Writing students made. In addition, she contended that Shaughnessy's research had ignored the privileged characteristics of academic discourse and the certainty that such discourse itself was not free from specific social and historical circumstances.

Such drastic shifts within the scholarly preoccupations of the journal understandably resulted also in a more fundamental change within how the Basic Writer's student identity was and persists for the most part, notwithstanding its internal contradictions, to be constructed. In some quarters, scholars now assert that the Basic Writer can be oppressed by the language of the classroom and, the role of the Basic Writing classroom and teacher, at times, has been to radicalize and call attention to the conflicting discourses operational within the language of the classroom. The Basic Writing student identity, then, has lately come to be constructed primarily as an array of larger institutional, cultural, and social forces which are in contestation with each other as well as the situation to which such theories might be applied.

This prevailing shift to a metaphor of "conflict" (and its related entitling metaphors, including terms such as "struggle," "diversity," and "shifting privilege"), despite internal disparities and variations, customarily constructs the Basic Writer's student identity according to the following precepts: 1) the Basic Writing student identity is generally presupposed to embrace and even embody conflict, 2) the Basic Writing student is presumed to appreciate and instantiate issues of race, class, and gender, as well as to benefit directly from the turn to social and political considerations over and against issues of "growth" or "initiation," 3) the Basic Writer's student identity is assumed to often be self-conceived as involving marginality, border residency, and sometimes not-so-subtle institutional oppression, and 4) the roles of the Basic Writing scholar and teacher often can entail politicizing or calling attention to the Basic Writer's problematic marginal position within the academy. ${ }^{7}$

After the publication of Lu's text within the journal, this construction of the Basic Writer's student identity gained more prominence. By Spring 1992, the Journal of Basic Writing contained numerous articles which granted variations on this new Basic Writing student identity, taking up topics of multiculturalism, dialogic teaching, and multiethnic classrooms. The Basic Writing student identity was no longer binaristic in its construction (developmental/matured, novice/initiated) but already always plural or multiple. For instance, Carol Severino's "Where the Cultures of Basic Writers and Academia Intersect: Cultivating a Common Ground" maintained that the figurative language used to 
describe both cultural literacy and academic literacy (e.g., "melting pot," "salad bowl, "bridge," and "gap") didn't concede commonalties between the two. Rather she called for generating such a common ground, and helping Basic Writers to exercise it, thus constructing Basic Writing student identity not as a bifurcated entity but as multiple or plural. G. Genevieve Patthey-Chavez and Constance Gergen's "Culture as an Instructional Resource in the Multiethnic Composition Classroom" also maintained that Basic Writing students' diverse backgrounds and preparations enhanced instruction. Such students, they contended, often facilitated their own instruction by bringing up issues of social origin that were relevant to themselves and to each other.

Despite a commonality in the sets of issues which were raised cyclically within the journal and the types of Basic Writing student identities they rendered possible, the Fall 1992's inner workings were equally eclectic, ranging from Basic Writers' workplace writing concerns (Eleanor Agnew's "Basic Writers in the Workplace: Writing Adequately for Careers after College") to their ability to achieve "empowerment" through recognizing how they could evaluate their own writing (Brenda Greene's "Empowerment and the Problem Identification and Resolution Strategies of Basic Writers"). Basic Writers' abilities to enter and alter the workplace as well as make their own assessments about their writing were foregrounded. Still other essays seemed to stray far afield from the earlier concerns of Basic Writing and its students, even from those scholars who had been very involved in the earliest issues of the journal and the very first constructions of the Basic Writer's identities. Andrea Lunsford's "Intellectual Property, Concepts of Selfhood, and the Teaching of Writing," for instance, spoke little about Basic Writing or its students, instead suggesting that if "social epistemic rhetoric" was to have a useful impact, it must forge a new pedagogy which resists masculinist assumptions, disempowering constructions of intellectual property and selfhood, and debilitating administrative networks. Given the burgeoning realization that the task of defining Basic Writing or the Basic Writer student identity unequivocally was perhaps itself problematic, scholars understandably began to construct the Basic Writer's identity according to other matters which impacted the Basic Writer's situation (i.e., workplace literacies, multiethnic literatures, and social epistemic rhetorics).

By Spring 1993 many of the same issues of defining Basic Writing and constructing student identity started to emerge within the Journal of Basic Writing. This time the definitions of the Basic Writer's identity dealt with issues of how politics, ideology, society, and culture construct that very identity. As a result, there was a lasting concern with the "political" difficulties of teaching Basic Writers and running Basic Writing programs (Karen Greenberg's "The Politics of Basic Writers"), the problematic way that Basic Writing programs sustained rac- 
ism by assisting a hierarchy of intelligence amongst races (William Jones' "Basic Writing: Pushing Against Racism"), as well as whether it made sense to separate Basic Writers into homogeneous classes (Peter Dow Adams' "Basic Writing Reconsidered"). The Basic Writer's student identity, though it varied from article to article, was describable as a constellation of societal forces which impacted it and shaped it, as gendered, raced, or classed.

Fall of 1993 in the Journal of Basic Writing brought a set of new texts which involved comparable attempts at a new construction of the Basic Writer's student identity. Increasingly the Basic Writer's student identity was constructed by scholars in conjunction with theoretical frameworks such as poststructuralism and postcoloniality aimed as de-marginalizing such students. For instance, Jane E. Hindman's "Re-inventing the University: Finding the Place for Basic Writers" offered a poststructuralist critique of basic writing placement and pedagogy, proposing that students learn to create their own discourse communities and to critique their own practices. The rather broadly-defined Basic Writer student identity was placed at the center of curricular development, her/his needs made to seem paramount in curricular and assignment design, but primarily in terms of a theoretical framework brought to bear upon her/his situation, in this case poststructuralism. Advocating an "empowering basic writing pedagogy," Hindman claimed, would involve uncovering the hidden positionality of academic discourse as well as helping students to more effectively develop a critical consciousness so that they might move from a "'marginalized' position at the center of an obscure, enigmatic system to an autonomous position on the 'margins'" (64/65), thereby fostering a deconstruction of authority within the Basic Writing composition classroom. Pamela Gay's "Reading Shaughnessy from a Postcolonial Perspective" in this issue, like Lu's text, criticized Shaughnessy's work, instead calling for a decolonizing of pedagogical practices and the need to foster a dialogic classroom. Rather she suggested that since social construction of student identities itself is inevitable, we must begin "constructing and reconstructing together from our different locations (a nexus of identities: gender, race, class, ethnicity, sexual orientation, and so on)" (35), in essence calling for a self-conscious self-construction of one's own identities. In contrast, Patricia Laurence's "The Vanishing Site of Mina Shaughnessy's Errors and Expectations" provided criticisms of both Lu's and Stephen North's characterizations of Shaughnessy's Errors and Expectations, instead historicizing the various political forces which shaped the text's methodologies and rhetorics. Not only was the construction of Basic Writing student identity becoming a territory of increasing debate and dispute alone, it would seem. The construction of previous scholars' research insofar as they reflected previous metaphoric investments of 
"growth or "initiation" itself became at least part of the rationale for contesting arguments' validities.

By 1994 and 1995, there was a continued and more entrenched undertaking within the Journal of Basic Writing to criticize erstwhile approaches to Basic Writing scholarship using the metaphor of conflict and other related figural language. The 1994 issues contained works such as Kathyrn R. Fitzgerald's “Computerized Scoring? A Question of Theory and Practice," Akua Duku Anokye's "Oral Connections to Literacy: The Narrative," and Kelly Belanger's "Gender and Teaching Academic Discourse: How Teachers Talk About Facts, Artifacts, and Counterfacts." Once more, however, despite wide variances in the topics taken up by these scholars, the Basic Writer's student identity was constructed and represented in terms of the class, ethnicity, or racial issues that impacted them, the kinds of assignments they accomplished as a result, or how such sociocultural traits impacted how they approached learning. The Fall 1995 issue contained Mary T. Segall's “Embracing a Porcupine: Redesigning a Writing Program" which claimed that students' writing skills can be improved with the help of a precollege composition class. While the identity of the Basic Writer constructed within these pages was becoming, in its rhetoric, increasingly diverse and conflictual, it was an identity which, though scholars who discussed it made specific efforts not to "construct" it in incapacitating manners, was predominantly understood as politicized, socialized, and culturally constituted. As such, the Basic Writer was understood as marginalized and ghettoized, but the outsider position could potentially be used as a position of empowerment and political agency. Within the scholarship just reviewed, then, very strong and very specific kinds of attempts to construct the Basic Writing student identity as constructed were made at the very moments when the history of the construction of student identity itself was being radically called into question.

The 1996 and 1997 issues preserved a focus on such concerns, beginning to extend them to questions of how students conceive of their own identities as well. While the conflict model still held sway in which the Basic Writer's identity was constructed, slowly a new metaphor seems to be emerging about students' own self-constructions of their identities. Such texts included Carol Severino's "An Urban University and Its Academic Support System Program: Teaching Basic Writing in the Context of an 'Urban Mission,', which exposes some of the political machinations involved in students being selected for such programs. Likewise, Rebecca Williams Mlynarczyk's "Finding Grandma's Words: A Case Study in the Art of Revising" offers criticism on the available research on revising and proposes some suggestions for Basic Writing teachers and their students. Likewise, Morris Young's "Narratives of Identity: Theorizing the Writer and the Na- 
tion" provides work which begins to look at how students themselves conceive of the tasks of writing and identity formation. Finally, Martha Marinara's Fall 1997 piece, "When Working Class Students 'Do' the Academy: How We Negotiate With Alternative Literacies" suggests that we need to view student identity in more complex., multifaceted ways since the very student who may be oppressed in one scenario can oppress another in a different one. Growing out of the conflict metaphor's predominance and existing alongside it, then, seems to be the emergence of a new metaphor which views the Basic Writer's identity as highly contextualized, only describable in terms of specific situations, specific activities, specific institutions, or specific moments.

\section{Commonalties in Previous Constructions of Basic Writing Student Identity: Envisioning Beyond Existing Metaphors}

A brief look back upon this cursory archaeological history of the representation of the Basic Writing student identities within the Journal of Basic Writing exhibits that, though many readings within Basic Writing scholarship have attempted to fix the identity of the Basic Writing student, inevitably many of these constructions have been more complicated than they appeared to be on the surface. Rather, many such apparently fixed identity constructions for the Basic Writer were themselves internally conflicted at various historical junctures, inevitably utilizing overlapping metaphors and models. As we have encountered it thus far, the history of the construction of the Basic Writing student identity is more than somewhat jagged, and far from completely consistent. However, as is clear, it has involved various inclinations, sometimes existing alongside each other within one scholarly text simultaneously.

Despite the critical value of this scholarship and its efforts to answer the question "Who is the Basic Writer?," as well as the fastidious attention it has paid to students' developmental, linguistic, and social environments, these three dominant constructions of the Basic Writer's student identity as a fixed, unified entity within the Journal of Basic Writing have held a great deal of power in the field. Additionally, at times they have also held several disconcerting traits in common, traits that are perhaps inevitable to some extent. Such characteristics are locatable not only within this journal, of course, but appear to be endemic to much of Basic Writing scholarship outside the journal as well. First, notwithstanding sometimes extremely different rhetorical approaches, the arguments we examined which utilize these metaphors seem to delimit the Basic Writer according to a deficit theory model, an etiological "problem" that the Basic Writer endures, be it cognitive, discursive, or social, in spite of professed efforts to work outside a di- 
agnosis/cure model. This seems to be the case in many instances, aside from whether the texts primarily utilize "growth" metaphors, "initiation" metaphors, or "conflict" metaphors. Not only, then, has the preoccupation with the question of "Who is the Basic Writer?" been somewhat crippling to Basic Writers, it would appear, but our metaphoric investments in growth, initiation, and conflict have not negated this tendency.

In her 1995 text It's Not Like That Here: Teaching Academic Writing and Reading to Novice Writers, Marcia Dickson points to this phenomenon, suggesting that the history of Basic Writing scholarship and our conceptions of Basic Writers have caused innumerable problems: "Such a positioning of writers/problems on a continuous line implies not only that students' abilities are easily identifiable, do not overlap in substantial ways, and can be measured adequately, but also that good teaching is merely a matter of applying the proper theory at the proper time" (viii). Dickson appropriately points to the fact that not only has Basic Writing scholarship been preoccupied with constructing Basic Writers' identities according to certain fixed, metaphoric allegiances, but that these metaphoric obligations themselves have resulted, at least in some significant part, from scholars' own theoretical investments.

Second, even when the scholarship (using any of these aforementioned metaphors) within the Journal of Basic Writing purports to be motivated by a desire to decenter the classroom or to shift privilege, the teacher's expertise and pedagogy are frequently suspiciously central to the answer provided to this "problem." Given the historical construction of Basic Writers' student identities according to scholars' own theoretical proclivities which we have witnessed, this phenomenon is perhaps not surprising. What is perhaps even more disturbing, though, is that these theoretical and metaphoric investments are not only instrumental in constructing Basic Writers' student identities, but also in suggesting the solutions to the "problems" these identity constructions occasion in the first place, a situation which, when considered in the faintest of light, does not emerge as incomparable to computer software hackers who create computer viruses and then later market antidotes. It is, of course, somewhat inevitable that scholars do produce constructions of student identities which their preferred theoretical models are likely to solve. However, the ways in which such metaphoric incarnations have acted as defining forces for Basic Writing student identities may have obscured other issues, particularly how students themselves deploy their own constructions of their identities through their composing processes.

The situation of the Composition teacher as hacker/expert and the Basic Writing student identity as virus/cure is unsettling for two reasons which transcend the momentary discomfort we may feel in the face of the analogy itself. First, at least one of these positions (spe- 
cifically the "conflict" model) holds that teacherly authority does indeed play a secondary role in its pedagogy, something which the evidence offered in this chapter indicates may not bear out. Indeed, first we may have to grant that teacherly authority, institutionally and societally produced, may be an inevitable part of the classroom environment, even the classroom environment which promotes "critical consciousness" which might help students battle oppressions. As Xin Liu Gale argues in her 1996 Teachers, Discourses, and Authority in the Postmodern Classroom, "Given the power relations between the teacher and the student in pedagogic communication, certain discourses privileged by various theorists and educationists can be used to secure the teacher's authority and to limit, exclude, and oppress students" (57). If this is indeed the case, this particular form of teacher authority newly comes in the guise of authorizing students to speak for themselves, implying that speech is relatively unmediated, and overlooking the power of authorization that the role of even the facilitative teacher itself still brings. Second, as mentioned above, perhaps more troubling still, our scholarship can operate to fill the vacuum in Basic Writers' identities in two ways: both by acting as creators of the viruses, principally in how our representations of our students construct their competencies and incompetencies, and as those who dispense its cures, including developmental curricula, discipline-specific writing classes, or multiethnic courses.

This means, in other words, that it is not impossible that Basic Writing student identity may have been heretofore at least partially constructed within Basic Writing scholarship according to what is lacking in the student, including grammatical prowess, facility with academic discourse, or an empowering societal position, as opposed to what positively is present or what our Basic Writers actually do accomplish within their verbal and written communications. These moments of disruption in the Basic Writer's student identity in early texts such as Yelin's offer us alternative approaches to how we conceive of students' identities and expose the ideologically invested and constructed nature of the Basic Writer's student identity. We must be constantly alert to the fact that despite our acute attempts to offer Basic Writing students empowerment and agency, our scholarship, even our socially and politically informed scholarship, oftentimes seems to effectively strip them of it, impacting our future scholarship as well as our teaching in potentially damaging ways.

This leaves an important question dangling, one for which there are no easy answers: What are some other ways of framing what our Basic Writing students are actually accomplishing within our classrooms as they themselves accomplish it? A version of this question may indeed be the next metaphoric investment or question that begins to hold sway in the journal. Such things are hard to fully understand when 
we are in the middle of them, as we all know. However, one might describe this new trend as involving a concentration upon Basic Writing students' various own identifications through interactions, as we have begun to see occurring to a much greater degree within the journal as well as outside it (Fox 1999; Gay 1998; Gray-Rosendale 1996, 1999, 2000; Gruber 1999; Harrington and Adler-Kassner 1998; Mutnick 1996) rather than attempts to describe their identity constructions according to various sets of critical values. These too will inevitably hold some of the same problematic aspects of previous constructions of the Basic Writer's identity in play as well, even as they struggle overtly to work against them. Challenges to the predominance of the conflict metaphoric investment, then, come in small forms - through contesting and disputing how oppositional politics function, through suggesting the contextual nature of politics' functions, and through students' own constructions of their politics. These challenges, too, hold pieces of the other metaphoric investments in play, themselves utilizing the metaphoric investments of developmentalism, initiation, and conflict. Should this new metaphoric allegiance come to gain prominence in the journal's Basic Writing scholarship, it too will likely be supplanted shortly by other, more immediately compelling metaphoric investments which utilize those that have come before in constructing their arguments. For this reason it makes sense that we should all work as much as possible to construct disruptive perspectives that operate to challenge the predominance of these metaphors as well as admit and continue to unearth the history of such metaphors' conversations with each other. We also may continue to improve our scholarship if we remind ourselves of this history, its disruptions and contradictions, and the fact that while the metaphors have changed, the issues and even the approaches to them are perhaps surprisingly consistent. Increasingly, this is a path our research must explore, and the Journal of Basic Writing, given its complex and interesting history as well as its proclivity for self-reflection and self-historicizing, is precisely the territory within which this will continue to productively occur.

\section{Notes}

1. I am greatly indebted to Harris' research $(1995 ; 1997)$ which established a critical foundation for viewing the history of Basic Writing. Harris indicated that the "growth" metaphor has involved a displacement of attention away from academic discourse specifically, encouraging a centralized focus on teachers learning to honor the skills students themselves bring to the classroom. This "growth" perspective 
emphasized mental conceptions rather than behavioral ones, and sequential stages rather than external, environmental concerns. Basic Writers were believed to remain in an early stage of language development. According to Harris, the "initiation" metaphor has implied that the academy formed a kind of 'discourse community' with its own distinctive ways of utilizing language with which many Basic Writers are not well-acquainted, suggesting that assimilation, acculturation or conversion to a discourse community outside oneself is an event Basic Writers often must undergo. Criticisms of both of these antecedent stages, Harris implies, finally gave rise to the predominance of the "conflict" model. This new approach emerged when it became clear that such" initiation" inevitably entailed "leaving behind old ways of interpreting in order to take on new forms of organizing experience" (30), and therefore assimilation, acculturation, and conversion to new, dominant, perhaps oppressive and self-negating, perspectives. As Harris suggests, this metaphor implies a need to value differences as well as cultural and social conflicts as they emerge within Basic Writing classes.

2. My use of the term "developmental" throughout this section is meant to refer more to scholars' terminological investments than it does one particular meaning attributed to the term. However, characteristically, many of those scholars who used the term in conjunction with the larger metaphor of "growth" drew largely from cognitive psychology, Piaget and Perry in particular, to make their claims.

3. Note that the journal's name change from Basic Writing to the Journal of Basic Writing would occur in 1986 with the growing professionalization of rhetoric and composition studies as a discipline as well as with Lynn Troyka's accession to the role of editor.

4. Clearly editorship impacted many of these shifts within the journal as well. While I cannot take this up in detail within this paper, several things should be said about the influence of editorship on the journal: 1) it impacted which texts were published and how they were arranged, especially in the early days before the journal became peer reviewed, 2 ) it shaped the ways in which special issues were put together and framed, and 3) it influenced how certain models came to hold sway as well as lost power. This is a very interesting aspect of the journal and one that deserves more attention than I can give it here.

5. Andrea Lunsford is among the few scholars whose work has been present throughout and drawn upon all three of the metaphoric investments of Basic Writing history that Harris delineates. As such, a study of her scholarship in the journal might prove a useful project, revealing the ways in which one scholar has taken up different rhe- 
torical tactics as she negotiated markedly divergent historical and disciplinary contexts.

6. For further developments in this line of thinking, see Horner and Lu 1999.

7. Nicholas Coles and Susan Wall in their 1991 "Reading Basic Writing: Alternatives To a Pedagogy of Accommodation" articulate the tenets of this new position rather well: "As long as academic discourse presents itself as the language of powerful 'insiders' who require that the students abandon their culture to join the 'club,' students will perceive academic culture as impersonal and alienating" (243). They urge that the language of the academy itself finally needs to be considered more fully as multiple and changeable rather than as one monolithic entity to which Basic Writers must adapt.

\section{Acknowledgments}

I would like to thank Jean Boreen, Sibylle Gruber, Jeanne Gunner, Cynthia Kosso, George Otte, Randi Reppen, and Trudy Smoke for their very helpful comments on this paper.

\section{Works Cited}

Adams, Peter Dow. "Basic Writing Reconsidered." Journal of Basic Writing. 12.1(1993): 22-36.

Agnew, Eleanor. "Basic Writers in the Workplace: Writing Adequately for Careers After College." Journal of Basic Writing. 11.2(1992): 2846.

Anokye, Akua Duku. "Oral Connections to Literacy: The Narrative." Journal of Basic Writing. 13.2(1994): 46-60.

Bartholomae, David and Anthony Petrosky. Facts, Artifacts, Counterfacts: Theory and Method for a Reading and Writing Course. Portsmouth, NH: Boynton/Cook Publishers, 1986.

-. "The Study of Error." College Composition and Communication. 31 (1980): 253-69.

-. "Teaching Basic Writing: An Alternative to Basic Skills." Journal of Basic Writing. 2:85-109.

-."The Tidy House: Basic Writing in the American Curriculum." Journal of Basic Writing. 12(1993):4-21.

Belanger, Kelly. "Gender and Teaching the Discourse: How Teachers Talk About Facts, Artifacts, and Counterfacts." Journal of Basic Writ- 
ing. 13.2 (1994): 61-82.

Berthoff, Ann. "Recognition, Representation, and Revision." Basic Writing. Fall/Winter 1981, Revision: 19-31.

Bizzell, Patricia. Academic Discourse and Critical Consciousness. Pittsburgh: U of Press, 1992.

-. "What Happens When Basic Writers Come To College?" College Composition and Communication. 37: 294-301.

Brereton, John. "The Doctorate Program in Composition at Wayne State University." Basic Writing. Spring/Summer 1981, Training Teachers: $14-22$.

Brown, Rexford. "Schooling and Thoughtfulness." Journal of BasicWriting. 10.1(1991): 3-15.

Coles, Nicholas and Susan Wall. "Conflict and Power in the Reader Responses of Adult Basic Writers." College English. 49(1987): 298314.

D’Eloia, Sarah. "Introduction." Basic Writing. Fall/Winter 1981, Training Teachers: 1-4.

-. "Introduction." Basic Writing. Spring/Summer 1981, Revision: 1-4.

-. "Introduction." Basic Writing. 4.1(Spring 1985), Basic Writing and Social Science Research: 1-3.

-. "Teaching Standard Written English." Journal of Basic Writing. 1.1(1975): 5-13.

Dickson, Marcia. It's Not Like That Here: Teaching Academic Writing and Reading to Novice Writers. Portsmouth, NH: Boynton Cook Publishers, 1995.

Dixon, Kathleen. "Intellectual Development and the Place of Narrative in 'Basic' and Freshman Composition." Journal of Basic Writing. 8.1(1989): 3-20.

Epes, Mary. "Tracing Errors to Their Sources: A Study of the Encoding Processes of Adult Basic Writers." Basic Writing. 4.1(Spring 1985), Basic Writing and Social Science Research: 4-33.

Fitzgerald, Katherine R. "Computerized Scoring? A Question of Theory and Practice." Journal of Basic Writing 13.2 (1994): 3-17.

Flower, Linda. "Revising Writer-based Prose." BasicWriting. Fall/Winter 1981, Revision: 62-74.

Foucault, Michel. Archaeology of Knowledge. Trans. A. Sheridan. New York: Pantheon, 1972.

-. The Order of Things: An Archaeology of the Human Sciences. New York: Vintage, 1970 and 1994.

Fox, Thomas. "Basic Writing as Cultural Conflict." Journal of Education. 172(1990): 65-83.

-. Defending Access: A Critique of Standards in Higher Education. Portsmouth: Boynton Cook/Heinemann, 1999.

Gale, Xin Liu. Teachers, Discourses, and Authority in the Postmodern Composition Classroom. Albany: State University of New York Press, 
1996.

Gay, Pamela. "Dialogizing Response in the Writing Classroom: Students Answer Back." Journal of Basic Writing. 17.1(Spring 1998): 317.

Goldberg, Marilyn. “Overfamiliarity: A Cognitive Barrier in Teaching Composition." Basic Writing. 4.1(Spring 1985), Basic Writing and Social Science Research: 34-43.

Gray-Rosendale, Laura. "Inessential Writings: Shaughnessy's Legacy in a Socially Constructed Landscape." Journal of Basic Writing. 17.2(Fall 1998): 42-75.

-. Rethinking Basic Writing: Exploring Identity, Politics, and Community in Interaction. Mahwah: Lawrence Erlbaum Associates, 2000.

-. "Revising the Political in Basic Writing Scholarship." Journal of Basic Writing. 15.2(Fall 1996): 24-49.

Greenberg, Karen L. "The Politics of Basic Writing." Journal of Basic Writing. 12.1(1993): 64-71.

Greene, Brenda. "Empowerment and the Problem of Identification and Resolution Strategies of Basic Writers." Journal of Basic Writing. 11.2(1992): 4-27.

Gruber, Sibylle. "On the Other Side of the Electronic Circuit: A Virtual Remapping of Border Crossings." Journal of Basic Writing. 18.1(Spring 1999): 55-75.

Harrington, Susan and Linda Adler-Kassner. "'The Dilemma that Still Counts': Basic Writing at a Political Crossroads." Journal of Basic Writing. 17.2(Fall 1998): 3-24.

Harris, Joe. "Negotiating the Contact Zone." Journal of Basic Writing. 14.1(1995): 27-43.

-. A Teaching Subject: Composition Since 1966. Upper Saddle River: Prentice Hall, 1997.

Hashimoto, Irvin. "Adult Learning and Composition Instruction." Basic Writing. 4.1(Spring 1985), Basic Writing and Social Science Research: 55-67.

Hays, Janice. "The Development of Discursive Maturity in College Writers." The Writer's Mind. Ed. Hays et al. Urbana, IL: NCTE, 1983.

-. "Models of Intellectual Development and Writing: A Response to Myra Kogen et al." Journal of Basic Writing. 6.2(1987): 11-27.

-. "Socio-Cognitive Development and Argumentative Writing: Issues and Implications From One Research Project" Journal of Basic Writing. 7.2 (Fall 1988): 42-67.

Hindman, Jane. "Reinventing the University: Finding the Place for Basic Writers." Journal of Basic Writing. 12.2(1993): 55-76.

Horner, Bruce and Min-Zhan Lu. Representing the "Other": Basic Writers and the Teaching of Basic Writing. Urbana: NCTE, 1999.

Jones, William. "Basic Writing: Pushing Against Racism." Journal of Basic Writing. 12.1(1993): 72-80. 
Kinder, Rose Marie. "A Piece of the Streets." Journal of Basic Writing. 10.1(1991): 67-72.

Kogen, Myra. "The Conventions of Expository Writing." Journal of Basic Writing. (1986): 24-37.

Laurence, Patricia. “Error's Endless Train: Why Students Don't Perceive Errors." Journal of Basic Writing. 1:1(1975): 22-42.

- . et al. "Symposium on Basic Writing, Conflict and Struggle, and the Legacy of Mina Shaughnessy." College English. 55.8 (December 1993): 879-903.

-. "The Vanishing Site of Mina Shaughnessy's Errors and Expectations." Journal of Basic Writing. 2(1993):18-28.

Lu, Min-Zhan. "Conflict and Struggle: The Enemies or Preconditions of Basic Writing?" College English. 54 (1992): 887-913.

-. "Professing Multiculturalism: The Politics of Style in the Contact Zone." College Composition and Communication. 45.4 (1994): 442-458.

-. "Redefining the Legacy of Mina Shaughnessy: A Critique of the Politics of Linguistic Innocence." Journal of Basic Writing. 10.1(1991): 26-40.

Lunsford, Andrea. "Aristotelian Rhetoric: Let's Get Back to the Classics." Journal of Basic Writing. 5(1978): 2-12.

-. "Intellectual Property, Concepts of Selfhood, and the Teaching of Writing." Journal of Basic Writing. 11.2 (1992): 61-73.

Marinara, Martha. "When Working Class Students 'Do' the Academy: How We Negotiate With Alternative Literacies." Journal of Basic Writing. Fall 1997. 16:2. 3-16.

Mlynarczyk, Rebecca Williams. "Finding Grandma's Words: A Case Study in the Art of Revising." Journal of Basic Writing. 15.1(1995): 3-22.

Moran, Charles. "A Model for Teacher Training Programs in the Field of Writing." Basic Writing. Spring/Summer 1981, Training Teachers: 64-78.

Murray, Donald. "Making Meaning Clear: The Logic of Revision." $B a-$ sic Writing. Fall/Winter 1981, Revision: 33-40.

Mutnick, Deborah. Writing in an Alien World: Basic Writing and the Struggle for Equality in Higher Education. Portsmouth: Boynton Cook, 1996.

Patthey-Chavez, G. Genvieve and Constance Gergen. "Culture as an Instructional Resource in the Multiethnic Composition Classroom." Journal of Basic Writing. 11.1(1992): 75-96.

Perry, William G. Jr. Forms of Intellectual and Ethical Development in the College Years: A Scheme. New York: Holt, Rinehart and Winston, 1968/1970.

Piaget, Jean. "Intellectual Evolution from Adolescence to Adulthood." Human Development. 15(1972): 1-12.

Pratt, Mary Louise. "Arts of the Contact Zone." Profession. 91 (1991): 
33-40.

-. "Criticism in the Contact Zone: Decentering Community and Nation." Critical Theory, Cultural Politics, and Latin American Narrative. Eds. Steven Bell, Albert LeMay, and Leonard Orr. Notre Dame: U of Notre Dame Press, 1993. 83-102.

Samuels, Marilyn Schauer. "Norman Holland's 'New Paradigm' and the Teaching of Writing." Journal of Basic Writing. 5(1978): 52-61.

Segall, Mary T.. “Embracing a Porcupine: Redesigning a Writing Program." Journal of Basic Writing. 14.2(1995):38-67.

Severino, Carol. "An Urban University and Its Academic Support System Program: Teaching Basic Writing in the Context of an 'Urban Mission.'" Journal of Basic Writing. 15.1 (1995): 39-56.

Shaughnessy, Mina. Errors and Expectations: A Guide for the Teacher of Basic Writing. New York: Oxford UP, 1977.

—. "Introduction." Journal of Basic Writing. 1.1(1975): 3.

-. "Some New Approaches Toward Teaching." Journal of Basic Writing. 13(1974): 103-116.

Sommers, Nancy. "Intentions and Revisions." Basic Writing. Fall/Winter 1981, Revision: 41-49.

Wiener, Harvey. "Preparing the Teacher of Writing." Basic Writing. Spring/Summer 1981, Training Teachers: 5-13.

Young, Morris. "Narratives of Identity: Theorizing the Writer and the Nation." Journal of Basic Writing. 15:2 (Fall 1996): 20-50.

Yelin, Louise. "Deciphering the Academic Hieroglyph: Marxist Literary Theory and the Practice of Basic Writing." Journal of Basic Writing. 2.1(1978): 13-29. 


\section{News and Announcements}

Conference announcement: $24^{\text {th }}$ Annual National Association for Developmental Education (NADE) Conference, March 15-19,2000 in Beloxi, Mississippi. Conference Theme "Meeting the Challenges and Serving as a Beacon for the $21^{\text {st }}$ Century." Featured Speakers Clifton Taulbert, Jana Stanfield, and John Roueche. For further information on NADE 2000, contact Vashti Muse at 601-857-3464 or museleagle@aol.com or vumuse@hinds.cc.ms.us.

Workshop announcment: The Institute for Writing and Thinking Workshops at Bard College, Annadale-on-Hudson, NY Spring/ Summer Workshops. Some of the topics Writing to Learn, Reading and Writing Nature, Writing to Learn Math and Science, Poetry: Reading, Writing, Teaching, July 9-14 Writing Retreat for Teachers, and Invention and the Art of Revision. For more information contact Ray Peterson at 914-758-7431 or peterson@bard.edu.

Call for proposals: $13^{\text {th }}$ Rhetoric and Composition Colloquium, Friday, April 28, 2000 at Murray State University in Murray, Kentucky. Colloquium Theme "Grading Matters: Evaluating Student Writing." Keynote Speaker Peter Elbow. Proposals accepted until April 1, 2000. For more information contact Gina Claywell at 270-762-2401 or gina.claywell@murraystate.edu.

Call for proposals and conference announcement: $5^{\text {th }}$ National Writing Centers Association Conference, November 2-4, 2000 at the Omni Harbor Hotel in Baltimore, Maryland. Theme is an exploration of issues of concern to those who work in writing centers. Deadline for proposals is February 15, 2000. For conference information visit the web site at http://www.english.udel.edu/wc/mawca/ nwcacon.html or contact Terrance Riley at riley@planetx.bloomu.edu.

Announcement: Computers in Writing-Intensive Classrooms Two-week summer workshop for teachers of English June 19-30, 2000 at Michigan Technological University. Workshop coordinator Cynthia Selfe. No previous computer knowledge is necessary for participation. One-to-one instruction will be provided on both Macintosh and PC platforms. For more information visit the web site at http:// www.hu.mtu.edu/ciwic. Contact early as enrollment is limited. 
Seminar announcement: Summer seminar in Rhetoric and Composition June 4-9, 2000 at Millikin University, Decatur, Illinois. Presenters include Janice Lauer on Writing as Inquiry and Action; Brian Huot on Assessment; Barbara Walvoord on Writing-Intensive-FirstYear Seminars; Bruce Ballinger on Teaching Research Writing; Davis Cooper on Service Learning and Composition; and Krista Radcliffe on Returning to the Personal in Composition Studies. For information contact Nancy C. Dejoy at 217-362-6413 or ndejoy@mail.millikin.edu.

Call for papers: JAC (Journal of Composition Theory) invites submissions of articles on a variety of topics related to writing, rhetoric, multiple literacies, and culture. Use current MLA style and send three copies, stripped of identifying information to Professor Lynn Worsham, Editor, JAC, Department of English, University of South Florida, Tampa, FL 33620-5550. For additional information contact her at 813-974-9536 orLworsham@chuma1.cas.usf.edu

Call for Proposals: 4th Annual Teaching of Writing Colloquia, Saturday, April 29, 2000 at Kent State University-Stark Campus, Canton, Ohio. Suggested topics include but are not limited to: course design, classroom activities, writing and classroom assignments, writing prompts, developmental writing, working with writing centers, working with disabled students, ESL, evaluating student writing. Mail, fax, or e-mail 100-200 word proposals to: Laurie Delaney, Kent State University, Stark Campus. 6000 Frank Ave. N.W. Canton, OH 447207599. ldelaney@stark.kent.edu. Proposal Deadline: Wednesday, March 1, 1999

Registration now is open for Computers and Writing 2000, May 25-28, 2000 Fort Worth, Texas, hosted by Texas Woman's University. The registration form is available at: www.eaze.net/ jfbarber/cw2k/ conf-registration.html. Registration deadline for presenters is April 30,2000 . Onsite registration is available for non-presenters. For more information, contact Dene Grigar, dgrigar@twu.edu, or visit the CW2K website at www.eaze.net/ jfbarber/cw2k/bridge.html 


\section{Bomposition and Rhetoric Studies, Ph. D. Program in English}

\section{The Graduate Benter of \\ The Gity University of New York}

For further information, write to:

Composition and Rhetoric Area Group, English Program

Graduate School and University Center The City University of New York 365 Fifth Avenue

New York, NY 10016-4309

Or, visit our English Program website: http://web.gsuc.cuny.edu/english/home.html

\section{Tel.: 212/817-8315}




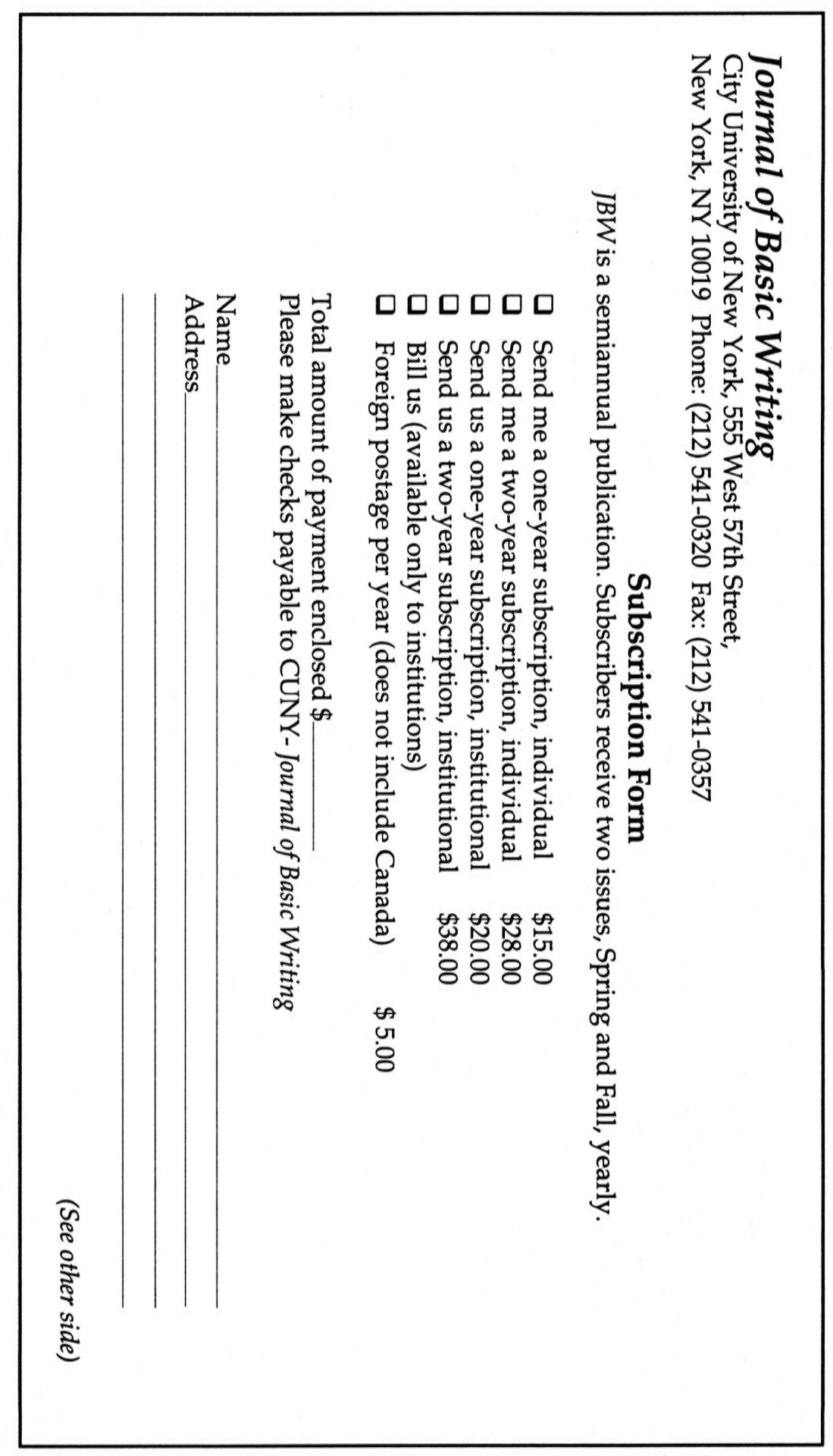




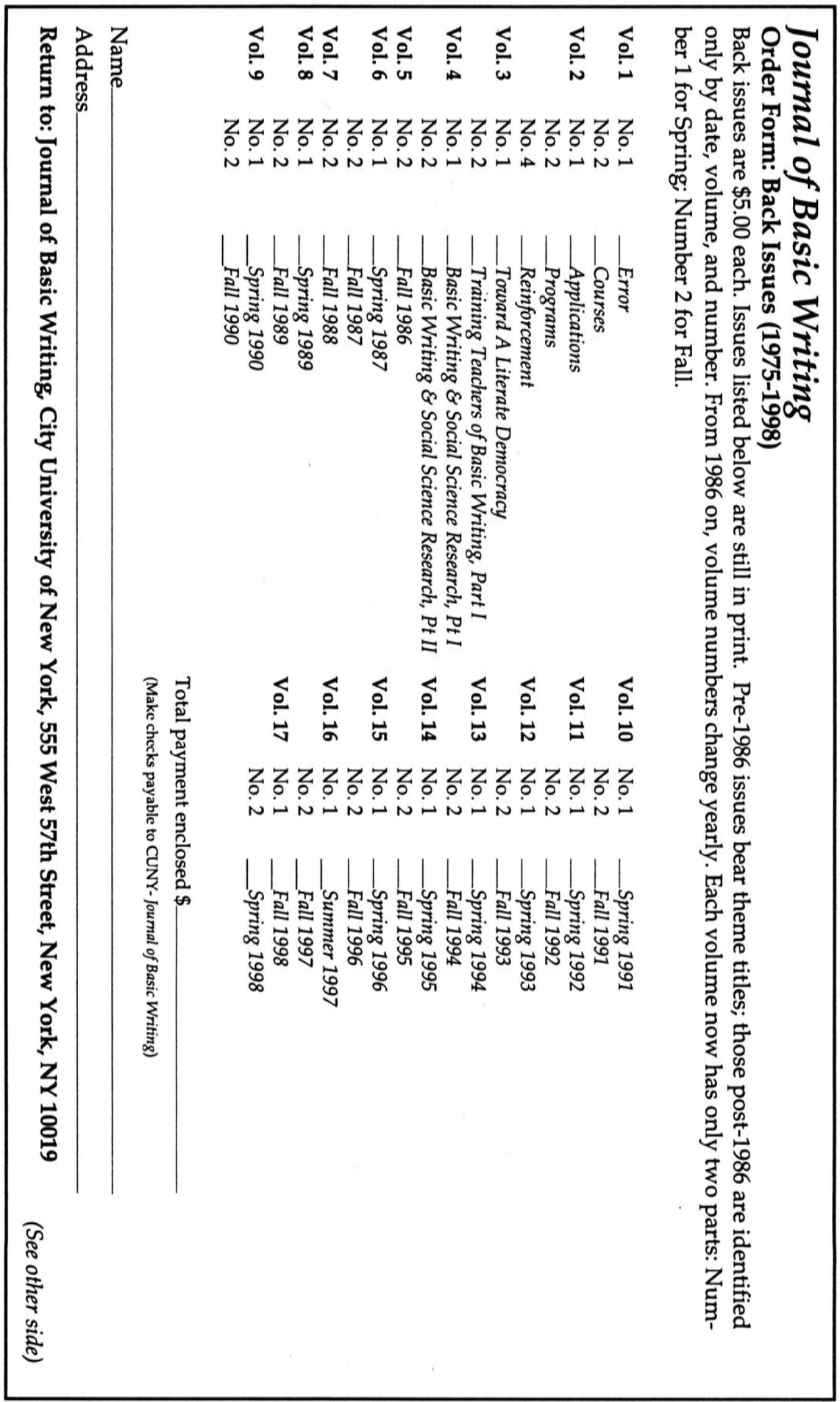




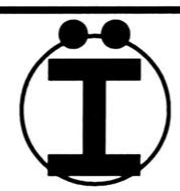

The paper used in this publication meets the minimum requirements of the American National Standard for Information Science -

Permanence of Paper for Printed Library Materials, ANSI Z39.48-1984.

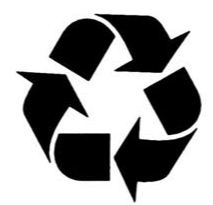

The text stock is also recycled.

\section{This publication is available in microform from UMI.}

Please send me information about the titles I've listed below:

Name

Title

Company/Institution

Address

City/State/Zip

Phone (__ )

\section{$\mathrm{U} \cdot \mathrm{M} \cdot \mathrm{I}$}

A Bell \& Howell Company 300 North Zeeb Road, Ann Arbor, Ml 48106 USA 800-521-0600 toll-free 313-761-4700 collect from Alaska and Michigan 800-343-5299 toll-free from Canada 


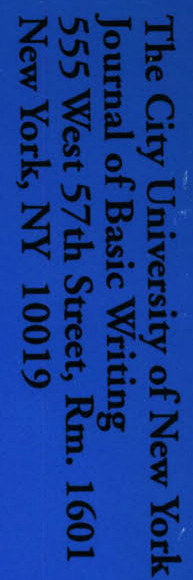

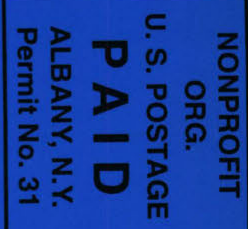

